\title{
BULLETIN DER \\ DEUTSCHEN SLAVISTIK 2011
}

\begin{tabular}{|c|c|c|c|c|c|c|}
\hline \multicolumn{7}{|c|}{ Chancteres lingure . Rutentica } \\
\hline$A \propto d$ & & 1000 & $O_{n}$ & Tht & pet & \\
\hline 546 & Buti $\quad b$ & $\Pi \pi \pi$ & $\mathscr{L}_{a k o \alpha \beta}$ & $e \in$ & $i c^{\prime}$ & ich \\
\hline R $\mathbf{T h} \boldsymbol{E}_{\Delta}$ & עyedic & Psp & Ente 1 & & itos $g_{i}$ & iii \\
\hline$\Gamma \Gamma$ & glagol g & GC & Slowo $s$ & 而步 & & iüs \\
\hline $1=2$ & dobro d & $\mathrm{I} z \gamma_{\mathrm{m}}$ & Jimendo $t$ & $\lambda \lambda$ & doe & \\
\hline $\mathcal{E}, \varepsilon$ & jest e & Yryoy & Yite ú & 恙紊落 & $b_{\bar{i}}$ & \\
\hline$S_{S .9}$ & 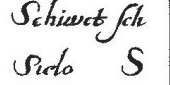 & $\mid \begin{array}{l}\alpha A \\
x \times x\end{array}$ & $\begin{array}{l}\text { phert phl } \\
\text { Chir ith }\end{array}$ & $\begin{array}{l}\Psi \gamma \\
\theta \theta_{1}\end{array}$ & $\beta \sqrt{x^{2}}$ & $p^{r}$ \\
\hline 333 & Zemla $Z$ & $\omega \approx$ & & m & 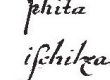 & \\
\hline$H_{n}$ & Gsche $i$ & 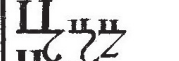 & & ONunzer & & \\
\hline $\begin{array}{l}I_{i} \\
K^{\prime} K_{u}\end{array}$ & $\begin{array}{ll}\mathscr{S}_{i} & i j\end{array}$ & $y^{2}$ & Treef $t$ & $\frac{1}{2} \frac{2}{h}$ & & \\
\hline$\lambda \lambda r$ & lübli 1 & $\Psi_{\mathrm{m}}$ & Tycha tych & $\frac{3}{4}$ & & \\
\hline $\ln / 42 \mathrm{~g}$ & Mluteri Ill & $71 b_{4}$ & $S_{e r} \quad j$ & 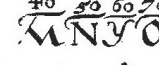 & & \\
\hline & $\mathcal{N}_{\text {ans }} n$ & $b_{161 b_{2}}$ & Seri & Iö́cmoAn & mon & \\
\hline
\end{tabular}

\section{Jahrgang 17, 2011}

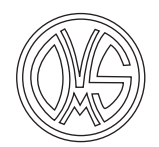

Verlag Otto Sagner

München - Berlin 2011 


\section{BULLETIN DER \\ DEUTSCHEN SLAVISTIK \\ 2011}

Characteris linguce . Rutenicae

\begin{tabular}{ll|lll|lll}
$A$ & Aas & $A$ & ONo & On & $\circ$ & tot $t$ & get
\end{tabular}

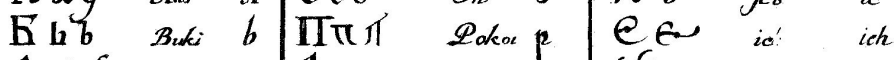

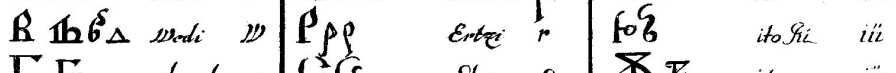

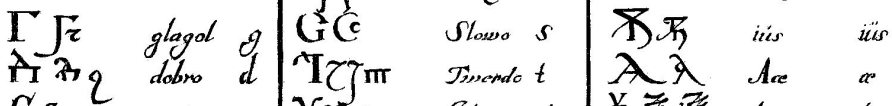

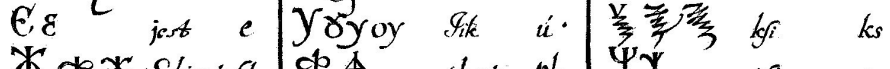

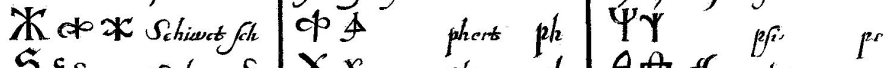

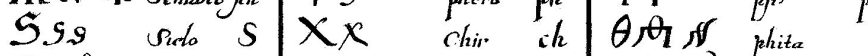

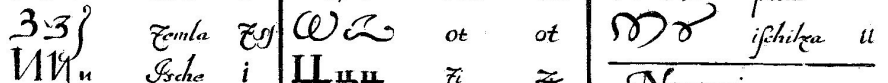

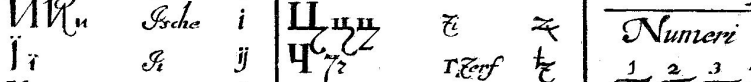

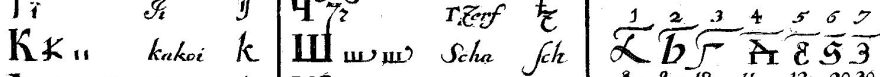

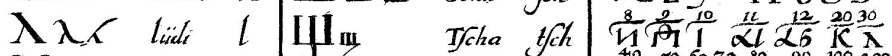

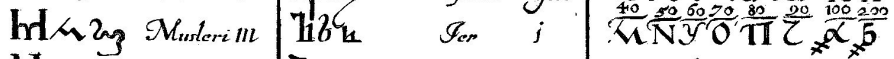

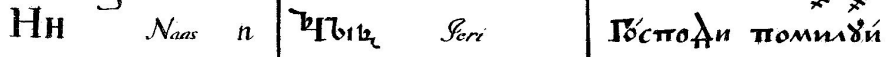

Jahrgang 17, 2011

Verlag Otto Sagner

München - Berlin 2011 


\title{
Herausgegeben von \\ Sebastian Kempgen und Ludger Udolph
}

\author{
und dem Redaktionskollegium
}

Hermann Fegert, Norbert Franz, Gerhard Giesemann, Miranda Jakiša, Ulrike Jekutsch, Ulrich Steltner

im Auftrage der Verbandsvorsitzenden

Monika Wingender

\begin{abstract}
Bibliografische Information der Deutschen Bibliothek: Die Deutsche Bibliothek verzeichnet diese Publikation in der Deutschen Nationalbibliografie; detaillierte bibliografische Daten sind abrufbar im Internet über http://dnb.ddb.de/
\end{abstract}

Online steht das Bulletin der deutschen Slavistik als Volltextversion sowohl über die Webseite des Slavistenverbandes (www.slavistenverband.de) wie über den Katalog der

Bayerischen Staatsbibliothek München (www.bsb-muenchen.de) zur Verfügung.

BSBB $\begin{gathered}\text { Bayerische } \\ \text { Ssaassibionthek }\end{gathered}$

ISSN 0949-3050 (gedruckt), 1618-6575 (Internet);

ISBN 978-3-86688-151-8; ISBN (eBook): 978-3-86688-152-5

(C) 2011 bei Kubon \& Sagner $\mathrm{GmbH}$

$\begin{array}{ll}\text { Heßstr. 39/41 } & \text { Friedrichstr. } 200 \\ \text { 80798 München } & 10117 \text { Berlin }\end{array}$

Telefon $+49(0) 8954218-107$

Telefax +49(089) 54 218-226

«Verlag Otto Sagner» ist ein Imprint der Kubon \& Sagner GmbH

Druck und Bindung:

Difo-Druck GmbH, Bamberg

Gedruckt auf alterungsbeständigem Papier 


\section{Bulletin der deutschen Slavistik 17, 2011}

\section{Zum Geleit}

M. Wingender: Wandel und Kontinuität

\section{Programmatisches}

D. Uffelmann: Plädoyer für eine crossmediale Slavistik .................... 7

U. Steltner: Nach Minsk!? ........................................................ 15

\section{Der deutsche Slavistenverband 2010/2011}

M. Wingender: Der deutsche Slavistenverband 2010/11

\section{Die deutsche Slavistik 2010/2011}

N. Franz: Who's Where an den slavistischen Seminaren

G. Giesemann: Habilitationen, Rufe, Emeritierungen / Pensionierungen, Ehrungen

W. Schmid: Dietrich Gerhardt 100 Jahre alt

K. Eimermacher: Jurij Striedter zum 85. Geburtstag ..........................

R. Lauer: Nekrolog auf Aleksandar Flaker

G. Giesemann: Gedenken an Alfred Rammelmeyer

V. Mokienko: Anna-Halja Horbatsch in memoriam

U. Schweier: Otto Sagner (1920-2011)

PD Dr. Thomas Bruns

PD Dr. Christoph Garstka $\quad$....................................................... 43

PD Dr. Henrike Schmidt ......................................................... $\quad 45$

PD Dr. Daniel Schümann ....................................................... 47

PD Dr. Barbara Sonnenhauser ................................................. 49

PD Dr. Dieter Stern .............................................................. 51

G. Giesemann: Tagungskurzberichte ........................................ 53

U. Steltner: Slavistische Veröffentlichungen ................................ 62

U. Steltner: Aus der deutschsprachigen slavistischen Forschung ......... 69

M. Jakiša: Slavistische Promotionen ....................................... 


\section{Wissenschaftliche Beiträge}

M. Jakiša: Theater in Disjunktion: Ivana Sajkos Rose is a rose is rose is a rose

H. Kirschbaum: Von der Schneeidylle zur Eishölle. Russland-Winterbilder im (anti-)imperialen intertextuellen Spannungsfeld zwischen Vjazemskij, Puškin, Ryleev und Mickiewicz

B. Sonnenhauser: Perspektivität und Textstruktur im Balkanslavischen

\section{Wort in die Zeit}

R. Hodel: Der siebte Bruder (Gedanken zu einer sich verändernden Rezeption in zwei politischen Kontexten)

Die Titelvignette ist eine der berühmten Abbildungen in Adam Olearius' Werk „Vermehrte Newe Beschreibung Der Muscowitischen vnd Persischen Reyse" von 1656, in der er im 22. Kapitel zum Thema „Von der Russen Schrifft / Sprache vnd Schulen“ die Übernahme ersterer von den Griechen mitteilt, wobei die Buchstaben aber "theils verstümlet / theils auch mit Sclavonischen Buchstaben vermehret" worden seien. - Slavische Alphabete in nicht-slavischen Texten sind ein eigener Forschungsgegenstand und können eine wertvolle Quelle zur Rekonstruktion des Bestandes, der Reihenfolge und der Namen der einzelnen Buchstaben in dem betreffenden Alphabet zur jeweiligen Zeit sein. 


\section{Wandel und Kontinuität}

\section{Von Monika Wingender (Gießen)}

Seit dem 1. Januar 2011 habe ich den Vorsitz des Deutschen Slavistenverbandes übernommen. Es freut mich, dass der DSV auch in der jetzigen Wahlperiode von einem Kollegium geführt wird. Mein Amtsvorgänger, Sebastian Kempgen, wird auch weiterhin zusammen mit Ludger Udolph und dem Redaktonskollegium das Bulletin der Deutschen Slavistik gestalten. Gerd Hentschel als Vorsitzender des Deutschen Slavistenkomitees vertritt unsere Interessen bei der Vorbereitung und Durchführung des nächsten Internationalen Slavistenkongresses, während die Dresdener und Bautzener Organisatoren zusammen mit Tilman Berger als Vorsitzendem der Slavistentagskommission für die Vorbereitung des Deutschen Slavistentages 2012 tätig sind. Die bereits in der letzten Wahlperiode amtierenden Vorstandsmitglieder Norbert Franz, Miranda Jakiša und Hermann Fegert stehen in der jetzigen Wahlperiode, beim Wandel im Vorsitz des Verbandes, für Kontinuität.

Als neue Vorsitzende möchte ich mich Ihnen kurz vorstellen. Die universitäre deutsche Slavistik habe ich an drei Standorten intensiv kennengelernt. In Bochum studierte ich und promovierte dort 1994 bei Helmut Jachnow. Anschließend wechselte ich auf eine Assistentenstelle bei Werner Lehfeldt in Göttingen, wo ich mich 2000 habilitierte. Im folgenden Jahr wurde ich auf die sprachwissenschaftliche Professur (Nachfolge Herbert Jelitte) an der Justus-Liebig-Universität Gießen berufen. Da nur ein Jahr später mit der Pensionierung von Gerhard Giesemann auch die Professur in der GieBener Literaturwissenschaft zur Wiederbesetzung anstand, war diese Umbruchsituation für die Gießener Slavistik - damals ein Zwei-Professoren-Institut - nicht ohne Risiko. Anders als an anderen SlavistikStandorten in Deutschland nahm die Universität Gießen die Neubesetzung von beiden Slavistik-Professuren innerhalb eines Jahres aber nicht zum Anlass der Streichung des Faches: Beide Neubesetzungen wurden zügig durchgeführt, und dies war entscheidend, als das Land Hessen Ende 2004 beschloss, die sogenannten kleineren geisteswissenschaftlichen Fächer in Hessen nicht mehr an mehreren Universitäten vorzuhalten, sondern an jeweils einer Universität in Hessen zu zentralisieren. Seit 2006 ist mit der Gründung des Gießener Zentrums Östliches Europa (GiZo) die gesamte hessische Slavistik und Osteuropäische Geschichte in Gießen konzentriert. Als damalige Dekanin wurde ich mit der Konzeption und Gründung des Osteuropazentrums in Gießen betraut. Als eine der Principal Investigators des seit 2006 durch die Exzellenzinitiative geförderten Gießener International Graduate Centre for the Study of Culture, als Mitglied des 
Senats der Universität Gießen (200709) und seit 2008 auch als Mitglied des Vorstands des Herder-Instituts Marburg konnte ich so die fruchtbare Verbindung von fachbezogener slavistischer und interdisziplinärer osteuropabezogener Forschung und Lehre nicht nur miterleben, sondern auch aktiv gestalten.

Wie sehr die Slavistik in den letzten Jahren beschnitten wurde, ist der Übersicht zu den kleinen Fächern unter http://www.kleinefaecher.de zu entnehmen. Die Welle der Schließungen von SlavistikStandorten in Deutschland ist in den letzten Jahren glücklicherweise abgeebbt. Doch nach wie vor wird das Schicksal mancher unserer Standorte diskutiert. Die Situation der Slavistik in Deutschland erheben wir auch auf der diesjährigen Verbandstagung in Halle zum Thema. Dort werden wir uns zudem insbesondere mit der Situation der Südslavistik in Deutschland beschäftigen.

Eines der Themen, das die Slavistik sowie auch die anderen Philologien in den nächsten Jahren intensiv beschäftigen wird, ist das Vorhaben eines Forschungsratings in den Geisteswissenschaften (vgl. die Empfehlungen des Wissenschaftsrates: http://www.wissenschaftsrat.de/down load/archiv/10039-10.pdf). Damit verbunden ist eine lebhafte Diskussion um die Festlegung von Evaluierungskriterien. Zunächst wird die Anglistik Pilotprojekt sein - Erfahrungen mit dem bisherigen Verlauf des Pilotprojekts diskutierten im Juni die Vorsitzenden der philologi- schen Fachverbände in Berlin. Der Deutsche Slavistenverband wird die Diskussion um das Forschungsrating in den Geisteswissenschaften auch weiterhin aktiv mitgestalten.

Die Umstellung auf BA-/MA-Studiengänge ist an vielen Standorten vollzogen - manche Institute stehen jetzt bereits in bzw. vor der Reakkreditierung. Die Diskussion um die Resultate von Akkreditierungsverfahren, die im Publikationsorgan des Deutschen Hochschulverbandes - Forschung \& Lehre - seit längerem einen großen Raum einnimmt, wird auch im Slavistenverband weiter geführt. Akkreditierung und Auditierung haben wir zu einem der Themen auf der diesjährigen Verbandstagung in Halle erhoben.

Im kommenden Jahr richten Dresden und Bautzen mit dem Deutschen Slavistentag den im 3-JahresRhythmus stattfindenden nationalen Kongress der Slavistinnen und Slavisten aus. Erstmalig hat ein Deutscher Slavistentag einen thematischen Schwerpunkt: Region, Sprache und Nation. Ein Jahr später, im September 2013, steht der Internationale Slavistenkongress in Minsk bevor. Angesichts der politischen Situation in Belarus diskutiert man vielerorts die Ausrichtung des Kongresses in diesem Land - im vorliegenden Bulletin setzt sich Ulrich Steltner damit auseinander.

Für Anregungen in Bezug auf die zukünftige Gestaltung des Deutschen Slavistenverbandes bin ich jederzeit sehr dankbar. 


\title{
Plädoyer für eine crossmediale Slavistik
}

\author{
Von Dirk Uffelmann (Passau)
}

Medienkonfigurationen sind historisch wandelbar und kulturell unterschiedlich. Digitale Technologien haben den Medienkonfigurationswandel in jüngster Zeit beschleunigt. Ein dominanter Trend dabei scheint die Konvergenz der einst distinkten Medien qua Digitalisierung zu sein.

Was bedeutet das für die Slavistik? Wird durch globale Medien wie das Internet eine Area-Spezialisierung und damit eine der rationes entis der Slavistik obsolet? Nein, denn das Modell einer sukzessiven Diffusion des Internets, im Zuge derer die Nachzügler aufholen (Rose 2006), ignoriert die Machtrelevanz technologischen Vorsprungs. Die einstige Zweite Welt hatte $\mathrm{zu}$ Beginn des Internet-Booms schlechte Karten, war ihre Kommunikationstechnologie doch durch das Comecon-Embargo ins Hintertreffen geraten.

$\mathrm{Zu}$ diesem globalen digital divide kommen divergente Mediennutzungskulturen, die einen international turn in den Internet Studies angezeigt sein lassen (Goggin/McLelland 2009). Es gilt, die "heterogene Ko-Konstitution von Technologie auf den transnationalen Bühnen“" (Ito 2005: 7) zu berücksichtigen, da diese nicht nur zu differenten Nutzungsarten derselben Technik, sondern zu (teils) unterschiedlichen Technologien führen. Damit werden kulturelle Differenzen und politische Grenzen relevant, weshalb das Desiderat der Internationalisierung der Internet-Forschung präziser als deren Inter-Nationalisierung zu fassen ist.

Nicht erst seit Morozovs Einspruch gegen "cyber-utopische“ Illusionen über die angeblich befreiend-demokratisierende Wirkung des Internets (2011) ist deutlich, dass zur Beschreibung der Internetkultur von Ländern, die wie die Nachfolgestaaten der Sowjetunion durch Errichtung neuer Grenzen gekennzeichnet sind, die zwischenstaatlichen Grenzen mit entscheidend sind (Krivolap 2009).

Für eine Forschung, die digitale Grenzziehungen, Grenzkontrollen und Grenzüberschreitungen berücksichtigt, bieten sich die Nachfolgestaaten der Sowjetunion eher an als das in den Schengen-Raum inkorporierte Ostmitteleuropa. Daher beschränke ich mich hier auf russischsprachige (aber gerade nicht exklusiv russländische) Beispiele.

Während die Alternativkultur der späten Sowjetunion mit dem Samzidat durch ein prä-gutenbergsches Paradigma geprägt war, haben Moskau, Petersburg oder Tallinn in den 1990er und 2000er Jahren den Sprung in ein post-gutenbergsches, elektronisches Medienzeitalter getan, während metropolenferne Gebiete, zumal im asiatischen Teil der ehemaligen Sowjetunion, zurückgefallen sind.

Man mag Eco zustimmen, dass auch im Internetzeitalter Rekurse ins Gutenbergsche Universum stattfinden (2000), weshalb die Vermittlung philologischer Kompetenzen für die slavistische Ausbildung unabdingbar bleibt; eine medienwissenschaftlich nachhaltige Slavistik kann nicht auf das literaturtheoretische Erbe des 20. Jh.s verzichten. Allerdings muss sie dem durch Medienwandel erweiterten Objektbereich Rechnung tragen. 
Seit dem 19. Jh. hatte die Slavistik eine Einengung erfahren; während Definitionen des Gegenstandsbereichs der Slavistik um 1900 noch multidisziplinär angelegt waren (etwa Rechtskulturen einbezogen wissen wollten; s. Franz 1994: 3f.), setzte sich im 20. Jh. eine „Konzentration der modernen Slavistik auf Sprachwissenschaft, Literaturwissenschaft und Landeskunde der slavischen Völker" (46) durch.

Im Zuge des cultural turn trat die Landeskunde als Kulturwissenschaft aus dem Schatten der philologischen Schwestern, und das Aufgabenfeld der Gesamtslavistik erweiterte sich wieder. Der digitale Medienwandel macht die Einbeziehung der Medienwissenschaft unausweichlich und bietet neue Kooperationschancen für slavistische Linguistik und Literaturwissenschaft.

Für letztere scheint die Herausforderung größer, denn mit der Computerlinguistik reagierte die Sprachwissenschaft frühzeitig auf den Medienwandel. Die Literaturwissenschaft stand länger in Gefahr, in „fataler Bindung an das Papier" (Ioskevič 2006: 61) die, gute alte Buchkultur' hochzuhalten, anstatt ihren Literaturbegriff ähnlich zu erweitern wie die Linguistik, die computervermittelte Kommunikation als eine ihrer Domänen umfasst.

Dabei ist der Literaturzentrismus, der die russische Kultur vom frühen 19. bis ins späte 20 . Jh. bestimmte, weiterhin relevant: Zum einen imprägniert der Lehrplan der Russischen Föderation Schüler/innen fortgesetzt mit dem Kanon der Klassiker der russischen Literatur; zum anderen sticht das russische Internet (Runet) im internationalen Vergleich durch die Quantität der literarischen Produktion (s. Schmidt 2010: 68) hervor.

Produktiv ist im Runet besonders die Verschränkung von literarischen Gattungen und politischer Parodie; in einer Vielzahl der Online-Gattungen überwiegt die imitative Komponente (574f.). Solche imitativen Bezüge lassen sich mit Mitteln der intertextuellen Parodie-Analyse angehen, ähnlich wie die Reaktion der Printliteratur auf digitale Medien (etwa bei Pelevin) mit dem erprobten Werkzeug der Intermedialität beschreibbar ist.

Beides wären Untersuchungsgegenstände, anhand derer sich intertextuelle und intermediale Konstellationen zwischen traditionellen Print- und neueren digitalen Medien trefflich illustrieren ließen. Die Folgen für die literaturtheoretischen Konzepte, die bisher inter-Bezüge in den Blick nahmen, überschreiten das textinterpretatorische Erkenntnisinteresse kaum, und dass die slavistische Literaturwissenschaft hier (mit) zuständig ist, lässt sich kaum bestreiten.

Aus kalifornischer Perspektive hat Gumbrecht die Konjunktur der Intertextualitätsforschung im deutschsprachigen Raum als einen Vorläufer des seinerzeitigen ,youthful enthusiasm " für Intermedialität ausgemacht (2003: 13, 16). Dass dies für die Slavistik gesteigert gilt, ist unabweisbar. Hier wurde gerade Kristevas These von Sinnkomplizierung durch Intertextualität angeeignet (s. Lachmann 1990) und die Werkzentrierung in Frage gestellt.

Während die Intermedialitätstheorie dagegen Intermedialität anfangs oft als einem literarischen Text „werkinternes Phänomen" (Wolf 1996: 86) begriff, ging Hansen-Löve über die werkinterne Perspektive hinaus, als er es unternahm, das „System der intermedialen Korrelationen" aufzuschlüsseln für die „kulturtypologische Beschreibung einer Epoche" (1983: 291, 294). Der terminologisch weiter gehende Vorschlag, von Transmedialität zu sprechen, bleibt bei Meyer 2006 auf „ästhetische Verfahren" (2006: 117) beschränkt, bei denen ,,in einem Medientext ein erkennbares Transfersignal zur Richtungsänderung des Mediums im 
Primärmedium vorhanden" sein müsse (119). Die Aufmerksamkeit galt da weiter primär dem Einzelmedium.

Doch kann beim Universalmedium Internet noch von diskreten Einzelmedien gesprochen werden? Wenn die analogen Informationsträger sukzessive digitalisiert werden, unterscheiden sich die Informationsarten eher gattungsmäßig denn in technisch-materieller Hinsicht. Auf diese Weise ergibt sich statt einer "Opposition“ zwischen analogen und digitalen Medien ein „Kontinuum" der einstmals materiell distinkten analogen, nun aber durch Digitalisierung technisch homogenisierten Gattungen ${ }^{1}$ im Multimedium Internet (Schröter/Böhnke 2004: 24).

Wenn kein Hardware-Determinismus in Anschlag gebracht wird, sondern nach den Differenzen zwischen verschiedenen digitalen bzw. digitalisierten Gattungen gefragt wird, ist Kittlers Nivellierungsprognose (1986: 7) mit Schröter zu widersprechen:

„Von einer $[\ldots]$ totalen Einebnung der Differenz zwischen verschiedenen medialen Formen [...] kann keine Rede sein. Vielmehr existieren durch Sampling und Simulation die Spezifika der verschiedenen Medien abgelöst von ihrer technischen Materialität als virtuelle Form auf derselben Basis des digitalen Codes." (2004: 396f.)

Ist der Intermedialitätsbegriff dem digitalen Sammelbecken Internet noch gewachsen? Passieren die Gattungsinteraktionen nicht sämtlich innerhalb des Internets? Die Interiorisierungsbeobachtung mag medienphänomenologisch triftig sein für die Bestimmung des Medienstatus des Internets. Auch mögen in technischer Hinsicht Grenzen aufgehoben werden:

„,Beruht intermediale Praxis auf der Existenz passierbarer medialer Gren-

1 Paech schlägt dafür mit Zima den Begriff des Stils vor (1998: 18), der mir jedoch, da enger als Gattung, weniger geeignet scheint. zen und multimediale Praxis auf der Möglichkeit ihrer Überlagerung, so wird eine zukünftige transmediale Praxis - darin der transnationalen Öffnung etwa in EU oder NAFTA entsprechend - aus der zumindest tendenziellen Aufhebung dieser Grenzen resultieren." (Freyermuth 2007: 114)

Was bei ,trans'-Präfixen wie in Transmedialität allerdings aus dem Blick gerät, sind die Produzent/inn/en und Rezipient/inn/en der digital(isiert)en Information und die Art, wie sie mit den Gattungen des Multimediums Internet interagieren. Soll das Internet zum Gegenstand kulturwissenschaftlicher Erforschung werden, müssen neben technischen Gegebenheiten unbedingt die kulturellen, sozialen, politischen Interaktionen von Menschen über das Internet in den Blick rücken. Diese sind es, welche die diversen digital(isiert)en Gattungen für ihre jeweiligen Zwecke - von sozialen über politische und kommerzielle bis $\mathrm{zu}$ ästhetischen - je neu konfigurieren und in ihren Interaktionen selbst von den technischen Möglichkeiten mit geprägt werden.

Die historische Kultur-, Medienund Sozialwissenschaft hat sich um die je verschiedenen Konfigurationen zwischen den digital(isiert)en Gattungen und ihren Nutzer/inne/n zu kümmern. Dabei interessieren weniger hybride Überblendungen und Vermischungen als dynamische Interaktionen. Spannend wird es da, wo sich Differentes kreuzt, wo Kreuzungen Konflikte freilegen.

Schon McLuhan hat die Vorstellung einer „Kreuzung“ zwischen den Medien stark gemacht (1994: 86), Kreuzung allerdings $\mathrm{zu}$ sehr genetisch als hybridisierende Verschmelzung konnotiert (85). Jenkins dagegen arbeitet zwar mit dem Verschmelzung suggerierenden Konvergenz-Begriff, hebt aber auf Kollisionen und Konflikte ab: 
"Welcome to convergence culture, where old and new media collide, where grassroots and corporate media intersect, where the power of the media producer and the power of the media consumer interact in unpredictable ways." (Jenkins 2006: 2)

Will man also konfliktgeladene Kreuzungen in den Blick nehmen, bedarf es eines neuen Begriffs, denn intermedial ist traditionell auf ästhetischintentionale Referenzen eines Mediums auf ein anderes fokussiert, und transmedial suggeriert das Verschwinden der Differenzen zwischen den Medien(gattungen).

Der mir geeignet scheinende Begriff existiert bereits: Crossmedialität. Bisher hat ihn allenfalls die Journalismusforschung für sich entdeckt. ${ }^{2}$ Für die Erforschung von menschlichen Interaktionen mit digital(isiert)en Medien kann das Konzept der Grenzkreuzung die Leitvorstellung liefern. Im Kontrast zum traditionellen Sender-EmpfängerModell haben wir es hier nämlich mit einer Vielzahl von Sendern, Empfängern und Sender-Empfängern zu tun, deren - teilweise anonymisierte - Konfiguration und Interaktion von einem einzelnen Sender nicht vorhergesteuert werden kann. Die Vielfalt der im crossmedialen Diskursraum potenziell beteiligten, einander kreuzenden Medien, Sender und Empfänger macht Top-Down-Kommunikation zur Illusion. Jenkins hat, auch wenn er nicht von Crossmedia spricht, eine entsprechende Vorstellung von „crossing": "circulation of content - across different media systems, competing media economies, and national borders" (Jenkins 2006: 3).

2 Siehe Hohlfeld et al. 2010. Mein Begriff von Crossmedialität ist ein deskriptiver, der nicht von strategisch geplanter multimedialer Lancierung einer (Werbe-)Botschaft (Cross-Promotion) ausgeht, sondern nicht steuerbare Größen wie Dialog und Interaktion umfasst.
Was ein Medium, das ein anderes "kreuzt", semantisch und potenziell auch sozial auslöst, lässt sich nicht mehr allein auf "intendierte", mit „Transfersignal“ angedeutete Referenzen auf ein anderes Medium beschränken wie in einer werkzentriert verstandenen Intermedialitätstheorie. Hier muss es gerade auch um digitale Konflikte gehen, für welche Begriffe wie Web War - als diskursive Variante von Cyber War - nicht mehr übertrieben erscheinen (s. Rutten 2010). Eine crossmedial angelegte slavistische Forschung nähert Linguistik, Literaturund Kulturwissenschaft also an die Sozialwissenschaften, an Mediensoziologie und politische Kommunikationsforschung an.

Aus der Perspektive benachbarter Fächer dürfte dies als Anschlussfähigkeit eines von Marginalisierung bedrohten Faches wahrgenommen werden. Die Herstellung punktueller Anschlussfähigkeit wird es Slavist/inn/en umgekehrt eher gestatten, ihre monomedialen ästhetischen Steckenpferde zu füttern.

An einem vom slavistischen Kanon fernen Beispiel von kasachisch-amerikanisch-russischer crossmedialer Interaktion wie der über Cohens Film Borat ließe sich trefflich (aber für das Bulletin der deutschen Slavistik zu raumgreifend) zeigen $^{3}$, wie Literaturwissenschaft, Linguistik, Kulturwissenschaft und politische Kommunikationsforschung zusammen kommen können.

Zudem ließe sich daran eine weitere Herausforderung für eine künftige Russistik vorführen - die inter-nationale: Blogs, Foren und Videoseiten im Internet sind eine Arena für Auseinandersetzungen innerhalb der russischsprachigen Community, die in

3 Eine Langfassung dieses Beitrags, die diesen Aspekt ausführt, erscheint in: Medien und Wandel. Hg. v. Institut für interdisziplinäre Medienforschung. Berlin: Logos 2011. 
Zeiten des World Wide Web aber mitnichten mehr eine ausschließlich russländische ist: Die Diaspora, gerade in den deutschsprachigen Ländern oder im so genannten Nahen Ausland, nimmt aktiven Anteil am Runet. Das russischsprachige Internet ist ein Forum für einen weiteren Strukturwandel der Öffentlichkeit (wenn ich hier Habermas' Habilitationsschrift von 1962 in Richtung Online-Kommunikation weiterdenken darf - auch gegen Habermas' eigene Reserve gegen das Internet; 2008). Es geht um die digitale Öffentlichkeit von des Russischen mächtigen Internet-Usern. Diese agieren von überall her auf der Welt und tragen die Perspektiven ihrer Aufenthaltsländer in das russische Internet hinein. Der russischen Staatsmacht ist es damit unmöglich, missliebige Russland-kritische Meinungen, heute etwa aus Estland, aus der russischen Öffentlichkeit herauszuhalten. Umgekehrt wird das Runet, das zu den großen Online-Sprachgemeinschaften auf der Welt zählt, von den repressiven Regimes anderer Länder mit russischsprachigen Minderheiten, etwa in Zentralasien, als potenzielle Bedrohung ihrer gesteuerten Öffentlichkeiten angesehen.

Die kasachstanische Internetzensur hatte borat.kz schon 2005 getroffen (Saunders 2007: 236). Als Sacha Baron Cohens Film Borat: Cultural Learnings of America for Make Benefit Glorious Nation of Kazakhstan in die Kinos kam, brandete Protest von kasachischer Regierungsseite auf, obwohl „Kasachstan" darin nicht mehr war als ein „empty signifier" (Schatz 2008: 54). Warum?

Allein eine der vielen online verfügbaren Versionen des englischsprachigen Trailers zum Film wurde bei Youtube $^{4}$ bis 01.04.2011 schon 853.291 Mal

4 http://www.youtube.com/watch? $\mathrm{v}=$ WH2CABcffAo, 15.01.2011. aufgerufen, „Best of Borat" ${ }^{\prime 5}$ 7.443.182 mal. Gerade auf russischsprachigen Video-Websites wie rutube.ru, rutracker.org (früher: torrent.ru) oder der russischsprachigen Variante von youtube.com findet sich eine große Zahl von Raubkopien aus und parodistischen Fortschreibungen von Borat. Die mehrheitlich von ethnischen Kasachen betriebene russischsprachige Website mit russischem Domain-Namen arba.ru reproduzierte am 12. März 2007 einen Bericht einer der wichtigsten russischen Nachrichtenseiten lenta.ru: „Граждане Казахстана скупают «Бората» в интернет-магазине [amazon.com]“ (Graždane 2007).

Der Film wurde in Kasachstan vor allem in russischer Synchronisation rezipiert, für deren Gestaltung grammatische Defizite der englischen Fassung reproduziert wurden: Aus „We like“ wird „Нраица!" ohne grammatisches Subjekt und in phonetischer Reduktion. Der Satz „Моя звай Борат, я к вам из Казахстан", undenkbar ohne das in Arsen'evs Dersu Uzala und den Verfilmungen von Babajan 1961 und Kurosawa 1975 verwendete russisch-chinesische Pidgin, hat Aufnahme in die Internetfolklore gefunden, was durch den russischen Vikicitatnik [Wikiquote] belegt wird. ${ }^{6}$

Die kasachische Regierung beunruhigten die wild wuchernden OnlineDebatten über Borat wie über die kasachische Politik zur Unterdrückung des Films, die insbesondere auf russischsprachigen Video-Websites über Borat stattfanden (s. bspw. Kazachstan 2007, Kinopersonaž 2007).

Das beunruhigte die kasachische Staatsführung nicht zuletzt deshalb, weil sich im Runet, etwa auf arba.ru, eine (mit Alexa Traffic Rank 847.681

5 http://www.youtube.com/watch? $\mathrm{v}=\mathrm{vFP}-\mathrm{MktgOKU \& feature=}$ related, 15.01.2011.

6 http://ru/wikiquote.org/wiki/

Саша_Барон_Коэн, 15.01.2011. 
[31.03.2011] allerdings nicht weit reichende) kasachische Öffentlichkeit artikulierte in einer Weise, die man elektronischen Tamizdat nennen könnte auf einer Seite mit russischem Domain-Namen, außerhalb des Zugriffs von Kazakhtelekom und kasachstanischem Informationsministerium.

Beeindruckt von der massiven Rezeption des Films im eigenen Lande über außerkasachstanische Websiten, setzte sich bei den politischen Entscheidungsträgern in Kasachstan allmählich die Wahrnehmung durch, dass ihr "protesting too much" (Schatz 2008: 56) verräterisch war und der Versuch, die Verbreitung des Films in Kasachstan zu beschränken (Schatz 2008: 58), einen Bestätigungseffekt gehabt hatte für die negativen Heterostereotype, die der Film auf Kasachstan projizierte.

Schließlich machte selbst Präsident Nazarbaev bei einer Pressekonferenz am 22. November 2006 in London einen postmodernen Versuch spielerisch-ironischer Selbstrevision: Er fragte ins Publikum, ob der Journalist Borat Sagdiev anwesend sei. Danach gab er dem Spectator ein Interview, das folgendermaßen überschrieben wurde: „In this exclusive article, Nazarbayev presents a different picture of his homeland to the caricature of Sacha Baron Cohen's film. It is a thriving, optimistic nation. We like!" (Nazarbayev 2006)

„We like" ist das hinlänglich bekannte Borat-Zitat. Was hier passiert, ist die Aneignung der Parodie als „brand“ (Saunders 2008: 79) - im Außenblick des Spectator. Doch scheint Ähnliches auch in Kasachstan zu passieren: Das negative Heterostereotyp kippt zum positiven Autostereotyp; Selbstorientalisierung wird zur Verkaufsstrategie. Die kasachische Seite entmarginalisiert sich selbst durch ihr Eingehen auf die satirischen Heterostereotype. ,Belohnt' wird dies von englischsprachigen Medien durch sprachliche Anerkennungssignale wie minorisierten Sprachgebrauch, was de facto eine Remajorisierung der subaltern-defizitären Sprechweise durch den hegemonialen Diskurs darstellt.

Es wäre blauäugig, am flexibleren Crossmedia-Management der kasachstanischen Staatsführung eine Abmilderung des autoritären Kurses ablesen zu wollen. Es ist ein „Authoritarianism 2.0" (Kalathil 2004: 43), in dem Nazarbaevs humorvoller Fernsehauftritt und konziliantes Zeitungsinterview über das Medium Internet weltweit zugänglich gemacht werden, wo sie das Image des autoritären Präsidenten crossmedial aufbereiten - Nazarbaev 2.0.

Was können wir daraus für die Slavistik lernen? Es kann mitnichten darum gehen, philologische Arbeitsweisen $\mathrm{zu}$ ersetzen, sondern sie einzubetten. Bei einem crossmedialen Ansatz werden erprobte literatur- und kulturwissenschaftliche Arbeitsformen mit Medien- und Medientechnik-Kompetenz verbunden. Haben Darntons History of Books und ihre russistische Umsetzung bei Dobrenko die Rezeptionsformen von Literatur in den Blick genommen, so sind bei Film und Internet z.B. Nutzungsstatistiken, Forumsdiskussionen, Filterversuche etc. einzubeziehen. Die literaturwissenschaftliche Rezeptionssoziologie muss mit der Mediennutzungsforschung $\mathrm{zu}$ einer „history of printed and digitalized information" verzahnt werden.

Aus der Kehrtwendung in Nazarbaevs Borat-Politik lässt sich lernen, dass in Zeiten einer global operierenden Online-Unterhaltungselektronik Stereotype und "transnational images" (Schatz 2008: 61) nicht mehr durch eine einzelne Staatsmacht kontrollierbar sind. $\mathrm{Ob}$ damit - entgegen Morozovs Bedenken - das Internet doch so etwas wie eine Teilermächtigung von Millionen Nutzer/inne/n 
gegenüber den Potentaten einzelner Staaten darstellt?

Wenn politisch subversiver Humor den sich digital Erheiternden auch nur virtuelle Erleichterung bringt, ist internationale Medienkompetenz doch eine vom Arbeitsmarkt diktierte Schlüsselqualifikation, die die slavistischen Institute ihren Absolvent/inn/en bisher zumeist schuldig bleiben. Um der Zukunftsfähigkeit des Studienfaches willen gilt es dies zu ändern.

\section{Literatur}

Eco, U. 2000. „From Internet to Gutenberg". Blesok 16,3 (2000). http:// www.blesok.com.mk/tekst.asp?lang=en g\&tekst=232, 03.01.2011.

Franz, N. 1994. Einführung in das Studium der Slavischen Philologie. Geschichte, Inhalte, Methoden. Darmstadt.

Freyermuth, G. 2007. „Thesen zu einer Theorie der Transmedialität". In: Intermedialität/Transmedialität. Hg. G. Freyermuth. Köln et al., 104-117.

Goggin, G., McLelland, M. (eds.) 2009. Internationalizing Internet Studies: Beyond Anglophone Paradigms. New York-London.

Graždane 2007. „Graždane Kazachstana skupajut ,Borata' v internet-magazine“. http://www.arba.ru/news/1570, 02.01. 2011.

Gumbrecht, H.U. 2003. „Why Intermediality - If at all?". In: Intermedialidad e hispanística. Frankfurt a.M., 13-17.

Habermas, J. 1962. Strukturwandel der Öffentlichkeit. Untersuchungen zu einer Kategorie der bürgerlichen Gesellschaft. Neuwied.

- 2008. „Hat die Demokratie noch eine epistemische Dimension? Empirische Forschung und normative Theorie". In: Ach, Europa. Kleine Politische Schriften XI. Frankfurt a.M., 138-191.

Hansen-Löve, A.A. 1983. „Intermedialität und Intertextualität. Probleme der Korrelation von Wort- und Bildkunst - Am Beispiel der russischen Moderne“. In: Dialog der Texte. Hamburger Kolloquium zur Intertextualität. Hg. W. Schmid, W.D. Stempel, Wien, 291-360.

Hohlfeld, R., et al. (Hg.) 2010. Crossmedia. Wer bleibt auf der Strecke? Beiträge aus Wissenschaft und Praxis. Berlin.

Ioskevič, Ja.B. 2006. Internet kak novaja sreda chudožestvennoj kul'tury. Sankt-Peterburg.

Ito, M. 2005. „Introduction“. In: Personal, Portable, Pedestrian: Mobile Phones in Japanese Life. Hg. v. M. Ito, D. Okabe u. M. Matsuda, Cambridge (MA), 1-16.

Jenkins, H. 2006. Convergence Culture: Where Old and New Media Collide. London-New York.

Kalathil, S. 2003. „Dot Com for Dictators“. Foreign Policy March/April 2003, 43-49.

Kazachstan 2007. „Kazachstan zajmetsja uničtoženiem nasledija Borata Sagdieva“. http://www.arba.ru/news/1329, 02.01.2011.

Kinopersonaž 2007. „Kinopersonaž Borat Sagdiev priznan gosdepom SŠA žertvoj kazachstanskoj cenzury". http://www. arba.ru/news/1541, 02.01.2011.

Kittler, F.A. 1986. Grammophon Film Typewriter. Berlin.

Krivolap, A. 2009. „Diskussija: Virtualizatsija belorusskoj vlasti v internete". Russian Cyberspace 1,1 (2009). http:// www.russian-cyberspace.com/pdf/ issue1/Virtualization-of-BelarusianPower_A-Krivolap.pdf, 20.04.2010.

Lachmann, R. 1990. Gedächtnis und Literatur. Intertextualität in der russischen Moderne. Frankfurt a.M.

McLuhan, M. 1994. Die magischen Kanäle. Understanding Media. Dresden.

Meyer, U. 2006. „Transmedialität (Intermedialität, Paramedialität, Metamedialität, Hypermedialität, Archimedialität). Das Beispiel der Werbung“. In: Transmedialität. Hg. U. Meyer, R. Simanowski, C. Zeller, Göttingen, 110-130.

Morozov, E. 2011. The Net Delusion: How not to Liberate the World. London et al.

Nazarbayev, N. 2006. „Who Needs Borat?“. The Spectator 25.11.2006, http:// www.spectator.co.uk/essays/all/26538/ who-needs-borat.thtml, 03.01.2011.

Paech, J. 1998. „Intermedialität. Mediales 
Differenzial und transformative Figuration". In: Intermedialität. Theorie und Praxis eines interdisziplinären Forschungsgebiets. Hg. J. Helbig. Berlin, 1430.

Rose, R. 2006. Internet Diffusion in Russia: A Model of a Laggard Catching up. Aberdeen.

Rutten, E. 2010. „Web Wars: Digital Diasporas and the Language of Memory". http://www.digitalicons.org/issue04/ files/2010/11/Rutten-4.11.pdf, 31.03.2011.

Saunders, R.A. 2007. „In Defence of Kazakshilik: Kazakhstan's War on Sacha Baron Cohen". Identities: Global Studies in Culture and Power 14 (2007), 225-255.

- 2008. „Buying into Brand Borat: Kazakhstan's Cautious Embrace of Its Unwanted 'Son'". Slavic Review 67,1 (2008), 63-80.

Schatz, E. 2008. „Transnational Image Making and Soft Authoritarian Kazakhstan“. Slavic Review 67,1 (2008), 5062.

Schmidt, H. 2010. Kleine Gattungen, große Graphomanen. Studien zu Soziologie und Ästhetik der russischen Literatur im Internet (1994-2009). Habilitationsschrift, FU Berlin, http://www.ruhr-uni-bochum. de/russ-cyb/library/texts/de/ schmidt_russische_literatur_im_internet .pdf, 18.02.2010.

Schröter, J. 2004. „Intermedialität, Medienspezifik und die universelle Maschine". In: Performativität und Medialität. Hg. S. Krämer, München, 385-411.

Schröter, J.; Böhnke, A. (Hg.) 2004. Analog/Digital - Opposition oder Kontinuum? Zur Theorie und Geschichte einer Unterscheidung. Bielefeld.

Wolf, W. 1996. „Intermedialität als neues Paradigma der Literaturwissenschaft?“. Arbeiten aus Anglistik und Amerikanistik 21 (1996), 85-116.

\section{Filmografie}

Borat: Cultural Learnings of America for Make Benefit Glorious Nation of Kazakhstan (Regie: L. Charles, USA 2006). 
Programmatisches

\section{Nach Minsk!?}

\section{Von Ulrich Steltner (Jena)}

Bekanntlich soll der 15. Internationale Slawistenkongress 2013 in Minsk stattfinden. Endlich in Minsk!, könnte man meinen; denn allen anderen slawischen Ländern wurde bereits die Ehre zuteil, den Kongress ausrichten $\mathrm{zu}$ dürfen. ${ }^{1}$ Gegen Minsk gab es bereits im Jahre 2003 Einwände, und die Runde ging dann nach einigem Hin und Her ja auch an Ohrid. Daher lässt sich wohl nicht sagen, das Internationale Komitee hätte das mit Minsk verknüpfte politische Problem übersehen. Minsk galt schon damals als Hauptstadt der "letzten Diktatur" in Europa, zumindest der letzten Diktatur stalinistischen Typs, - die Herrschaftsausübung von Bat'ka Lukašenko wurde schon damals kritisch beobachtet und kommentiert. Deren vorläufiger und im Westen bemerkter Höhepunkt waren die Vorgänge um die Wahlen am 19. Dezember 2010, als Kandidaten der Opposition, die ohnehin keine wirkliche Chance gehabt hatten, noch am Wahlabend

1 Die heutige Gemengelage im Süden der Slavia muss hier gewissermaßen außer Acht gelassen werden. Immerhin fand der Kongress zweimal in Jugoslawien statt (Belgrad 1955 und Ljubljana / Zagreb 1978) sowie zweimal in Nachfolgestaaten: 2003 in Slowenien (Ljubljana) und 2008 in Makedonien (Ohrid). Im Übrigen sind mit der Ehre durchaus finanzielle Verpflichtungen verbunden, die letztlich eine staatliche Unterstützung notwendig machen.

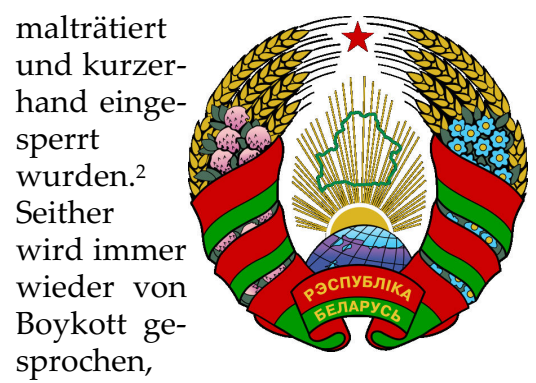

einem Boykott, der auf den ersten Blick durchaus plausibel erscheint. Soll man etwa die Selbstdarstellung eines Unrechts-Regimes unterstützen, sich gar zu nützlichen Idioten machen lassen und somit allen denjenigen ein falsches Signal übermitteln, denen in Weißrussland die Menschenrechte verwehrt werden? Soll man nicht lieber ein Zeichen setzen, z.B. eine Protestresolution verschicken und ansonsten einfach zuhause bleiben? (Man würde nach dem Protest vermutlich sowieso kein Visum mehr bekommen.) Als bedeutende Vorbilder werden gern die Olympischen Sommerspiele angeführt: 1936 in Deutschland und 2008 in China - aber dienten sie vor allem der Reputation der Diktaturen? 1980 in der UdSSR - aber war der Boykott des Westens wirklich

2 Vgl. die stattliche Liste URL http:// www.freebelarusnow.org/en/victimsgallery. Darüber hinaus verschwinden Personen einfach ohne jede Spur; vgl. URL http://www.human-rights-belarus.org/deutsch/Dokumentation-Verschwundene-Belarus-Lukaschenko. html. 
ein Erfolg? Schon diese Beispiele zeigen das ganze Dilemma eines der Situation angemessenen Verhaltens. Zudem lässt sich der Slawistenkongress wohl kaum mit dem Groß-Event Olympia vergleichen. Trifft es Lukašenko wirklich, wenn wir Deutsche dabei fehlen, selbst wenn wir mit 45 Plätzen die zweitstärkste Delegation nach Russland (60 Plätze) stellen? Oder schaden wir hinfort nicht nur uns selbst und der Wirkung unserer Forschungen in der slawischen Welt? Auf den zweiten Blick hat ein Boykott doch seine Tücken.

Natürlich steht zu erwarten, dass der Kongress propagandistisch ausgeschlachtet werden wird. Um noch ein Beispiel anzuführen, sei an Gerhard Schröders europäischen Alleingang 1998 erinnert, als er, damals noch niedersächsischer Regierungschef und Kanzlerkanndidat der SPD, Lukašenko zur Hannover-Messe herzlich begrüßte. Das Echo ist auf der Web-Site der Weißrussischen Botschaft in Berlin, um im Bilde zu bleiben, noch immer „zu hören". ${ }^{3}$

Indes scheint noch gar nicht ausgemacht zu sein, dass der weißrussischen Regierung die Veranstaltung überhaupt in den Kram passt. Der Kongress würde eine Menge westlicher Intellektueller ins Land bringen, die zudem in aller Regel des Russischen mächtig sind und sich deshalb ohne Weiteres verständigen können, wenn auch sicherlich nicht unkontrolliert. Die Behinderungen, denen der Internationale Weißrussisten-Kongress im vorigen Jahr von Seiten der Regierung aus- gesetzt war, lassen ahnen, dass es letztlich sogar einen Boykott sozusagen "von der anderen Seite“ geben könnte. Der brauchte sich gar nicht in Verboten zu äußern, sondern könnte beispielsweise die Finanzierung des Projektes oder sonstige notwendige logistische Unterstützung betreffen. Dem sollte auf keinen Fall Vorschub geleistet werden. Es wäre dagegen wohl sinnvoller, mit speziell auf Weißrussland, d.h. seine Sprache, Literatur und Kultur bezogenen Themen aufzuwarten, als explizit und demonstrativ politisch zu handeln.

Schließlich sei noch angemerkt, dass die westliche, insbesondere die westdeutsche Slawistik bis Mitte oder Ende der 80er Jahre des vergangenen Jahrhunderts eine durchaus politische Funktion wahrgenommen hat, nämlich die Erinnerung an offiziell Vergessenes und Verfemtes wachzuhalten und stets die ganze Kultur der slawischen Länder in den Blick zu nehmen und nicht etwa nur den jeweils opportunen Ausschnitt. So löckte die Slawistik einerseits wider den Stachel, war aber andererseits auf Kontakte mit dem „Reich des Bösen“ (Ronald Reagan) angewiesen. Diese waren seit den 70er Jahren möglich und wurden gern genutzt. Ein BoykottAufruf gegen Minsk hätte auch ein Quentchen Heuchelei; denn Weißrussland könnte man eventuell als zu vernachlässigende Größe betrachten - im Unterschied zur alten Sowjetunion! Jede/r muss also wissen, was er oder sie tut, wenn er oder sie nach Weißrussland fährt, und muss sich persönlich entscheiden.

3 Vgl. URL http://www.germany.

belembassy.org/de/bilateral/. 
Im Überblick

\section{Der Deutsche Slavistenverband 2010/2011}

Vorsitzende:

Stellvertreter:

Schriftführerin:

Kassenwart:

\section{Der Vorstand des Verbandes}

Prof. Dr. Monika Wingender (Gießen)

Prof. Dr. Norbert Franz (Potsdam)

Prof. Dr. Miranda Jakiša (Berlin)

PD Dr. Hermann Fegert (Göttingen)

\section{Kommissionen des Verbandes}

\section{Slavistentagskommission}

Tilman Berger

Monika Wingender

Gerhard Giesemann

Renate Belentschikow

Tilman Berger

Jochen Raecke

Schamma Schahadat

Holger Kuße

Ludger Udolph

Christian Prunitsch

Dietrich Scholze

Gerd Hentschel

Karl Gutschmidt

Monika Wingender

Sebastian Kempgen

Dietrich Scholze

Hans Rothe

Gerhard Giesemann

Ulrike Jekutsch

Ulrich Steltner

Vorsitzender

Mitglied qua Amt

Literaturwissenschaft

Sprachwissenschaft

Ausrichter 2009, Tübingen

Ausrichter 2009, Tübingen

Ausrichterin 2009, Tübingen

Ausrichter 2012, Dresden

Ausrichter 2012, Dresden

Ausrichter 2012, Dresden

Ausrichter 2012, Bautzen

\section{Deutsches Slavistenkomitee}

Vorsitzender, im Präsidium des MKS

Mitglied (letzter Vorsitzender)

Mitglied (Verbandsvorsitzende)

Mitglied (letzter Verbandsvors.)

Mitglied (Sorabistik)

Ehrenmitglied

Mitglied

Mitglied

Mitglied

\section{Maprjal}

Renate Belentschikow

Beauftragte des Slavistenverbandes, im Präsidium von Maprjal 


\section{Mitgliederschaft}

Der Deutsche Slavistenverband hat derzeit (Juli 2011) 249 Mitglieder, darunter die unten aufgeführten, seit der Drucklegung des letzen Bulletins neu aufgenommenen. Die Mitgliederzahl hat damit seit dem letzten Jahr (2010: 233) einen weiteren erfreulichen Aufschwung genommen, der vornehmlich auf die Öffnung des Verbandes für die Promovierten zurückgeht.

Von den 249 Mitgliedern sind 158 Professoren/innen, 25 sind Privatdozenten/innen, 66 sind Promovierte. In einer aktiven Berufstätigkeit sind 182 Mitglieder, 67 sind im Ruhestand. Im Ausland tätig bzw. ansässig sind 27 Mitglieder. Die Zahl der Promovierten im Verband ist nunmehr bereits mehr als doppelt so hoch wie die der Privatdozenten/innen und inzwischen mehr als ein Drittel des Anteils der Professoren/innen.

\section{Neue Mitglieder (Juli 2010-Juli 2011)}

Dr. Anna Ananieva, Universität Mainz

Dr. Natalia Brüggemann, Universität Hamburg

Dr. Elena Chkhaidze, Universität Bochum

Dr. Matteo Colombi, Universität Leipzig

Dr. Elena Dieser, Universität Würzburg

Dr. Jeanette Fabian, Humboldt-Universität zu Berlin

Prof. Dr. Susanne Frank, Humboldt-Universität zu Berlin

Dr. Gudrun Heidemann, Universität Wrocław (PL)

Dr. Anke Hennig, Freie Universität Berlin

Dr. Alfrun Kliems, Universität Leipzig

Dr. Grzegorz Krajewski, Universität Freiburg

Dr. Renata Makarska, Universität Tübingen

Dr. Olav Müller-Reichau, Universität Leipzig

Dr. Sead Porobić, Universität Hamburg

Dr. Lisanne Sauerwald, Universität München

Dr. Matthias Schwartz, Freie Universität Berlin

Dr. Katharina Sperl, Hochschule Heilbronn

Dr. Nadine Thielemann, Universität Potsdam

Dr. Robert Zangenfeind, Universität Leipzig

Der Verband freut sich über die große Zahl der neuen Mitglieder, heißt alle herzlich willkommen und lädt auch weiterhin alle promovierten Slavistinnen und Slavisten zur Mitarbeit und Mitgliedschaft ein. Auf der Webseite des Verbandes (www.slavistenverband.de) finden sich Informationen über die Voraussetzungen und Modalitäten, ebenso die gültige Satzung des Verbandes. 
Die deutsche Slavistik im Überblick

\title{
Who's Where \\ an den Slavistischen Seminaren und Instituten \\ und auf anderen slavistischen Professuren der Bundesrepublik Deutschland
}

\author{
Stand: Sommersemester 2011 \\ Zusammengestellt von Norbert Franz (Potsdam)
}

1. Lehrstuhlbezeichnungen, Professuren und Inhaber/innen derselben

2. An der Einrichtung tätige Hochschuldozent(inn)en oder andere habilitierte Mitarbeiter/innen

3. Honorarprofessuren, Stipendiaten/innen, Gastdozenten/innen

4. Entpflichtete Professorinnen und Professoren

\section{Bamberg: Otto-Friedrich-Universität Slavistik}

1. Slavische Sprachwissenschaft: Prof. Dr. Sebastian Kempgen; Slavische Literaturwissenschaft: Prof. Dr. Elisabeth von Erdmann; Slavische Kunst- und Kulturgeschichte: Prof. Dr. Ada Raev

2. PD Dr. Anna Rothkoegel (venia für Slavische Philogie / Literaturwissenschaft); PD Dr. Daniel Schümann (venia für Slavische Literaturwissenschaft)

4. Entpflichtet: Prof. Dr. Peter Thiergen

Bautzen/Budyšin: Sorbisches Institut e.V./Serbski institut z.t.

Abt. Kultur- und Sozialgeschichte: Prof. Dr. Dietrich Scholze (zugleich Institutsdirektor);

Abt. Empirische Kulturforschung/Volkskunde: PD Dr. Elka Tschernokoshewa;

Abt. Sprachwissenschaft: Dr. habil. Sonja Wölke;

Abt. Zentralbibliothek/Kulturarchiv: Dr. Franz Schön;

Abt. Niedersorbische Forschungen Cottbus: Dr. Hauke Bartels

\section{Berlin: Freie Universität}

Peter Szondi-Institut für Allgemeine u. Vergl. Literaturwissenschaft und Osteuropainstitut

1. Professur für Allgemeine und Vergleichende Literaturwissenschaft und Slavische Literaturen: Prof. Dr. Georg Witte

2. PD Dr. Henrike Schmidt (venia für Slavische Philologie) 


\section{Berlin: Humboldt-Universität Institut für Slawistik}

1. Ostslawische Sprachen: Prof. Dr. Luka Szucsich; Kulturen Mittel- und Osteuropas: z.Z. vertreten durch Prof. Dr. Sabine Hänsgen; Ostslawische Literaturen und Kulturen: Prof. Dr. Susanne Frank; Süd- und Ostslawische Literaturen (J): Prof. Dr. Miranda Jakiša; Südslawische Sprach- und Kulturwissenschaft: Prof. Dr. Christian Voss; Westslawische Literaturen (Polonistik, J): vacat; Westslawische Literaturen und Kulturen (Bohemistik/Slowakistik): z.Z. vertreten durch Prof. Dr. Tomaš Glanc; Westslawische Sprachen: Prof. Dr. Alicja Nagórko; Fachdidaktik Russisch: Prof. Dr. Anka Bergmann

2. PD Dr. Brigitta Helbig-Mischewski (venia für Slawische Literaturen und Kulturen); PD Dr. Gerd-Dieter Nehring (venia für Slawistik und Albanologie)

3. DAAD-Gastlehrstuhl „Siegfried-Unseld“: Prof. Dr. Tatjana Tolstaja (SS 2011), DAAD-Gastdozentin: Prof. Dr. Ewa Geller (SS 2011)

4. Entpflichtet: Prof. Dr. Erika Günther; Prof. Dr. Heinrich Olschowsky; Prof. Dr. Barbara Kunzmann-Müller; Prof. Dr. Manfred Jähnichen; Prof. Dr. Wolfgang Gladrow; Prof. Dr. Fred Otten; Prof. Dr. Bertold Brandt; Prof. Dr. Peter Zajac

\section{Bielefeld: Universität}

Fakultät für Linguistik und Literaturwissenschaft

1. Slavistik/Literaturwissenschaft: gestrichen

4. Entpflichtet: Prof. em. Dr. Hans Günther

\section{Bochum: Ruhr-Universität}

\section{Seminar für Slavistik/Lotman-Institut}

1. Slavische Philologie (Sprachwissenschaft): Prof. Dr. Tanja Anstatt; Slavische Philologie (Literaturwissenschaft): Prof. Dr. Mirja Lecke; Russische und sowjetische Kultur: Prof. Dr. Bernd Uhlenbruch

2. PD Dr. Ulrike Goldschweer (venia für Slavische Literaturwissenschaft), PD Dr. Manfred Schruba (venia für Slavische Literaturwissenschaft)

4. Entpflichtet: Prof. em. Dr. Karl Eimermacher; Prof. em. Dr. Helmut Jachnow; Prof. Dr. Christian Sappok

\section{Bonn: Rheinische Friedrich-Wilhelms-Universität Arbeitsbereich Slavistik der Philosophischen Fakultät}

2. PD Dr. Riccardo Nicolosi, AOR (Literaturwissenschaft); J.-Prof. Dr. Vladislava Zhdanova, AOR (Sprachwissenschaft)

4. Entpflichtet: Prof. em. Dr. Dr. h.c. mult. Hans Rothe; Prof. em. Dr. Helmut Keipert

\section{Bremen: Universität}

\section{Seminar für Ost- und Mitteleuropäische Studien}

1. Ost- und westslavische Kultur- und Literaturgeschichte: Prof. Dr. Wolfgang Kissel; Westslavische Kulturgeschichte, Polonistik, Soziologische Theorien: Prof. Dr. Zdzisław Krasnodębski

3. Prof. Dr. Galina Michaleva (RGGU Moskau), Politikwissenschaft

4. Entpflichtet: Prof. Dr. Klaus Städtke 


\section{Dresden: Technische Universität Institut für Slavistik}

1. Slavische Sprachgeschichte und Sprachwissenschaft: Prof. Dr. Holger Kuße; Slavistik / Literaturwissenschaft: Prof. Dr. Ludger Udolph; Polnische Kultur- und Landesstudien: Prof. Dr. Christian Prunitsch

3. Erasmus-Mundus-Stipendiat: Prof. Dr. Vladimir Kantor (Moskau)

4. Entpflichtet: Prof. Dr. Ute Köhler; Prof. Dr. Karl Gutschmidt; apl. Prof. Dr. Rosemarie Thiemt

\section{Erfurt: Universität \\ Philosophische Fakultät}

1. Slawistische Literaturwissenschaft: Prof. Dr. Holt Meyer

2. Apl. Prof. Dr. Christina Parnell (Slavische Literaturwissenschaft)

\section{Erlangen: Friedrich-Alexander-Universität Institut für Slavistik}

1. Slavistische Linguistik: gestrichen; Slavische Literaturwissenschaft: gestrichen

4. Entpflichtet: Prof. Dr. Klaus Steinke

\section{Frankfurt am Main: Johann Wolfgang-Goethe-Universität Institut für Vergleichende Sprachwissenschaft, Phonetik und Slavische Philologie}

1. Die Slavistik in Frankfurt wurde geschlossen.

4. Entpflichtet: Prof. Dr. Gerd Freidhof

\section{Frankfurt an der Oder: Europa-Universität Viadrina Kulturwissenschaftliche Fakultät}

1. Osteuropäische Literaturen: Prof. Dr. Christa Ebert; Gerd-Bucerius-Stiftungsprofessur für Kultur und Geschichte Mittel- und Osteuropas: Prof. Dr. Werner Benecke; Deutsch-polnische Literatur- und Kulturbeziehungen und Gender Studies: Prof. Dr. Bożena Chołuj

\section{Freiburg: Albert-Ludwigs-Universität Slavisches Seminar}

1. Slavistik (Slavische Philologie): Prof. Dr. Juliane Besters-Dilger; Slavistik (Slavische Philologie): Prof. Dr. Elisabeth Cheauré

2. Apl. Prof. Dr. Peter Drews (venia für Slavische Philologie)

4. Entpflichtet: Prof. Dr. Eckhard Weiher

\section{Gießen: Justus-Liebig-Universität Institut für Slavistik}

1. Slavische Philologie (Sprachwissenschaft): Prof. Dr. Monika Wingender; Slavische Philologie (Literaturwissenschaft): Prof. Dr. Reinhard Ibler; Slavische Philologie (Literaturwissenschaft): Prof. Dr. Alexander Graf; Slavische Sprach- und Kulturwissenschaft (Ost- und Westslavistik): Prof. Dr. Thomas Daiber

2. PD Dr. Konstantin Lappo-Danilevskij (venia für Slavische Literaturwissenschaft)

3. DAAD-Gastdozentin: Prof. Dr. Damina Shaibakova (Almaty / Kazachstan)

4. Entpflichtet: Prof. em. Dr. Gerhard Giesemann 


\section{Göttingen: Georg-August-Universität Seminar für Slavische Philologie}

1. Slavische Philologie (Sprachwissenschaft): Prof. Dr. Uwe Junghanns; Slavische Philologie (Literaturwissenschaft): Prof. Dr. Matthias Freise

2. PD Dr. Hermann Fegert (venia für Slavische Philologie [Sprachwissenschaft])

4. Entpflichtet: Prof. em. Dr. Reinhard Lauer; Prof. em. André de Vincenz; Prof. Dr. em. Werner Lehfeldt

\section{Greifswald: Ernst-Moritz-Arndt-Universität Institut für Slawistik}

1. Slawische Sprachwissenschaft: Prof. Dr. Manfred Niemeyer; Slawische Literaturwissenschaft: Prof. Dr. Ulrike Jekutsch; Ost- und Westslavische Philologie: Prof. Dr. Alexander Wöll

2. PD Dr. Cornelia Mannewitz (venia für Russische Sprache der Gegenwart)

3. Prof. h.c. (Univ. Kostroma), Dr. h.c. (Univ. St. Petersburg) Dr. phil. Harry Walter

4. Entpflichtet: Prof. Dr. Valerij Mokienko

\section{Halle-Wittenberg: Martin-Luther-Universität Institut für Slavistik}

1. Slavische Philologie/Sprachwissenschaft: Prof. Dr. Swetlana Mengel; Slavische Philologie/Literaturwissenschaft: Prof. Dr. Gabriela Lehmann-Carli; Südslavistik (Schwerpunkt Literaturwissenschaft): Prof. Dr. Angela Richter

\section{Hamburg: Universität \\ Institut für Slavistik}

1. Slavistik Sprachwissenschaft: Prof. Dr. Marion Krause; Slavistik Sprachwissenschaft: Junior-Professor Dr. Bernhard Brehmer; Slavistik Literaturwissenschaft: Prof. Dr. Anja Tippner; Slavistik Literaturwissenschaft: Prof. Dr. Robert Hodel

4. Entpflichtet: Prof. Dr. Volkmar Lehmann; Prof. Dr. Dr. h.c. Wolf Schmid

\section{Heidelberg: Ruprecht-Karls-Universität Slavisches Institut}

1. Slavische Sprachwissenschaft: Prof. Dr. Jadranka Gvozdanović; Slavische Literaturwissenschaft: Prof. Dr. Urs Heftrich

2. apl. Prof. Dr. Alexander Bierich (venia für Slavische Sprachwissenschaft); PD Dr. Christoph Garstka; Dr. habil. (Universität Sofia) Blagovest Zlatanov Velichkov

3. Gastprofessor: Prof. Dr. Anatolij A. Polikarpov (Moskau)

4. Entpflichtet: Prof. Dr. Horst-Jürgen Gerigk; Prof. Dr. Baldur Panzer; Dr. habil. DSc. (Univ. Sofia) Rumjana Zlatanova

\section{Heidelberg: Institut für Übersetzen und Dolmetschen}

1. Russistik u. bes. Berücksichtigung der Übersetzungswissenschaft: Prof. Dr. Jekaterina Lebedewa 


\section{Jena: Friedrich-Schiller-Universität Institut für Slawistik}

1. Slawische Philologie (Sprachwissenschaft): Prof. Dr. Jiřina van Leeuwen-Turnovcová; Slawische Philologie (Literaturwissenschaft): Prof. Dr. Andrea Meyer-Fraatz; Südslawistik: Prof. Dr. Thede Kahl

2. PD Dr. Christine Fischer (venia für Slawische / Vergleichende Literaturwissenschaft)

4. Entpflichtet: Prof. Dr. Ulrich Steltner; Prof. Dr. Gabriella Schubert

\section{Kiel: Christian-Albrechts-Universität Institut für Slavistik}

1. Slavische Kultur- und Literaturwissenschaft: Prof. Dr. Michael Düring; Slavische Philologie (Sprachwissenschaft): Prof. Dr. Norbert Nübler

4. Entpflichtet: Prof. Dr. Annelore Engel; Prof. Dr. Armin Knigge

\section{Köln: Universität Slavisches Institut}

1. Slavische Sprachwissenschaft: vacat; Slavische Literaturwissenschaft: vacat

3. Gastdozenten: Assoz. Prof. Dr. Andrej Bojadžiev, Gastdozent für Bulgarisch; Prof. Dr. Mária Vajíčková, Gastdozentin für Slovakisch

4. Entpflichtet: Prof. em. Dr. Bodo Zelinsky; Prof. Dr. Ulrich Obst

\section{Konstanz: Universität}

\section{FB Sprachwissenschaft / FB Literaturwissenschaft}

1. Slavistik (Sprachwissenschaft): Prof. Dr. Walter Breu; Slavistik (Slavische Literaturen und Allgemeine Literaturwissenschaft): Prof. Dr. Jurij Murašov; Slavische Literaturwissenschaft (J): Prof. Dr. Dr. Tanja Zimmermann

3. Mitarbeiter in DFG Projekten: PD Dr. Dmitrij Zakharine; Dr. habil. Konstantin Bogdanov

4. Entpflichtet: Prof. Dr. Renate Lachmann; Prof. Dr. Igor P. Smirnov

\section{Leipzig: Universität \\ Institut für Slavistik}

1. Ostslavische Sprachwissenschaft: Prof. Dr. Gerhild Zybatow; Ostslavische Literaturwissenschaft und Kulturstudien: Prof. Dr. Birgit Harreß; Westslavische Sprach- und Übersetzungswissenschaft: Prof. Dr. Danuta Rytel-Schwarz; Westslavische Literaturwissenschaft und Kulturstudien: Prof. Dr. Wolfgang F. Schwarz; Südslavische Sprach- und Übersetzungswissenschaft einschl. Südosteuropa-Linguistik: Prof. Dr. Uwe Hinrichs; Fachdidaktik (Didaktik der slawischen Sprachen): Prof. Dr. Grit Mehlhorn; Kulturstudien Ostmitteleuropas: Prof. Dr. Stefan Troebst

4. Entpflichtet: Prof. Dr. Jürgen Udolph (Deutsch-slavische Namensforschung); Prof. Dr. Ernst Eichler; Prof. Dr. Karlheinz Hengst; Prof. Dr. Karlheinz Kasper; Prof. Dr. habil. W. Sperber; Prof. Dr. sc. Walter Wenzel

\section{Institut für Angewandte Linguistik und Translatologie}

2. PD Dr. Wladimir Kutz

4. Entpflichtet: Apl. Prof. Dr. Eberhard Fleischmann (venia für Russische Übersetzungswissenschaft) 


\section{Institut für Sorabistik}

1. Sorbische Sprachwissenschaft: Prof. Dr. Eduard Werner; Sorbische Literaturwissenschaft: Hon.-Prof. Dr. Dietrich Scholze; Sorbische Literaturwissenschaft: Juniorprof. Dr. Tomasz Derlatka

2. Sorbische Sprachpraxis: PD Dr. Timo Meškank

\section{Magdeburg: Otto-von-Guericke-Universität Institut für fremdsprachliche Philologien}

1. Slavistische Sprachwissenschaft: Prof. Dr. Renate Belentschikow; Slavistische Literaturwissenschaft: Prof. Dr. Gudrun Goes

2. PD Dr. phil. habil. Andrea Scheller (venia für Slavistische Sprachwissenschaft)

4. Entpflichtet: HD Dr. Christine Heyer (Fachdidaktik Russisch)

\section{Mainz: Johannes Gutenberg-Universität Institut für Slavistik}

1. Slavische Sprachwissenschaft (Ostslavische und Westslavische Sprachen): Prof. Dr. Björn Wiemer; Slavische Literaturwissenschaft (Ostslavische und Südslavische Literaturen): Prof. Dr. Frank Göbler; Slavische Literaturwissenschaft mit bes. Berücksichtigung der westslavischen Literaturen: Univ.-Prof. Dr. Alfred Gall

2. PD Dr. habil. Una Patzke (venia für Slavische Sprachwissenschaft); Apl. Prof. Dr. Johann Meichel (venia für Slavische Literaturwissenschaft / Ostslavische Literaturen); PD Dr. habil. Rainer Goldt (venia für Slavische Literaturwissenschaft)

3. Prof. Dr. Marek Stanisz (Universität Rzeszów)

4. Entpflichtet: Prof. Dr. Wolfgang Girke; Prof. Dr. Brigitte Schultze

\section{Fachbereich Translations,- Sprach- und Kulturwissenschaft}

1. Russisch: Prof. Dr. Birgit Menzel; Polnisch: Prof. Dr. Erika Worbs

\section{Mannheim: Universität \\ Slavisches Seminar}

1. Slavistische Linguistik: gestrichen; Slavische Literaturwissenschaft: gestrichen

4. Entpflichtet: Prof. Dr. Dagmar Burkhart; Prof. Dr. Josip Matešić

\section{Marburg: Philipps-Universität}

\section{Fachbereich Fremdsprachliche Philologien, Fachgebiet Slawische Philologie}

1. Lehrstühle nach Gießen verlagert

2. Apl. Prof. Dr. Andrej N. Sobolev (venia für Slawische Sprachwissenschaft, Südslawische Sprachwissenschaft und Balkanlinguistik); PD Dr. Claudia Radünzel (venia für Slawische Philologie (Sprachwissenschaft)); PD Dr. Andrea Uhlig (venia für Slawische Philologie (Literaturwissenschaft))

4. Entpflichtet: Prof. Dr. Dr. h.c. Helmut Wilhelm Schaller

\section{München: Ludwig-Maximilians-Universität Institut für Slavische Philologie}

1. Slavische Philologie (Sprachwissenschaft): Prof. Dr. Ulrich Schweier; Slavische Philologie (Literaturwissenschaft): Prof. Dr. Aage Hansen-Löve; Slavische Philologie (Literaturwissenschaft): Prof. Dr. Miloš Sedmidubský 
2. PD Dr. Raoul Eshelman (venia für Slavische Philologie, Literaturwissenschaft); PD

Dr. Svetlana Kazakova (venia für Slavische Philologie, Literaturwissenschaft); PD

Dr. Barbara Sonnenhauser (venia für Slavische und Allgemeine Sprachwissenschaft)

4. Entpflichtet: Prof. Dr. Peter Rehder; Prof. Dr. em. Josef Schrenk; Prof. Dr. Renate Döring-Smirnov

\section{Münster: Westfälische Wilhelms-Universität Slavisch-Baltisches Seminar}

1. Slavische Philologie: gestrichen; Slavische u. Baltische Philologie u. bes. Berücks. d. ost- und westslav. Literaturen: Prof. Dr. Alfred Sproede

4. Entpflichtet: Prof. Dr. em. Friedrich Scholz

\section{Oldenburg: Carl-von-Ossietzky-Universität} Slavistik

1. Professur für slavistische Sprachwissenschaft: Prof. Dr. Gerd Hentschel; Professur für slavistische Literaturwissenschaft (J): Prof. Dr. Gun-Britt Kohler

2. Slavistische Sprachwissenschaft: PD Dr. Thomas Menzel

4. Entpflichtet: Prof. em. Dr. Rainer Grübel

\section{Passau: Universität \\ Lehrstuhl für Slavische Literaturen und Kulturen}

1. Lehrstuhl für Slavische Literaturen und Kulturen: Prof. Dr. Dirk Uffelmann

3. Dr. Il'ja Kukulin (Moskau)

\section{Potsdam: Universität \\ Institut für Slavistik}

1. Slavische Sprachwissenschaft: Prof. Dr. Peter Kosta; Ostslavische Literaturen und Kulturen: Prof. Dr. Norbert Franz; Westslavische Literaturen und Kulturen: Prof. Dr. Magdalena Marszałek

4. Entpflichtet: Prof. em. Dr. Herta Schmid

\section{Regensburg: Universität Institut für Slavistik}

1. Slavische Sprachwissenschaft: Prof. Dr. Björn Hansen; Slavische Literaturwissenschaft: Prof. Dr. Walter Koschmal; Bohemicum / Bohemistik und Westslavistik: Prof. Dr. Marek Nekula; Allgemeine und Vergleichende Literaturwissenschaft: Prof. Dr. Dorothee Gelhard

2. Apl. Prof. Dr. Ernst Hansack (venia für Slavische Philologie); PD Dr. Sabine Koller (venia für Slavische Literaturwissenschaft)

4. Entpflichtet: Prof. Dr. Klaus Trost; Prof. Dr. Erwin Wedel; Apl. Prof. Dr. Heinz Kneip

\section{Rostock: Universität Institut für Slawistik}

1. Professuren gestrichen

4. Entpflichtet: Prof. Dr. Oskar Müller; Prof. Dr. Witold Kośny; Prof. Dr. Ursula Kantorczyk 


\section{Saarbrücken: Universität des Saarlandes Fachrichtung 4.4: Slavistik}

1. Slavische Sprachwissenschaft: Prof. Dr. Roland Walter Marti

4. Entpflichtet: Prof. Dr. Wolfgang Gesemann

\section{Fachrichtung 4.6: Angewandte Sprachwissenschaft sowie Übersetzen und Dolmetschen}

1. Russisch: gestrichen

4. Entpflichtet: Prof. Dr. Hildegard Spraul

\section{Fachrichtung 4.7: Allgemeine Linguistik}

2. Slavistische Computerlinguistik: PD Dr. Tania Avgustinova

\section{Trier: Universität \\ Slavistik (Fachbereich II)}

1. Slavische Literaturwissenschaft: Prof. Dr. Henrieke Stahl

2. Slavische Philologie: PD Dr. Thomas Bruns

3. Mercator-Gastprofessur: Prof. Dr. Valerij Dem'jankov (Moskau)

4. Entpflichtet: Prof. Dr. Gerhard Ressel

\section{Tübingen: Eberhard-Karls-Universität}

\section{Slavisches Seminar}

1. Slavische Philologie II (Sprachwissenschaft): Prof. Dr. Tilman Berger; Slavische Philologie I (Literaturwissenschaft): Prof. Dr. Schamma Schahadat; Transkulturelle Ostmitteleuropa-Studien: Juniorprof. Dr. Irina Wutsdorff

2. PD Dr. Ludmilla Golubzowa (venia für Slavische Sprachwissenschaft)

3. Humboldt-Stipendiat: Dr. Václav Petrbok; DAAD-Gastdozentin: Doz. Dr. Khrystyna Nazarkevych

4. Entpflichtet: Prof. Dr. em. Ilse Kunert; Prof. Dr. Rolf-Dieter Kluge; Prof. Dr. Jochen Raecke; Apl. Prof. Dr. Dietrich Wörn (venia für Slavische Philologie); PD Dr. Sigrun Bielfeldt (venia für Slavische Philologie / Russische Literatur- und Geistesgeschichte)

\section{Würzburg: Julius-Maximilians-Universität}

\section{Neuphilologisches Institut - Slavistik}

1. Professur Slavische Philologie (Literaturwissenschaft): Prof. Dr. Andreas Ebbinghaus

4. Entpflichtet: Prof. Dr. Christian Hannick (Slavische Philologie) 
Personalia

\section{Habilitationen, Rufe, Emeritierungen / Pensionierungen, Ehrungen}

\section{Zusammengestellt von Gerhard Giesemann (Gießen)}

Herr Prof. Dr. Valerij Dem'jankov (Staatl. Univ. Moskau und Russ. Akademie der Wiss.) ist für die Zeit von November 2010 bis Oktober 2011 auf die Mercator-Gastprofessur (Universität Trier) berufen worden.

Frau Prof. Dr. Jadranka Gvozdanović (Universität Heidelberg) wurde im Januar 2011 mit dem Preis der "American Association of Teachers of Slavic and East European Languages" (AATSEEL) für das beste Buch in der slav. Linguistik des Jahres 2009 und 2010 für ihre Publikation „Celtic and Slavic and the Great Migrations. Reconstructing Linguistic Prehistory“, Heidelberg, geehrt.

Frau Prof. Dr. Ulrike Jekutsch (Universität Greifswald) wurde 2011 zum ordentlichen Mitglied der Akademie der Wissenschaften zu Hamburg gewählt.

Herr Prof. Dr. Sebastian Kempgen (Universität Bamberg) wurde für eine weitere Amtszeit (2011-2014) als Vizepräsident der Otto-Friedrich-Universität Bamberg wiedergewählt.

Frau Dr. Sabine Koller hat sich im Mai 2011 an der Universität Regensburg (venia legendi für Slavische Literaturwissenschaft) habilitiert.

Frau Prof. Dr. Marion Krause hat zum 15. Oktober 2010 den Ruf auf eine Professur an der Universität Hamburg erhalten und angenommen.

Herr Prof. Dr. Gero Fischer (Universität Wien) wurde zum 30. September 2010 pensioniert.

Herr Prof. Dr. Werner Lehfeldt (Universität Göttingen) wurde am 29. Oktober 2010 vom Institut russkogo jazyka Rossijskoj akademii nauk (Moskau) zum Dr. h. c. ernannt und am 30. September 2011 emeritiert.

Frau Prof. Dr. Magdalena Marszałek hat im Oktober 2010 einen Ruf auf die Professur für Slavische Literatur- und Kulturwissenschaft / Schwerpunkt Polonistik an der Universität Potsdam erhalten und angenommen.

Frau Prof. Dr. Swetlana Mengel (Universität Halle-Wittenberg) ist auf eine einmonatige Gastprofessur an der Geisteswissenschaftlichen Universität Vjat$k a$ (Russland) berufen worden.

Herr Prof. Dr. Ulrich Obst (Universität Köln) wurde im Juli 2011 pensioniert.

Frau Dr. Larisa Schippel hat im Oktober 2010 einen Ruf auf die Professur für Transkulturelle Kommunikation an die Universität Wien erhalten. 
Herr Dr. Daniel Schümann hat sich im Januar 2011 an der Universität Bamberg (venia legendi für Slavische Literaturwissenschaft) habilitiert.

Frau Dr. Barbara Sonnenhauser hat sich im Dezember 2010 an der Universität München (venia legendi für Slavische und Allgemeine Sprachwissenschaft) habilitiert.

Frau Prof. Dr. Rosemarie Thiemt (Universität Dresden) wurde im September 2010 pensioniert.

Frau Prof. Dr. Anja Tippner (Universität Salzburg) hat einen Ruf an die Universität Hamburg erhalten und zum Wintersemester 2011/12 angenommen.

Herr Prof. Dr. Stephan Troebst wurde im Juni 2010 für 12 Monate als Fellow an das Imre-Kertész Kolleg an der Friedrich-Schiller-Universität Jena berufen.

Frau Dr. Irina Wutsdorff ist zum März 2011 auf die Juniorprofessur Transkulturelle Ostmitteleuropastudien an der Universität Tübingen berufen worden.

Herr Prof. Dr. Peter Zajac (HU Berlin) wurde im März 2011 pensioniert.

Frau PD Dr. Rumjana Zlatanova (Universität Heidelberg) wurde am 30. September 2010 pensioniert.

Frau Dr. Tanja Zimmermann hat sich im Juni 2011 an der Universität Konstanz (venia legendi für Slavische Literaturwissenschaft und Kunstgeschichte) habilitiert.

Der Verband gratuliert allen Genannten zu Habilitation, Ruf, Ernennung, Ehrung und zur wohlverdienten Pensionierung / Emeritierung. 
Würdigungen

\title{
Dietrich Gerhardt 100 Jahre alt
}

\author{
Von Wolf Schmid (Hamburg)
}

Am 11. Februar 2011 wurde Dietrich Gerhardt, emeritierter Ordentlicher Professor am Institut für Slavistik der Universität Hamburg, 100 Jahre alt.

Dietrich Gerhardt gehört zu den herausragenden Persönlichkeiten der deutschen Slavistik. Er hat die Entwicklung der slavischen Philologie in der alten Bundesrepublik, auf deren Territorium das Fach vor dem Zweiten Weltkrieg nur durch einen einzigen Lehrstuhl vertreten war, maßgeblich beeinflußt und die Slavistik in Hamburg, wo er 17 Jahre als Ordinarius lehrte, entscheidend geprägt.

1911 in Breslau geboren, studierte Gerhardt in Halle a. d. Saale und in Breslau Germanistik, vergleichende Sprachwissenschaft, Phonetik und Slavistik. 1941 promovierte er mit einer Dissertation über Gogol' und Dostoevskij in ihrem künstlerischen Verhältnis (1970 in München nachgedruckt). Von 1939 bis 1942 arbeitete er am Institut für Phonetik in Braunschweig. In der Slavistik lehrte Gerhardt seit 1946. Zunächst in Erlangen, wo er Lehrbeauftragter für Slavische Philologie und Vorstand des Seminars war; dann, seit 1948, als Extraordinarius in Münster. 1959 wurde Gerhardt als Nachfolger von Vsevolod Setschkareff auf den Lehrstuhl für Slavistik an der Universität Hamburg berufen, wo er bis zu seiner Emeritierung im Jahre 1976 lehrte.

Gerhardt war von 1962 bis 2006 Mitglied der Joachim-Jungius-Gesellschaft (die in Hamburg den einer Akademie der Wissenschaften vergleichbaren Status hatte) und stand ihr von 1968 bis 1972 als Präsident vor. Er hat zahlreiche Rufe an deutsche und ausländische Universitäten erhalten und war 1960/61 Gastprofessor in Havard.
Dietrich Gerhardt ist ein auf seltene Weise vielseitiger Wissenschaftler. Als Slavist hat er sowohl in der Sprachwissenschaft als auch in der Kultur- und Literaturgeschichte der slavischen Völker internationale Geltung erlangt. Im Mittelpunkt seiner slavistischen Interessen steht die russische Literatur, deren Werke er von der altrussischen Zeit bis zur jüngsten Vergangenheit, vom Igorlied bis zu Andrej Bitov in geistreichen und immer hochinformativen Essays behandelt hat. In seinen philologischen und kulturgeschichtlichen Studien hat sich Gerhardt neben dem Russischen vor allem auch dem Tschechischen und den „kleinen" Slavinen wie dem Slovenischen oder Polabischen gewidmet.

Bereits seine erste Publikation, der 1936 in den Germanoslavica erschienene Artikel Paul Fleming und Rußland, begründete einen Forschungsschwerpunkt, dem sich Gerhardt besonders verpflichtet fühlt, die slavisch-westeuropäische Wechselseitigkeit. Nicht nur Fragen der Übersetzung haben ihn hier immer wieder beschäftigt, in ausführlichen Studien hat er etwa auch das Russlandbild in Frankreich rekonstruiert und ist den Einflüssen La Rochefoucaulds in der Geschichte der russischen Bildung nachgegangen.

Selbst die in solch beeindruckender Breite betriebene Slavistik bietet dem enzyklopädisch gebildeten Gelehrten noch zu wenig Raum für die Entfaltung seiner reich gefächerten Interessen. So hat er in zahlreichen Publikationen Probleme verschiedener anderer philologischer Fächer behandelt, etwa nach der Heimat Walthers von der Vogelweide gefragt, zum Wangerooger Friesisch geforscht, über breto- 
nische Glossen aus Merseburg und das Gotische auf der Krim gearbeitet und sich sogar Spezialfragen der ural-altaischen Sprachen gewidmet. Seit seinen wissenschaftlichen Anfängen, die mit der Schriftleitung des Archivs für die gesamte Phonetik (1940-1942) verbunden waren, nehmen einen bedeutenden Teil seiner wissenschaftlichen Tätigkeit die allgemeine Phonetik und die Namenskunde ein. Davon profitiert nun wieder die Literaturwissenschaft, etwa wenn die Onomastik geistreich der Deutung von Čechovs Humoreske Ein Pferdename (Lošadinaja familija) dienstbar gemacht wird.

Gerhardts Kreativität ist in den 35 Jahren, die seit seiner Emeritierung ins Land gegangen sind, keineswegs versiegt. Wem ist es schon vergönnt, im 86. Lebensjahr ein vierhundertseitiges Buch mit hochoriginellen Befunden vorzulegen, wie es Gerhardt mit seiner Monographie zu dem deutschen Spruchdichter Süßkind von Trimberg (erschienen Bern u.a. 1997) getan hat, den die große Heidelberger Liederhandschrift als Juden darstellt. Für den kritischen wissenschaftlichen Gestus des Jubilars ist der Untertitel des Buchs charakteristisch, der „Berichtigungen zu einer Erinnerung" ankündigt.

Nach dem Trimberg-Buch hat sich Gerhardt nicht in den wissenschaftlichen Ruhestand begeben. Im Jahr 2008 erschien als Band 1 der Neuen Abhandlungen der Akademie der Wissenschaften zu Göttingen das Buch Wer kauft Liebesgötter? Metastasen eines Motivs. Ausgehend von Goethes Gedicht Die Liebesgötter auf dem Markte geht Gerhardt den Verwandlungen des spätantiken Motivs der Liebesgötter in der Moderne nach - in der bildenden Kunst, der Literatur und der Musik. Die Untersuchung führt von Stabiae und Pompeji über Goethe und Thorvaldsen bis hin zu Puškin und schließt mit Überlegungen zur Jahrtausendwende $a b$.

Abstrakter Theorie abhold und großzügiger Generalisierung wenig geneigt, findet Gerhardt sein Objekt im konkreten Einzelnen. Und so ist die wissenschaftliche Gattung, in der er brilliert, die fein ziselierte Miniatur. Mit seinem stupenden Wissen und ausgehend von einer immer interessanten, nicht selten durchaus ungewöhnlichen Fragestellung versteht er es, auch am zunächst unbedeutend anmutenden Detail das Grundsätzliche und Allgemeine aufscheinen zu lassen, von dem unmittelbar zu sprechen er sich scheut. Die Fülle des Wissenswerten, die er dabei, vornehmlich in seinen berühmten Fußnoten, ausbreitet, wird auch dort, wo sie den Leser zu überfordern droht, durch prägnante Darstellung, stilistische Eleganz und geistreiche Polemik in der Balance des Annehmlichen gehalten.

Eine bedeutende Rolle in Gerhardts Leben spielt die Musik. Selbst ein Meister auf der Oboe, gehörte er in seinem Münsteraner "Collegium musicum" zu denen, die wesentlich zur Wiederentdeckung der Barockmusik beitrugen.

Gerhardts wissenschaftliches Wirken wurde zum 60. und 65. Geburtstag jeweils durch eine Festschrift gewürdigt: Sodalicium Slavizantium Hamburgense (Red. J. Schröpfer, Amsterdam 1971); Korrespondenzen (hg. von A. Engel-Braunschmidt und A. Schmücker, Gießen 1977). Zum 90. Geburtstag hat sein Enkel Johannes Gerhardt eine 155 Titel umfassende „Bibliographie der wissenschaftlichen Schriften von Dietrich Gerhardt 1936-2000" zusammengestellt, und sein Sohn Ludwig Gerhardt hat unter Mithilfe vieler Mitglieder der großen Familie die Gelegenheitsgedichte des Jubilars in dem schönen Bändchen Anlässe versammelt.

Selbst wer sich methodisch anders orientiert, sein Objektfeld enger absteckt und eher der von Gerhardt stets kritisch betrachteten Spezialisierung und Szientifizierung der Philologie das Wort redet, wird die große wissenschaftliche Leistung des Jubilars aufrichtig anerkennen und ihm Bewunderung zollen für die auch in unserem Fach nicht eben häufige Verbindung von Vielseitigkeit, Gelehrsamkeit und Eleganz. 
Würdigungen

\section{Jurij Striedter zum 85. Geburtstag}

\section{Von Karl Eimermacher (Bochum-Berlin)}

Jurij Striedter gehört zu den herausragenden deutschen Literaturwissenschaftlern der Nachkriegszeit, für den eine bewegte, kulturelle Grenzen überschreitende Biographie charakteristisch ist.

Geboren 1926 in Nowgorod, aufgewachsen in Leningrad, Reval/Tallin und Posen, studierte er nach 1945 Germanistik, Philosophie und Slawistik in Heidelberg, Paris und Berlin. 1959 wurde er an der Freien Universität Berlin (FU) habilitiert und zum Professor für Slawische Philologie ernannt. 1966 wechselte er an die Reformuniversität Konstanz. 1977 wurde er an die Harvard University berufen, wo er bis 1996 lehrte. Heute lebt er mit seiner Frau Emanuela in Tampa (Florida).

Bis zum Erscheinen seiner „Momente. Erinnerungen an Kindheit und Jugend (1926-1945). Von Stalins Sowjetrussland zu Hitlers, Großdeutschem Reich"“ (Bochum 2010) kannte man Jurij Striedter nur aufgrund seiner Lehrund Forschungstätigkeit. Im Anschluss an die "Momente" lassen sich heute jedoch Striedters Persönlichkeitsentwicklung und sein Wirken als akademischer Lehrer relativ abgerundet würdigen.

Die "Momente“ veranschaulichen Striedters prägende Jahre bis 1945. Aus Miniaturen des engen häuslichen Mikrokosmos, die aus der hellwachen Perspektive des Kindes Jura erzählt werden, entsteht zunächst ein russischbaltisch-deutscher Mikrokosmos, der für Striedters Grundhaltungen, Ängste und Sehnsüchte lebenslang bestimmend gewesen ist.
Mit der wachsenden Zahl von Verwandten und Freunden sowie wechselnden Lebensräumen und Sprachen (Russisch, Estnisch, Deutsch), erweitert sich vor dem Hintergrund von Stalinismus und Faschismus sein Erfahrungsund Wissenshorizont zu einem komplizierten Geflecht rationaler wie emotionaler Bezugsgrößen. Ansichten und Meinungen der Erwachsenenwelt werden dem Jugendlichen einsichtig und erscheinen ihm vorbildhaft. Romantische Ideologien und gängige Mythen der Zeit, aber auch Zweifel an ihnen und distanzierte Nachdenklichkeit beeinflussen zunehmend mehr sein Verhalten, als er noch kurz vor Ende des Krieges zum Militär eingezogen wird und für kurze Zeit in amerikanische Gefangenschaft gerät.

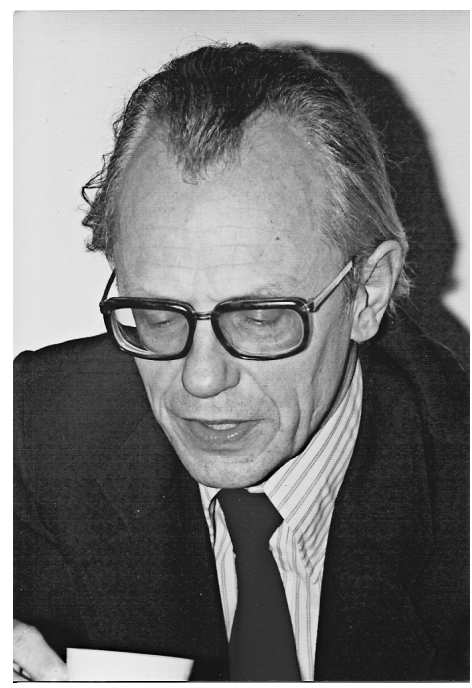


Mit neunzehn Jahren bricht für Striedter eine Zeit in eigener Verantwortung an, verbunden allerdings wieder mit zahlreichen Ortswechseln. Er studiert zunächst Germanistik (u. a. bei Paul Böckmann) und Philosophie (bei Karl Jaspers und Hans-Georg Gadamer) in Heidelberg und Slawistik (1951 in Paris und an der FU Berlin 1953-1959), wo er 1960 zum Professor ernannt wird.

Striedters literaturwissenschaftliche Lehrveranstaltungen wirkten Anfang der sechziger Jahre wie kleine Sensationen. Sie machten neugierig, weil sie den bis dahin bekannten Bewertungsklischees nicht entsprachen. Ideologisch unvoreingenommen, versuchte Striedter eine Neueinschätzung der russischen und sowjetrussischen Literatur. Seine Analysen waren literaturund kulturorientiert und projiziert auf übergreifende Zusammenhänge der russischen und europäischen Literatur. Damit wurde auch - wie in den anderen modernen Philologien - in der Slawistik Literatur als Literatur zentraler Lehrgegenstand. Unvergesslich ist sein Engagement in Diskussionen, seine Neugier für Unbekanntes und sein Einfallsreichtum, unterschiedlichste Problembereiche ad hoc miteinander $\mathrm{zu}$ verbinden und Probleme auf das Wesentliche zu reduzieren. Genaues Zuhören und gezieltes Nachfragen zeichnen ihn aus, als Anfang der sechziger Jahre seine akademische Laufbahn beginnt. Tradierte Denk- und Bewertungsnormen nahm Striedter sehr ernst, war ihnen jedoch nicht sklavisch verfallen. Die Fähigkeit, alles immer wieder in Frage zu stellen und neu zu denken, ist ein Grundmerkmal von Striedters Umgang mit Literatur. Obwohl er durch Publikationen den Russischen Formalismus und Tschechischen Strukturalismus nach Deutschland und später in die USA vermittelt hat und ihm besonders an systematischen Untersuchungsgesichtspunkten des Literarischen gelegen war, wandte er sich vehement gegen jeden literaturwissenschaftlichen Reduktionismus. Er war Komparativist im besten Sinne, liebte typologische Vergleiche von formalen wie inhaltlichen Sachverhalten und verfolgte die Wechselbeziehungen ästhetischer Objekte mit gesellschaftspolitischen Bezügen. Dabei ging er wie selbstverständlich davon aus, dass die größte Adäquatheit einer Untersuchung dann gegeben sei, wenn der offene Charakter einer Interpretation der potentiellen Offenheit der Untersuchungsobjekte entspricht. In dieser Grundhaltung traf er sich mit den Trägern der Gruppe „Poetik und Hermeneutik" (1963 bis 1993), deren Vor- und Mitdenker er von Anfang an war. Die konzeptionelle Brücke zu dieser Gruppe, in die Striedter auch Dmitrij Tschižewskij, ehemals Mitträger des Prager Strukturalismus, einführte, war ein weiteres Moment, um der Slawistik den Anschluss an den Entwicklungsstand der Literaturwissenschaft in den anderen Philologien zu ermöglichen. Nicht zuletzt auch aufgrund dieses breiten philologischen Ansatzes war Striedter langjähriges Mitglied in den zentralen Gremien der Deutschen Forschungsgemeinschaft.

Jurij Striedter brauchte weder Nachahmer noch gehorsame Schüler. Und so war es das anregende Ambiente selbständig denkender junger Wissenschaftler, welches das Gefühl einer verbal nicht beschworenen Gruppe entstehen ließ: Es herrschte eine Atmosphäre des wechselseitigen Vertrauens, das auf der Offenheit von Meinungsvielfalt beruhte. Hierdurch entstand ein Arbeitsklima, das die Unabhängigkeit des Einzelnen garantierte und Verantwortung eines jeden für das Fach wie für die Kollegen förderte. Diese Grundhaltung bestimmte auch seine Tätigkeit als Vorsitzender des Verbandes in den Jahren 1970-71. 
Nachruf

\title{
Nekrolog auf Aleksandar Flaker
}

\author{
von Reinhard Lauer (Göttingen)
}

Er gehörte zu den bekanntesten Slawisten der Gegenwart. Kroate, aus dem polnischen Białystok gebürtig, in der Wissenschaft ausgreifend von den russisch-kroatischen Literaturbeziehungen über die Stilepochenforschung bis zu unterschiedlichen intermedialen Themen, hat Aleksandar Flaker ein umfangreiches Euvre hinterlassen, dem er ganz zu Ende seines Lebens noch seine "Autotopographie", seine an polnische und kroatische Orte gebundene Lebensgeschichte anfügte.

Flaker war eine ungewöhnlich anregende Persönlichkeit, die sich in der slawischen und slawistischen Welt, auf Konferenzen und Symposien umtat und, nach seiner Emeritierung, ein gefragter Gastprofessor, in den Vereinigten Staaten ebenso wie in Wien oder Göttingen, war. Ich kannte ihn seit 1955. Ich nahm damals an einem Ferienkurs in Zadar teil. Er war damals Assistent und nahm die Spätankömmlinge im Hafen in Empfang. Ich glaubte, den jungen Gor'kij vor mir zu sehen.

Die Slawistik kam nicht ohne seine fundamentalen Begriffe aus. Das Konzept der Stilformation hatte er gemeinsam mit Zdenko Škreb in den 1970er Jahren entwickelt. Darunter verstand er ein Ensemble von Verfahren, Gattungen und Themen, die durch eine Generalfunktion gebündelt wurden. Erst mit einer solchen Konstruktion konnten die
Epochenbegriffe eindeutig beschrieben und mit historischen und ideologischen Gegebenheiten der Zeit sinnvoll verbunden werden. Er hat dies am Beispiel des Realismus demonstriert, den er als Verfahren der Soziographie und der (unmetaphorischen) Benennung definierte, während er die Moderne als „Desintegration des Realismus" beschrieb. Sein literaturwissenschaftliches Denken war durch den russischen Formalismus und Strukturalismus geprägt worden, die er jedoch selbständig weiterentwickelte. Seine Materialkenntnis war unerschöpflich; in Diskussionen und Polemiken zeigte sich schnell, daß Aleksandar Flaker mehr wußte als die anderen.

Der Zagreber Russistik hat er seit 1969 seinen unverwechselbaren Stempel aufgedrückt. Seine Arbeiten über Gogol', Turgenev, Dostoevskij, Čechov, Tolstoj und vor allem seine Bücher über die russische Avantgarde, "Poetik als Widerspruch" (1982) und "Die russische Avantgarde“ (1984), gehören zum Grundlegenden im Fach.

Flaker hat wesentliche Beiträge auch zur kroatischen Literatur, namentlich zu dem kroatischen Altmeister Miroslav Krleža, geleistet. Immer war sein Blick auf die Gesamtheit der europäischen Literaturen und ihre Wechselbeziehungen gerichtet. Sein wohl bekanntestes Buch über die "Jeansprosa“ (1976), 
von dem eine deutsche Ausgabe vorliegt, peilte das damals aktuelle Phänomen von vornherein komparativistisch an. Nicht anders seine

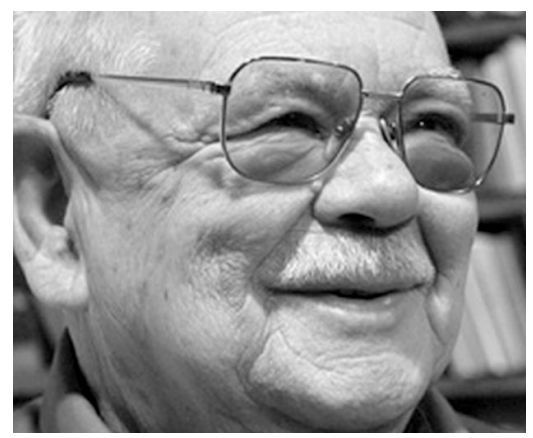

Vedouten, die in dem Buch „Wort, Bild, Stadt" (1995) ausgeführt sind. Vieles aus Flakers Schaffen wurde ins Deutsche (und andere Sprachen) übersetzt. Jetzt, nach seinem Tode, sollte unbedingt eine Auswahl aus seinen Werken in deutscher Sprache erscheinen. Denn fast alles, was Aleksandar Flaker geschrieben hat, verdient Beachtung und veraltet nicht. Er war, wie eine kroatische Zeitschrift schrieb, eine „kulturelle Institution“.

Früh war er nach Zagreb gekommen, besuchte dort das Gymnasium und studierte Slawistik. Zagreb war die Stadt seiner Wahl, dort ist er am 25. Oktober 2010 gestorben.
Foto: http://wwww.index.hr/vijesti/clanak/preminuougledni-slavist-aleksandar-flaker/519843.aspx 
Nachruf

\title{
Gedenken an Alfred Rammelmeyer
}

\author{
von Gerhard Giesemann (Gießen)
}

Der 100. Geburtstag Alfred Rammelmeyers am 13. Januar 2010 (31. Dezember 2009 a. St.) ist Anlass genug, an ihn und seine Tätigkeit für den Aufbau der deutschen Slavistik nach dem zweiten Weltkrieg in Deutschland $\mathrm{zu}$ erinnern. In Moskau geboren, hat Rammelmeyer in den 30er Jahren bei Max Vasmer in Berlin Slavistik studiert, weiterhin Romanistik (Eduard Wechssler), Kirchengeschichte (Erich Seeberg) und indogermanische Sprachwissenschaft. Seine Stationen nach dem Krieg waren Kiel, dann Marburg und schließlich Frankfurt am Main. Alfred Rammelmeyer blieb trotz verschiedener Rufe in Hessen. Mit seinem Lebenswerk verbunden ist vor allem das Slavische Seminar in Frankfurt am Main. Die Würdigung Alfred Rammelmeyers soll sich nicht in der Auflistung seines wissenschaftlichen Werkes erschöpfen; das ist zur Genüge und aus verschiedenen Anlässen, auch in dieser Zeitschrift, geschehen. Vielmehr wird das Augenmerk auf die bleibenden Verdienste Rammelmeyers in seinem hochschulpolitischen und gesellschaftlichen Engagement gerichtet.

In zwei Jahrzehnten schuf er Voraussetzungen für den Wiederaufbau und den Ausbau der deutschen Slavistik durch seine Tätigkeit in Gremien mit überregionaler Wirkung, durch Strategien zur Organisation von Bibliotheken und Aus- bildungsformen und durch seine Bemühungen um Internationalisierung der slavischen Seminare, wo politisch Verfolgte und notleidende Gelehrte aus den damaligen kommunistischen Diktaturen vorübergehende Wirkungsstätten fanden. Das war eine große Bereicherung der deutschen Slavistik in einer Zeit, wo es mühevoll für die Studierenden war, im ost- oder südosteuropäischen Ausland Kurse belegen zu können oder gar Studienplätze zu erhalten.

Alfred Rammelmeyer hat an den Universitäten Kiel, Marburg/Lahn und Frankfurt die slavischen Seminare neu begründet und ausgebaut. Kontakte zum Hessischen Kultusministerium ermöglichten die Einrichtung einer sehr gut ausgestatteten und in allen Slavinen hervorragend bestückten Bibliothek. Sein besonderes Augenmerk galt den Mikrofilmierungen von Beständen, die auf dem Buchmarkt nicht mehr zu erwerben waren. So hatte Frankfurt eine wertvolle Bibliothek von russischen Zeitschriften des 18. und 19. Jahrhunderts erhalten. Das Seminar wurde dank Rammelmeyer mit Lektoraten fast aller slavischer Sprachen ausgestattet. Er trug wesentlich dazu bei, dass an den höheren Schulen Hessens Russisch als Unterrichtsfach eingeführt wurde. Seine Mitgliedschaften hat Rammelmeyer immer in den Dienst der Slavistik und darüber hinaus für 
Belange der Universitäten gegenüber ministeriell-politischer Vorstellungen eingesetzt und auch gegen Einwirkungsversuche von außen sich gewehrt. Seine Öffentlichkeitsarbeit ist bemerkenswert: Belange der Forschung vertrat er als Mitglied des Forschungsrates des Landes Hessen, dem er in den 60er Jahren 10 Jahre lang angehörte, ebenso dem Kuratorium des „Ostkundlichen Kollegs des Landes Hessen“, von 1965 bis 1970 vertrat er die hessischen Universitäten im Rundfunkrat des Hessischen Rundfunks.

1963 wurde Alfred Rammelmeyer zum Rektor der Johann Wolfgang Goethe-Universität gewählt, die während seiner Amtszeit das 50jährige Bestehen feierte. Aufgaben im DAAD, der DFG und im Vorsitz der Osteuropakommission der Westdeutschen Rektorenkonferenz nahm er neben seinen Amtspflichten gewissenhaft wahr, da er glaubte, an übergeordneter Stelle dem Wohle der Universitäten und ihrer Studierenden wirken zu können. In den schwierigen Jahren der "Go-in" und der Seminarbesetzungen im Zusammenhang mit den angedachten Universitätsreformen bat ihn die Hochschulleitung um Verlängerung seines Prorektorats. Er kämpfte auf diesem Posten bis 1970, dann trat er zusammen mit allen hessischen Rektoren aus Protest gegen das Hessische Universitätsgesetz von 1970 von seinem Amt zurück.

Hauptsächlich in den „Frankfurter Abhandlungen zur Slavistik" sind die Dissertationen erschienen, die Alfred Rammelmeyer in seiner Marburger und Frankfurter Zeit angeregt hatte, gut betreute, jedoch in ihrer eigenständigen Entwicklung nicht eingeschränkte Arbeiten. Sie hatten zu großen Teilen das Ziel der Erforschung der Literatur- und Geistesgeschichte des russischen 18. Jahrhunderts in seinen Gattungen und seinen Verbindungen zur deutschen, französischen und italienischen Kultur. Sie sind ein Denkmal ordentlicher Betreuung und freier geistiger Entwicklung.

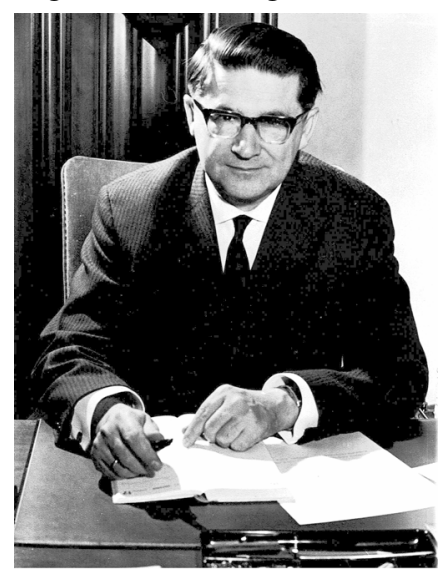

Alfred Rammelmeyer hat die Slavistik in Deutschland nach dem 2. Weltkrieg entscheidend mitgeprägt und die Notwendigkeit gesehen, diese Philologie sowohl in der Gesellschaft als auch in universitärer Lehre und Forschung tatkräftig $\mathrm{zu}$ fördern und in schwierigsten Zeiten des Kalten Krieges und universitärer Umbrüche authentisch zu vertreten. Seine aus der Marburger und Frankfurter Zeit hervorgegangenen Schülerinnen und Schüler haben versucht und versuchen, sich solche Maßstäbe zu eigenen zu machen. Der aus Anlass seines 100 . Geburtstages erschienene "Gedenkband für Alfred Rammelmeyer" ist ein nachträglicher Dank an den Lehrer. 
Nachruf

\title{
Anna-Halja Horbatsch in memoriam
}

\author{
von Valerij Mokienko (Greifswald)
}

Am 11. Juni 2011 hörte das Herz von Dr. Anna-Halja Horbatsch auf zu schlagen. Das Herz einer Slawistin, die weit über Deutschland hinaus nicht nur durch ihre wissenschaftliche Arbeit zur ukrainischen Literaturwissenschaft und ihre unermüdliche herausgeberische Tätigkeit bekannt war, sondern auch durch ihr ständiges Bestreben, die ukrainische Kultur Deutschland näher $\mathrm{zu}$ bringen und die deutsche Kultur der Ukraine. Der Symbiose dieser beiden großen europäischen Kulturen hat sie ihr gesamtes Leben gewidmet.

Anna-Halja Horbatsch wurde am 22. März 1924 im Süden der Bukovina in der Siedlung Brodina geboren. Seit 1941 lebte und arbeitete sie in Deutschland. In der slawistischen Welt ist sie als Autorin der Arbeiten „Epische stilistische Mittel der Kosaken-Dumen“, "Ol'ha Kobyljans'ka und die deutsche Kultur", "Ukrainische Märchen der Karpaten" u.a. bekannt. Sie übersetzte Werke von M. Kocjubyns'kyj, H. Chotkevyč, V. Stus, V. Marčenko, Ju. Andruchovyč u.a. ins Deutsche und gab diese heraus. Darüber hinaus stellte sie eine Reihe von Anthologien ukrainischer Prosa und ukrainischer Novellen über Čornobyl' zusammen, übersetzte diese ins Deutsche und veröffentlichte sie. Anna-Halja war die Initiatorin der Übersetzung einer Serie von Arbeiten der „Samizdat-Litera- tur" der Ukraine. In Vorträgen und Artikeln befasste sie sich mit Untersuchungen zu den ukrainisch-deutschen und ukrainisch-rumänischen literarischen Beziehungen.

Im Jahre 1995 gründete sie zusammen mit ihrem Ehemann, dem bekannten Ukrainisten Olexa Horbatsch, den Brodina Verlag, in dem Werke ukrainischer Schriftsteller erschienen, die dadurch in Deutschland bekannt werden konnten. „Keine andere slawische Kultur ist einem einzelnen Menschen so sehr zu Dank verpflichtet, wie die ukrainische Literatur Anna-Halja Horbatsch", bemerkte einmal Hans Rothe. Für ihre Verdienste wurde sie mit dem Internationalen IvanFranko-Preis des Schriftstellerverbandes der Ukraine geehrt (1994), mit dem Königin-Olga-Orden III. Klasse, mit dem Elena-Teliga-Preis (2009) und mit anderen Auszeichnungen.

Mit der Greifswalder Universität war Anna-Halja Horbatsch durch enge Bande verbunden. Als im Jahre 1995 auf Initiative des damaligen Direktors des Instituts für Slawistik, Herrn Prof. Manfred Niemeyer, der erste Lehrstuhl für Ukrainistik in Deutschland eingerichtet wurde, begrüßte ihr Mann, Prof. Olexa Horbatsch, dessen Gründung und vermachte testamentarisch seine reiche Bibliothek eben der Greifswalder Universität. Nach seinem Tode im Jahre 1997 erfüllte Anna- 
Halja Horbatsch den Willen ihres Gatten, und der Lehrstuhl für Ukrainistik erhielt die Bibliothek ihres Mannes als Geschenk. AnnaHalja Horbatsch unterhielt einen ständigen freundschaftlichen Kontakt und wissenschaftliche Verbindungen mit Frau Prof. Ulrike Jekutsch, mit Herrn Dr. Rolf Göbner und dem Verfasser dieser Zeilen. Besonders intensiv wurden unsere Kontakte nach der Gründung des Greifswalder Ukrainikums im Jahre 1996, das organisatorisch und finanziell zunächst von der BoschStiftung und später durch die Krupp-Stiftung wesentlich unterstützt wurde. Anna-Halja Horbatsch half uns, das wissenschaftliche Lehrprogramm des Ukrainikums zu organisieren und umzusetzen, stellte uns Bücher ihres Verlags zur Verfügung, hielt Vorlesungen und leitete Seminare. Wir erinnern uns sehr gerne daran, wie sie zusammen mit unseren Studentinnen und Studenten in unserm Slawistenkeller ihre liebsten ukrainischen Lieder sang. Dank der engen Kontakte mit Anna-Halja Horbatsch konnten in der Greifswalder Slawistik mehrere bedeutende ukrainistische Projekte verwirklicht werden. Eines von ihnen ist die Vorbereitung und der Druck der monumentalen Arbeit von Olexa Horbatsch "Argo v Ukraïni", die 2006 in L'viv auf Kosten von AnnaHalja erschien. Dieses Buch hat in der Ukraine und in der gesamten slawistischen Welt eine sehr große Resonanz gefunden.

Anna-Halja Horbatsch ist in ihrem 88. Lebensjahr von uns gegangen. Sie hat uns verlassen, aber sie hat tiefe Spuren in der deutschen und der europäischen Ukrainistik hinterlassen. Und nicht nur ihre Arbeiten und die unikale ukrainistische Bibliothek, die der Greifswalder Universität überlassen wurde, werden sie in unserem Gedächtnis belassen. Die Existenz und die Entwicklung des einzigen Lehrstuhls für Ukrainistik, der heute durch Herrn Prof. Alexander Wöll weitergeführt wird, sind ein Garant dafür, dass die Sache, für die Anna-Halja Horbatsch und ihr Ehemann das ganze Leben über gelebt und gearbeitet haben, erfolgreich fortgesetzt werden wird.

Wir werden ihr ein ehrendes Angedenken bewahren.

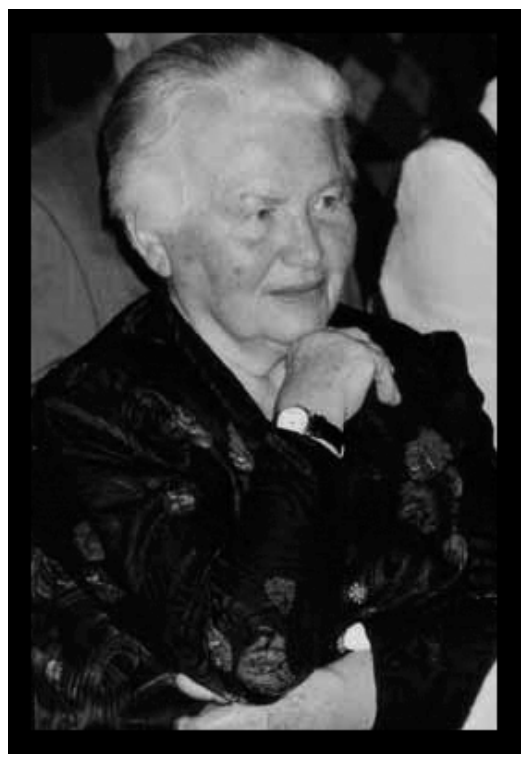

Foto: http://dug-rhein-neckar.de/

(Deutsch-ukrainische Gesellschaft Rhein-Neckar) 
Nachruf

\section{Otto Sagner (1920-2011)}

\section{von Ulrich Schweier (München)}

Es ist nicht selten die persönliche, anläßlich einer seiner vielen und ausgedehnten Reisen geschlossenen Bekanntschaft mit Otto Sagner, an die sich viele mit Freude und Stolz erinnern werden - Reisen, die ihn, häufig in Begleitung seiner Frau, an Slavistikinstitute deutscher Universitäten, zu Buchausstellungen und Buchmessen sowie zu Institutionen und Partnern in ganz Ost- und Südosteuropa führten. Nun hat sich diese persönliche Erinnerung an einen der großen deutschen Buchhändler, Verleger und Kenner der osteuropäischen Länder und Kulturen mit der tiefen Trauer über seinen Tod am 18. März 2011 verbunden.

Für die deutsche und bereits früh auch für die internationale Slavistik war Otto Sagner bedeutend mehr als der Inhaber der 1947 gemeinsam mit Georg Kubon gegründeten, seit den späten 1950er Jahren unweit der Universität in München ansässigen Versandbuchhandlung und des Verlags Kubon \& Sagner. Das schnell aufblühende und expandierende Unternehmen war unter der Leitung und Gestaltung Otto Sagners nicht nur zu einem der weltweit führenden und bedeutendsten Import- und Exportunternehmen auf dem Gebiet der slavistischen Fachliteratur, sondern durch die Persönlichkeit Otto Sagners zu einem natürlichen und geradezu un- verzichtbaren Bestandteil der Slavistik selbst geworden.

Die meisten deutschen slavistischen Fachbibliotheken wären in ihrer heutigen Form ohne die nicht selten mit hohem persönlichem Engagement Otto Sagners beschafften Ergänzungen und aktuellen Bestandslieferungen nicht denkbar. Jeder einzelne Slavist, jeder an Sprachen, Literaturen und Kulturen Ost- und Südosteuropas Interessierte konnte sich darauf verlassen, auch schwerst zugängliche Fachliteratur über Kubon \& Sagner zu erhalten. Die renommierten Reihen des Verlags Otto Sagner, seien es etwa die von Peter Rehder herausgegebenen "Slavistischen Beiträge" oder "Sagners Slavistische Sammlung", wurden mit beständiger persönlicher Unterstützung Otto Sagners zu wichtigen Publikationsorganen, die jungen Nachwuchsslavisten ebenso wie etablierten Fachkollegen weltweite Verbreitung ihrer Forschungsarbeiten sichern und gewährleisten konnten.

Otto Sagner hat als Buchhändler und Verleger auch erfahren, wie rasante Globalisierungsverläufe und weitreichende politische Veränderungen auf Unternehmungsstrategien Einfluß nehmen und neue Entscheidungen verlangen können. Diesen Erfahrungen und den erforderlichen Weichenstellungen für die Zukunft hat er sich nie entzogen, vielmehr hat er sich ihnen mit 
seiner bewundernswerten Mischung aus feinem Humor und hoher Vitalität bis ins hohe Alter gestellt und an ihnen gearbeitet.

Otto Sagner hat für sein einzigartiges Lebenswerk eine Fülle von Anerkennung weit über die Slavistik hinaus erfahren und zahlreiche internationale Auszeichnungen entgegennehmen dürfen. Gleichsam als an eine jener Auszeichnungen, die Otto Sagner seinerseits an die deutsche Slavistik vergeben hat, erinnere ich mich sehr gerne daran, daß er 2005 die Einladung zum 9., in München stattfindenden Deutschen Slavistentag in einem Telephongespräch persönlich mit großer Freude angenommen und an der Eröffnungsveranstaltung als Ehrengast teilgenommen hat.

Wir werden Otto Sagner immer in ehrender Erinnerung behalten.

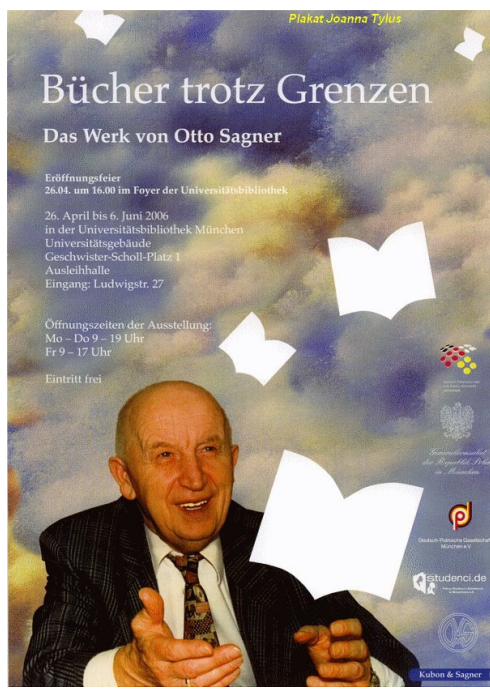

Abb. (C) Verlag Kubon \& Sagner. Verwendung mit freundlicher Erlaubnis. 
Personalia

\section{PD Dr. Thomas Bruns}

Thomas Bruns, Jg. 1966, studierte von 1985 bis 1991 Russisch und Französisch an der Johannes-Gutenberg-Universität Mainz, Fachbereich Angewandte Sprach- und Kulturwissenschaften (FASK) in Germersheim, mit dem Abschluss Dipl.-Übersetzer. Nach einem Jahr Übersetzertätigkeit folgte von 1992 bis 1997 ein Lehramtsstudium an der Westfälischen Wilhelms-Universität Münster, abgeschlossen mit dem 1. Staatsexamen für Russisch Sek. II und Französisch für Sek. I u. II. Das Studium schloss Auslandsaufenthalte in Dijon, Moskau und Belgrad ein. Daneben arbeitete er als freiberufliche Fremdsprachenlehrkraft (Französisch, Russisch) bei der DBP TELEKOM.

1996 erhielt er eine Stelle als Wissenschaftlicher Mitarbeiter am FB II: Slavistik der Universität Trier. 1998-2001 absolvierte er ebendort ein Promotionsstudium mit den Fächern Slavische und Französische Philologie. Die Dissertation zum Thema "Russische Internet-Terminologie. Unter vergleichender Berücksichtigung des Französischen und des Deutschen. Mit einem lexikographischen Teil D-R / R-D und D-F / F-D" wurde mit Summa cum laude bewertet und mit dem Förderpreis des Freundeskreises der Universität ausgezeichnet. 2001 erhielt er eine Stelle als Wissenschaftlicher Assistent (C1) in Trier.

2005 erfolgte die Berufung in die ministerielle Arbeitsgruppe des
Landes Rheinland-Pfalz zur Ausarbeitung Curricularer Standards für das Fach Russisch an Gymnasien. 2005 und 2006 nahm er auf Einladung der WUS Austria mehrfach als EU-Experte an ECTS-Seminaren in Montenegro und Bosnien-Hercegovina teil.

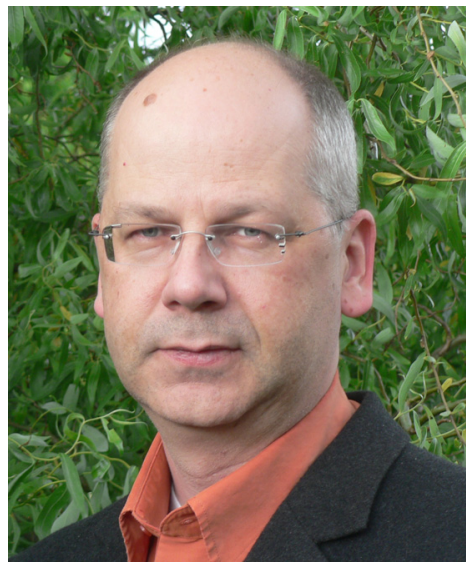

Seit 2007 arbeitet er als Lehrkraft für besondere Aufgaben im Fach Slavistik der Universität Trier mit den Schwerpunkten russische/slavische Sprachwissenschaft, Altkirchenslavisch, Sprachpraxis Russisch und $\mathrm{B} / \mathrm{K} / \mathrm{S}$, russische Fachdidaktik, berufsbezogene Kompetenzen.

Seit Anfang 2010 betreut er nebenamtlich die Rubrik "Buchtipps" in der Zeitschrift "Praxis Fremdsprachenunterricht Russisch".

2010 habilitierte er sich in Trier und erhielt die Venia legendi für Slavische Sprachwissenschaft. Das Thema seiner Habilitationsschrift 
lautete „Sprache, Nation und Internet. Politik und Medien in den Nachfolgestaaten Jugoslawiens und der Sowjetunion".

\section{Homepage:}

http://www.uni-trier.de/index.php? id $=13885$

\section{Publikationen (in Auswahl und ohne Rezensionen):}

\section{Monographien:}

- Sprache, Nation und Internet. Politik und Medien in den Nachfolgestaaten Jugoslawiens und der Sowjetunion. Hamburg 2010.

- Einführung in die russische Sprachwissenschaft. Mit einem historischen Teil. Tübingen 2007.

- Russische Internet-Terminologie. Unter vergleichender Berücksichtigung des Französischen und des Deutschen. Mit einem lexikographischen Teil $D-R / R$ $D$ und $D-F / F-D$. Frankfurt am Main 2001.

\section{Sammelbände:}

- Metropole - Provinz. Urbanität und Ruralität in den slavischen Sprachen, Literaturen und Kulturen. Frankfurt am Main 2008. (mit Gerhard Ressel)

- Sprache - Literatur - Kultur: Studien zur slavischen Philologie und Geistesgeschichte. Festschrift für Gerhard Ressel zum 60. Geburtstag. Frankfurt am Main 2005. (mit Henrieke Stahl)

- Slavistik - Computer - Internet. Rechneranwendungen in einer Geisteswissenschaft. Frankfurt am Main 2002.

\section{Aufsätze:}

- Anmerkungen zum historischen Verhältnis des Bulgarischen und des Mazedonischen (vom 9. bis zum 21. Jahrhundert). In: Anzeiger für Slavische Philologie, Band XXXVIII (2010), 11-32.

- Что нас ждет на компьютерном экране, когда мы бродим по Интер-
Hemy. In: Lebende Sprachen, 54. Jg., Heft 4/2009, 188-189.

- Govorimo hrvatski / srpski / bosanski na nastavi - Redewendungen für die kroatische / serbische / bosnische Unterrichtssprache. In: Moderne Sprachen (MSp) 53/1 (2009), 81-98.

- Что нового в Интернете? Russische Internet-Neologismen. In: Lebende Sprachen, 54. Jg., Heft 1/2009, 38-44.

- Russ. cocatb $=$ engl. suck $=$ franz. sucer $=d t$. saugen? oder: Von der linguistischen Wertigkeit eines Staubsaugers. In: Lebende Sprachen, 54. Jg., Heft 1/2009, 7-11.

- Cetinje - eine Stadt zwischen Hütten und Palästen. Eine Betrachtung anhand zeitgenössischer Text- und Bilddokumente. In: Bruns, Thomas / Ressel, Gerhard (Hrsg.): Metropole Provinz: Urbanität und Ruralität in den slavischen Sprachen, Literaturen und Kulturen. Frankfurt am Main 2008, 23-36.

- Das Adjektiv national und seine lexikalischen Nachbarn im zwischensprachlichen Vergleich deutsch - russisch serbisch/kroatisch. In: Zeitschrift für Slawistik 51 (2006) 3, 321-332.

- Das funktional-semantische Feld der Temporalität im Serbischen und Kroatischen. In: Zeitschrift für Slawistik 51 (2006) 1, 94-101.

- Nikola I - ein vergessener König? In: Bruns, Thomas / Stahl, Henrieke (Hgg.): Sprache - Literatur - Kultur: Studien zur slavischen Philologie und Geistesgeschichte. Festschrift für Gerhard Ressel zum 60. Geburtstag. Frankfurt am Main 2005, 107-126. 
Personalia

\section{PD Dr. Christoph Garstka}

Im Wintersemester 2010/11 hat sich Christoph Garstka nach einem Vortrag über „Puškin und Mickiewicz Aspekte einer problematischen Dichterfreundschaft" an der Universität Heidelberg habilitiert und die venia legendi für das Fach Slavische Literaturwissenschaft erhalten. In seiner Habilitationsschrift "Geschichte und kommunistische Gegenwart. Historiosophische Positionen und ihre narrative Präsentation in Essay und Roman der Volksrepublik Polen" zeigt er in transgenerischer Perspektive Narrative der polnischen Geschichtsschreibung in ihren Traditionszusammenhängen auf und diskutiert Formen der Verweigerung und Dekonstruktion erzählerischer Präsentation von Geschichte.

Christoph Garstka studierte bis zum Magisterabschluss 1997 Slavistik und Germanistik in Heidelberg und St. Petersburg (als DAAD-Stipendiat) und ist durch seinen akademischen Lehrer Prof. Gerigk ebenfalls an die Allgemeine und Vergleichende Literaturwissenschaft herangeführt worden. Er promovierte 2002, unterstützt durch ein Stipendium der Landesgraduiertenförderung Baden-Württemberg, mit einer Arbeit zur Panegyrik in Russland: „Das russische Herrscherlob. Katharina II., Lenin und Stalin im russischen Gedicht. Ein Beitrag zur Ästhetik und Rhetorik politischer Lyrik." Anschließend war er von 2003 bis 2010 als wissenschaftlicher
Assistent am Lehrstuhl für Slavische Literaturwissenschaft (Prof. Heftrich) in Heidelberg beschäftigt. Seine Schwerpunkte in Lehre und Forschung liegen in der russischen und polnischen, in jüngster Zeit auch tschechischen Literatur vom 18. bis ins 20. Jahrhundert. Methodologisch ist er dabei einer historisch-hermeneutischen Tradition verpflichtet, die sich narratologischen und kulturwissenschaftlichen Fragen in interdisziplinärer Perspektive öffnet.

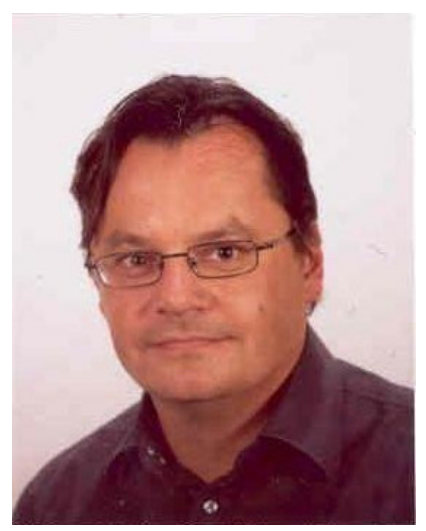

\section{Publikationen}

\section{Monographien}

- Arthur Moeller van den Bruck und die erste deutsche Gesamtausgabe der Werke Dostojewskijs im PiperVerlag 1906-1919. Eine Bestandsaufnahme sämtlicher Vorbemerkungen und Einführungen von Arthur Moeller van den Bruck und Dmitrij S. Mereschkowskij unter Nutzung 
unveröffentlichter Briefe der Übersetzerin E. K. Rahsin. Mit ausführlicher Bibliographie. Geleitwort von Horst-Jürgen Gerigk. Frankfurt/M. u.a.: Lang 1998 (= Heidelberger Publikationen zur Slavistik: B, Literaturwissenschaftliche Reihe; Bd. 9), $170 \mathrm{~S}$.

- Das Herrscherlob in Russland. Katharina II., Lenin und Stalin im russischen Gedicht. Ein Beitrag zur Ästhetik und Rhetorik politischer Lyrik. Heidelberg: Winter 2005 (= Beiträge zur slavischen Philologie; Bd. 11).

- Geschichte und kommunistische Gegenwart. Historiosophische Positionen und ihre narrative Präsentation in Essay und Roman der Volksrepublik Polen, 1944-1989. [Habilitationsschrift, in Druckvorbereitung]

- „Wie viel Elend und Hunger! Wie viel Trauer und Wege!“ Die nationalsozialistische Verfolgung und Vernichtung der Roma und Sinti in der künstlerischen Erinnerung Osteuropas. Hg. mit F. Fischer von Weikersthal, U. Heftrich und H.-D. Löwe. Köln, Weimar: Böhlau 2008.

\section{Aufsätze (Auswahl)}

- Intellektuelle im Deutschen Kaiserreich. In: Jutta Schlich (Hg.): Intellektuelle im 20. Jahrhundert in Deutschland. Ein Forschungsreferat (Internationales Archiv für Sozialgeschichte der Literatur. 11. Sonderheft), Tübingen 2000, S. 115-160.

- „Den Osten aus der Tiefe erkennen". Der ,deutsche Dostojewskij' im Piper-Verlag. In: West-Östliche Spiegelungen - Neue Folge. Russen und Deutsche im 20. Jahrhundert, Bd. 1-3; hier Bd. 2: „Stürmische Aufbrüche und enttäuschte Hoffnungen", hrsg. von Karl Eimermacher und Astrid Volpert, München 2006, S. 749-782.
- Spiridon Drožžin und Christian Wagner: Bauerndichtung in Russland und Deutschland - ein kulturtypologischer Vergleich. In: Wiederentdeckung eines Autors. Christian Wagner in der literarischen Moderne um 1900, hrsg. v. Burckhard Dücker und Harald Hepfer, Göttingen 2008, S. 194-209.

- Obraz Ekateriny II v pol'skoj okkazional'noj literature vremeni Stanislava Avgusta Ponjatovskogo. In: Okkazional'naja literatura $v$ kontekste prazdničnoj kul'tury Rossii XVIII veka. Pod red. P. Bucharkina, U. Ekuč, N. Kočetkovoj, St. Peterburg 2010, S. 212-219.

- The Revolution of 1905 in Polish Literature. Andrzej Strug's The Story of One Bomb and Henryk Sienkiewicz's Whirlpools. In: Rethinking the Russian Revolution of 1905: Transcultural Perspectives. Heinz-Dietrich Löwe zum 65. Geburtstag. Hg. v. F. Fischer von Weikersthal, F. Grüner, F. Schedewie (im Druck). 
Personalia

\section{PD Dr. Henrike Schmidt}

Henrike Schmidt, derzeit als Privatdozentin am Peter-Szondi-Institut für Allgemeine und Vergleichende Literaturwissenschaft der Freien Universität Berlin und als freie Wissenschaftlerin und Übersetzerin tätig, beschäftigt sich in ihren slavistischen Forschungen mit den Themenfeldern der Intermedialität und der Gattungsästhetik, der Literatursoziologie und der Folklore sowie der digitalen und Netzkultur, mit einem Schwerpunkt im Bereich der russischen und der bulgarischen $\mathrm{Li}$ teratur.

Nach dem Studium der Slavischen Philologie, der Osteuropäischen Geschichte und der Volkswirtschaft in Bonn, Köln und St. Petersburg promovierte sie im Jahr 2000 im Rahmen eines DFG-Graduiertenkollegs am Lotman-Institut für russische und sowjetische Kultur der Ruhr-Universität Bochum mit einer Arbeit zum Thema Wortmusik, Schrifttanz, Textbilder. Intermediale Sprachkonzeptionen in der russischen Poesie des 20. Jahrhunderts. Die Monographie wurde elektronisch auf dem Bibliotheksserver der Ruhr-Universität Bochum veröffentlicht und umfasst neben vielfältigen Illustrationen auch eine Reihe von originären Tonaufnahmen russischer Dichter/innen.

Die praktische Nutzung und theoretische Erforschung der ,Neuen Medien' steht seither im Focus ihrer Aktivitäten. So habilitierte sie sich im Jahr 2010 am Fachbereich
Philosophie und Geisteswissenschaften der Freien Universität Berlin mit der Schrift „Kleine Gattungen, große Graphomanen. Studien zur Ästhetik und Soziologie der russischen Literatur im Internet (1994-2009)“.

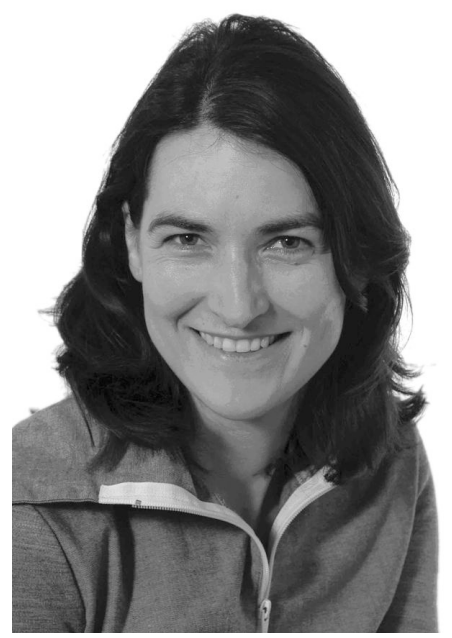

Henrike Schmidt ist Mit-Begründerin und Herausgeberin der internationalen Online-Zeitschrift Digital Icons. Studies in Russian, Eurasian and Central European New Media (peer-reviewed, www.digitalicons. org) und setzt sich für die Praxis wissenschaftlicher Veröffentlichung als Open Access ein. Die Nutzung digitaler Kulturtechnologien und Kulturtechniken stellt auch einen Schwerpunkt ihrer Lehre dar, über die Einbeziehung von Blogs, sozialen Netzwerken oder Video-Kon- 
ferenzen in die Seminararbeit. Für ihr Engagement in diesem Bereich hat sie gemeinsam mit Dr. Katy Teubener im Jahr 2005 den Altdorfer Leibniz-Preis Ars inventoria und kreative wissenschaftliche Arbeit: Kreativität und Neue Medien in Theorie und Praxis erhalten.

Neben den russistischen Forschungsschwerpunkt ist in den vergangenen Jahren die Beschäftigung mit der Literatur der bulgarischen Moderne und Postmoderne getreten. Als Stipendiatin des bulgarischen Wissenschaftskollegs in Sofia wird Henrike Schmidt im Winter 2011 zum Thema "The Creation of the Literary Canon as Art. Fictitious Anthologies in (Post)Modern Bulgarian Literature" forschen.

Henrike Schmidt war als wissenschaftliche Mitarbeiterin und Vertretungsprofessorin an verschiedenen universitären Einrichtungen (Lotman-Institut für russische Kultur der RUB, Osteuropa-Institut der FU Berlin, Szondi-Institut für AVL der FU Berlin) u.a. in selbst eingeworbenen DFG-Projekten tätig. Als Übersetzerin ist sie auf die Übertragung avantgardistischer, klangsprachlicher und visueller Dichtung der Moderne und Postmoderne (Nina Chabias, Sergej Birjukov, Anna $\mathrm{Al}^{\prime}$ čuk) spezialisiert.

\section{Publikationen (in Auswahl)}

- Wortmusik, Schrifttanz, Textbilder. Intermediale Sprachkonzeptionen in der russischen Poesie des 20. Jahrhunderts. Elektronische Publikation. RuhrUniversität Bochum 2002. Mit Illustrationen und Tonbeispielen. http://www-brs.ub.ruhr-uni-bochum .de/netahtml/ HSS/Diss/SchmidtHenrike.
- „,Avangard est' avangard'? K voprosu o sovremennom literaturnom avangarde". Canadian-American Slavic Studies 36/4 (2002), 377-390.

- „Fizionomija čužogo. Obrazy čeloveka - Obrazy goroda v putevych zametkach A. Konstantinova“. In: Tat'jana Civ'jan et al. (red.): Balkanskie čtenija 2005, Moskva 2005.

- Nina Chabias. Guttapercha des gänsehäutigen Gehänges. Gedichte. Herausgegeben, aus dem Russischen übersetzt und kommentiert von Henrike Schmidt. Mit einem Vorwort von Sergej Birjukov und Illustrationen von Djamal Djumabaeva. Leipzig: Edition Erata 2008.

- Anna Altschuk. schwebe zu stand Gedichte. Aus dem Russischen von Gabriele Leupold, Henrike Schmidt und Georg Witte. Mit einem Nachwort von Michail Ryklin und einem Werkstattbericht von Gabriele Leupold und Henrike Schmidt. Berlin: Suhrkamp 2010.

- „Li(?)teratura. Zur sprachphilosophischen Lyrik Anna Al'čuks". Zeitschrift für Slavische Philologie, 67 (2010), 1, 71-97.

- „,Digital'nye derevenščiki / ,Digital Villager Writers'. Russian Online Projects from the Countryside". Studies in East European Thought, 63 (2011). DOI: 10.1007/s11212-0119137-z

- Russische Literatur im Internet. Zwischen digitaler Folklore und politischer Propaganda. Bielefeld: Transcript 2011. 
Personalia

\section{PD Dr. Daniel Schümann}

Geboren 1973 in Erlangen, 19942000 Studium der Slavistik, Anglistik und Germanistik in Bamberg, Kazan' und London. Lehramts- und Magisterabschluss. 1997-2000 Stipendiat der Studienstiftung des deutschen Volkes. 2003 Rigorosum, 2005 Promotion zum Dr. phil. in Slavischer Philologie und Anglistik in Bamberg. Thema der Dissertation: Oblomov-Fiktionen. Zur produktiven Rezeption von I.A. Gončarovs Roman Oblomov im deutschsprachigen Raum. Januar 2011 Venia legendi für Slavische Literatur- und Kulturwissenschaft in Bamberg. Thema der Habilitationsschrift: Kampf ums Da(bei)sein. Darwin-Diskurse und die polnische Literatur bis 1900. Forschungsaufenthalte $u$. a. in Krakau, Warschau und Cambridge, z. T. gefördert von der Fritz Thyssen Stiftung. 2000-2005 Wissenschaftlicher Mitarbeiter bei Prof. Dr. Peter Thiergen, Bamberg. 2005-2010 Wissenschaftlicher Assistent bei Prof. Dr. Elisabeth von Erdmann, Bamberg. 2010-2011 Lehrstuhlvertretung (Prof. Dr. Bodo Zelinsky) an der Universität zu Köln. Mitgliedschaft im Dt. Slavistenverband und in der Deutschen Dostojewskij-Gesellschaft.

\section{Forschungsschwerpunkte}

Idee des ,neuen Menschen' in Russland, Polen und Deutschland. Deutschsprachige und polnische Oblomov-Rezeption. Polnische und russische Italienbilder (20., 21. Jahrhundert). Auseinandersetzung mit Darwins Theorien in Polen. Geschichte polnischer Naturvorstellungen im 19. und 20. Jahrhundert. Russische Klassiker im deutschen Radio. Polnische Sibirienbilder in Belletristik, Journalistik und Memoirenliteratur.

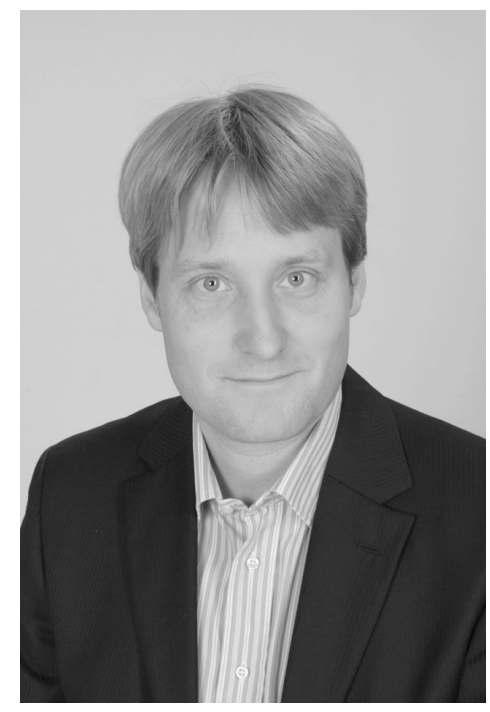

\section{Publikationen (Auswahl)}

- Die Suche nach dem ,neuen Menschen' in der deutschen und russischen Literatur der Jahrhundertwende. Frank Wedekinds MineHaha und Michail Petrovič Arcybaševs Sanin. Mit einer Zusammenfassung in russischer Sprache / S annotaciej na russkom jazyke. München 2001 (= Vorträge und Abhandlungen zur Slavistik 40). 
- Oblomov-Fiktionen. Zur produktiven Rezeption von I. A. Gončarovs Roman Oblomov im deutschsprachigen Raum. Würzburg 2005 (= Literatura 16).

- Integration durch Erzählen. Zum Icherzähler in Gustaw Herling-Grudzińskis ,italienischer Prosa'. In: Polonistik im deutschsprachigen Bereich. Aufgaben und Perspektiven ihrer Entwicklung, hrsg. von Danuta RytelKuc, Wolfgang Schwarz und HansChristian Trepte. Hildesheim / Zürich / New York 2005 (= westostpassagen 1), 255-273.

- Kunst $=$ Natur $-x$ oder Gibt es einen polnischen Naturalismus? Zeitschrift für Slawistik 52/3 (2007), 251-277.

- Struggle for or Against Participation? How Darwinism Came to Partitioned Poland. In: The Reception of Charles Darwin in Europe, hrsg. von Eve-Marie Engels und Thomas Glick, Bd. 1. London / New York 2008 (= The Athlone Critical Traditions Series: The Reception of British and Irish Authors in Europe), 244-258. 
Personalia

\section{PD Dr. Barbara Sonnenhauser}

Im Wintersemester 2010/2011 wurde Barbara Sonnenhauser mit der Arbeit Subjektivität der Sprache und sprachliche Subjektivität. Dargestellt am Beispiel des Bulgarischen, Makedonischen und Russischen an der LMU München habilitiert (venia legendi „Slavische und Allgemeine Sprachwissenschaft"). Seit April 2011 ist sie Akademische Oberrätin auf Zeit im Institut für Slavische Philologie der LMU München.

Nach einem Studium der Slavistik, Turkologie und Ost- und Südosteuropäischen Geschichte an der LMU München absolvierte sie 2002-2005 ein Promotionsstudium im Rahmen des Graduiertenkollegs „Universalität und Diversität: Sprachliche Strukturen und Prozesse $^{\prime \prime}$ an der Universität Leipzig, das sie mit der Verteidigung ihrer Arbeit Yet there's method in it. Semantics, pragmatics and the interpretation of the Russian imperfective aspect abgeschlossen hat. Im Anschluß an ihre Promotion war sie von 20052011 als wissenschaftliche Assistentin der Slavistik in München tätig (Lehrstuhl Prof. Dr. Ulrich Schweier).

Ihre Forschungsinteressen umfassen u.a. die Semantik und Interpretation von Aspekt, Ereignisstruktur und Verbsemantik, Diskursstrukturen, Subjektivität, Formen der Redewiedergabe, sprachliche Indexikalität und linguistische Semiotik. Im Zentrum stehen dabei neben dem Russischen v.a. die südslavischen Sprachen (insbesondere Bulgarisch und Makedonisch). Seit August 2011 bearbeitet sie als Projektleiterin das DFG-geförderte Projekt Perspektivität im Balkanslavischen: semantische Grundlagen und diskurspragmatische Relevanz.

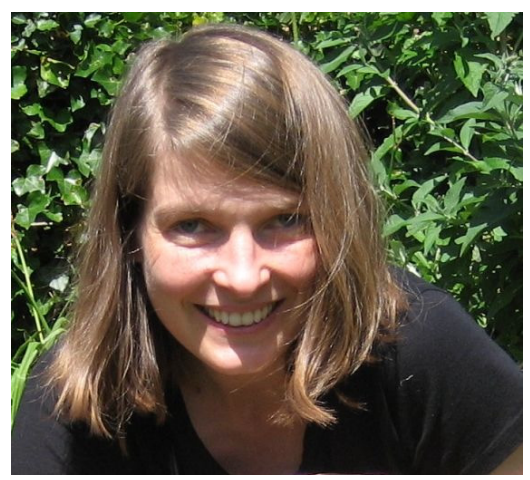

\section{Publikationen}

\section{Monographien}

- Subjektivität in der Sprache und sprachliche Subjektivität. Dargestellt am Beispiel des Makedonischen, Bulgarischen und Russischen. Habilitationsschrift. LMU 2011. Erscheint München 2011 (Specimina Philologiae Slavicae).

- Yet there's method in it. Semantics, pragmatics, and the interpretation of the Russian imperfective aspect. München 2006. 


\section{Aufsätze (in Auswahl)}

- 'Renarrativ' und indirekte Rede im Bulgarischen. Die Welt der Slaven 56/1, 2011, 131-154.

- The event structure of verbs of emotion in Russian. Russian Linguistics 34/2, 2010, 331-353.

- The Macedonian tripartite article: a discourse-oriented account. Makedonski jazik 60, 2009, 123-136.

- Parentheticals and the dialogicity of signs. Sign Systems Studies 37/1, 2009, 199-232.

- Aspect interpretation in Russian - a pragmatic account. Journal of Pragmatics 40/12, 2008, 2077-2099.

- On the linguistic expression of subjectivity: towards a sign-centered approach. Semiotica 172, 2008, 1/4, 323-337.

- Aspekt und Aorist/Imperfekt im Bulgarischen - eine intervall-basierte Analyse. Die Welt der Slaven 51, 2006, 116-140. 
Personalia

\section{PD Dr. Dieter Stern}

Im Sommersemester 2010 hat sich Dieter Stern an der Humboldt-Universität zu Berlin mit der venia legendi für Slavische Philologie habilitiert. In seiner Habilitationsschrift „Das Tajmyr-Pidgin-Russische im Kontext der Landnahme Sibiriens" hat er die Genese einer Kontaktvarietät des Russischen einer soziohistorischen Erklärung zugeführt und zugleich eine eingehende Beschreibung ihrer linguistischen Strukturen vorgelegt. Die Arbeit beruht im Kern auf Audiodaten, die in den Jahren 2000 und 2005 in eigener Feldforschung erhoben wurden.

$\mathrm{Zu}$ den aktuellen Forschungsschwerpunkten von Dieter Stern gehören interaktionell und konversationsanalytisch angelegte Untersuchungen $\mathrm{zu}$ elementaren Kontaktsituation auf mehrsprachigen informellen Grenzmärkten (Feldaufenthalte 2002 und 2009), sowie eine Reihe weiterer kontaktlinguistischer Erscheinungen, wie dem Balkansprachbund und Suržyk/ Trasjanka. Methodisch verbindet er eine bewußt theorieneutrale Linguistik mit qualitativen soziolinguistischen Verfahren, namentlich aus dem Bereich der Ethnographie der Kommunikation. Sein Anliegen ist es, die ethnographische Feldforschung inerhalb der slavistischen Linguistik zu stärken. Darüberhinaus ist er in der historisch-vergleichenden Sprachwissenschaft und der mediävistischen Philologie des Slavischen beheimatet.
Dieter Stern studierte an der Universität Bonn Slavistik, Anglistik und Indogermanistik. Er promovierte dort 1998 mit einer editionsphilologischen Arbeit über ein handschriftliches Kantional des frühen 18. Jh. aus dem Kloster Suprasl'. Von 1999 bis 2003 war er wissenschaftlicher Mitarbeiter der Arbeitsstelle der Patristischen Kommission der nordrheinwestfälischen Akademie der Wissenschaften in Bonn.

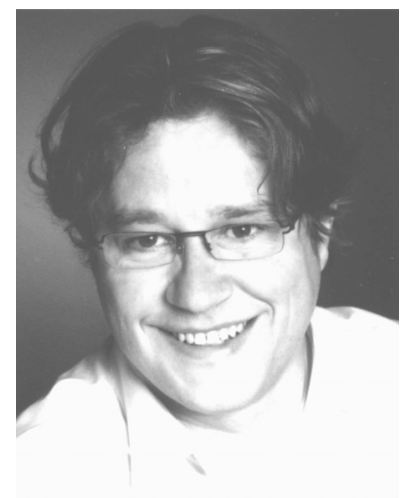

Von 2003-2007 war er wissenschaftlicher Assistent am Institut für Slawistik der Humboldt-Universität zu Berlin (Lehrstuhl Prof. Dr. Fred Otten). Von 2007 bis 2010 war er als Akademischer Oberrat auf Zeit mit der Vertretung des sprachwissenschaftlichen Lehrstuhls am Slavistischen Seminar der Universität Bonn betraut. Zum Oktober 2010 folgte Dieter Stern einem Ruf 
auf den Lehrstuhl für Altslavisch und slavisches Mittelalter an der Universität Gent.

\section{Publikationen}

\section{Monographien}

- Die Liederhandschrift F 19-233 (15) der Bibliothek der Litauischen Akademie der Wissenschaften: Eine kommentierte Edition. Köln-Wien-Weimar 2000.

- Incipitarium liturgischer Hymnen in ostslavischen Handschriften des 11.-13. Jahrhunderts, besorgt von Dieter Stern, herausgegeben von Hans Rothe, 3 Bde., Paderborn 2008.

\section{Herausgabe}

- Bibel, Liturgie und Frömmigkeit in der Slavia Byzantina. Festgabe für Hans Rothe zum 80. Geburtstag, herausgegeben zusammen mit Dagmar Christians und Vittorio S. Tomelleri, München 2009.

- Marginal Linguistic Identities. Studies in Slavic contact and borderland varieties, herausgegeben zusammen mit Christian Voß, Wiesbaden 2006.

\section{Mitarbeit}

- Gottesdienstmenäum für den Monat Februar, 1. Teil: 1.-9. Feb., herausgegeben von H. Rothe, bearbeitet von Dagmar Christians, Vittorio S. Tomelleri, Dieter Stern \& Arnd Wöhler, Paderborn 2003.

- Gottesdienstmenäum für den Monat Dezember, 3. Teil: Väter, Vorväter, 20.-24. Dez., herausgegeben von $\mathrm{H}$. Rothe, bearbeitet von Dagmar Christians, Dieter Stern \& Arnd Wöhler, Opladen 1999.

\section{Aufsätze (in Auswahl)}

- The Taimyr Pidgin Russian Morphology Enigma. International Journal of Bilingualism 13-3 (2009) 378395.
- Europa in Asien - die linguistische Seite der russischen frontier-Bildung in Sibirien. In: Eurolinguistik: Entwicklungen und Perspektiven. Akten der Internationalen Tagung vom 30.9. -2.10.2007 in Leipzig, ed. Uwe Hinrichs, Norbert Reiter \& Siegfried Tornow [Eurolinguistische Arbeiten, 5], Wiesbaden 2008, 281-295.

- Der heilige Erasmus in der byzantinischen und slavischen Hymnographie. Liturgische Hymnen nach byzantinischem Ritus bei den Slaven in ältester Zeit, ed. Hans Rothe \& Dagmar Christians, Paderborn 2007, 352381.

- Balkansprachen und Kreolsprachen: Versuch einer kontakttypologischen Grenzziehung. Zeitschrift für Balkanologie 42-2 (2006) 206-225.

- Myths and Facts about the Kiakhta Trade Pidgin. Journal of Pidgin and Creole Languages 20-1 (2005), 175187.

- Taimyr Pidgin Russian (Govorka). Russian Linguistics 29 (2005), 289318.

- Die Genese russischer Pidgins. In: Slavistische Linguistik 2002. Referate des XXVIII. Konstanzer Slavistischen Arbeitstreffens Bochum, 10.-12.9.2002, ed. Marion Krause \& Christian Sappok, München 2004, 283-303.

- Kolonialsprache Russisch. In: Die slawischen Sprachen im aktuellen Funktionieren und historischen Kontakt. Beiträge zum XIII. Internationalen Slawistenkongress vom 15. bis 21. August 2003 in Ljubljana, ed. Wolfgang Gladrow [Berliner Slawistische Arbeiten, 23], Frankfurt am Main 2003, 69-97.

- Russische Pidgins. Die Welt der Slaven 47-1 (2002) 1-30. 


\section{Tagungskurzberichte}

\section{Zusammengestellt von Gerhard Giesemann (Gießen)}

\section{Otto-Friedrich-Universität Bamberg}

Vom 6. - 10. September 2010 fand auf Einladung von Sebastian Kempgen das XXXVI. „Konstanzer Linguistische Arbeitstreffen“ statt. In 15 Vorträgen stellten die festen Mitglieder des Kreises und ihre Gäste aktuelle Forschungsarbeiten zur slavischen Sprachwissenschaft vor. Die Publikation der Beiträge erfolgt im Wiener Slawistischen Almanach.

\section{Humboldt-Universität Berlin}

Vom 7. - 9. Juli 2011 fand die internationale Tagung „Partisans. Narrative, Staging and Afterlife. A Workshop on Partisan Rhetoric and Visual Culture in and beyond Yugoslavia“" statt, organisiert von Miranda Jakiša. Die Tagung befasste sich mit dem ,Nachleben' partisanischer Rhetorik und Bildkultur in globalen wie insbesondere in nach-jugoslavischen Kontexten.

Finanzierung: Fritz-Thyssen-Stiftung.

Zu Ehren Renate Lachmanns fand vom 29. - 31. Mai 2011 die Festtagung „Evidenz und Zeugenschaft. Poetische und mediale Strategien im Umgang mit dem Unzugänglichen" statt. Die Tagung ging der Frage nach, wie Texte mit den Strategien von Evidenz und Zeugenschaft auf prinzipiell unzugängliches Bezug nehmen und dieses vergegenwärtigend ins Spiel bringen.

Finanzierung: Konstanzer Exzellenzcluster 16 „Kulturelle Grundlagen von Integration".

Vom 11. - 12. Mai 2011 fand die internationale Tagung „Doing Gender - Doing the Balkans. Dynamics and Persistence of Gender Relations in South-Eastern Europe" statt. Am Beispiel Ex-Jugoslawiens sollte gezeigt werden, wie (Bürger)Kriege zu einer Neuverhandlung von Männlichkeit und Weiblichkeit führen.

Vom 8. - 9. April 2011 führte der Fachbereich Fachdidaktik Russisch unter Leitung von Frau Anka Bergmann eine Tagung zum Thema „Kompetenzorientierung und Schüleraktivierung im Russischunterricht" durch. Ziel war es, Fragen der aktuellen fremdsprachendidaktischen Diskussion zu Prinzipien eines kompetenzorientierten Unterrichts mit Blick auf die spezifischen Rahmenbedingungen des schulischen Russischunterrichts in Deutschland aufzugreifen.

Unter der Leitung von Luka Szucsich, Kristine Bentzen (Tromsø), Roland Hinterhölzl (Venedig), Augustin Speyer (Göttingen) fand vom 23. - 25. Februar 2011 im Rahmen der 31. Jahrestagung der Deutschen Gesellschaft für Sprachwissenschaft, Universität Göttingen, die Tagung „Word Order Variation and Typology: The German Middle Field in a Comparative and Diachronic Perspective" statt: Dabei wurde die typologische und theoretische Einordnung der "freien Wortstellung" bzw. der Informationsstrukturierung mit einem Schwerpunkt auf germanischen und slavischen Sprachen diskutiert. 
Luka Szucsich, Natalia Gagarina, Elena Gorishneva und Joanna Leszkowicz leiteten gemeinsam das „19. Jahrestreffen der JungslavistInnen“ vom 16. - 18. September 2010: Vorstellung aktueller Forschungsarbeiten ohne thematische, methodische oder theoretische Einschränkungen im Rahmen des Jahrestreffens sprachwissenschaftlich arbeitender SlavistInnen (seit 1992).

\section{Rheinische Friedrich-Wilhelms-Universität Bonn}

Vom 7. - 9. April 2011 fand unter der Leitung von Riccardo Nicolosi zusammen mit Ingo Stöckmann die Tagung „Umstrittene Moderne. Die kulturellen Hegemonien des Naturalismus" statt. Ausgangspunkt für die in- und ausländischen Teilnehmer aus Germanistik, Anglistik / Amerikanistik, Romanistik, Slavistik, Skandinavistik und Komparatistik war die These, dass der Signifikant ,Naturalismus' im ausgehenden 19. Jh. einen Bezugspunkt für hegemoniale Kämpfe um die Besetzung dieses Paradigmas und um den Eintritt in die kulturelle Moderne bildet.

Förderung: Excellenzcluster 16 „Kulturelle Grundlagen von Integration“ der Uni Konstanz; Phil. Fak. der Universität Bonn.

\section{Technische Universität Dresden}

Am 12. November 2010 fand das 5. Bohemicum Dresdense: „Tschechisch bis 1775 historische Kontinuität oder Geschichte mit Sollbruchstellen?" statt, veranstaltet vom Institut für Slavistik und der Brücke-Most-Stiftung. Förderung: Brücke-MostStiftung.

Diskutiert wurde die wechselvolle Geschichte der tschechischen Sprache bis zum Beginn der „Wiedergeburt“. Vorträge: L. Udolph: „Die ersten tschechischen Wörter"; H. Keipert: „Temno und Obrození als Bezeichnungen von Epochen“; V. Velčovský: „Auswirkungen der Verneuerten Landesordnung des Erbkönigreichs Böhaimb auf die tschech. Sprachsituation“; S. Newerkla: „Kontinuität und Wandel in der Minderheitensituation - Tschechisch in Wien bis 1775".

\section{Albert-Ludwigs-Universität Freiburg}

Vom 4.-5. November 2010 fand unter der Leitung von Juliana Besters-Dilger, Achim Rabus, zusammen mit Stefan Pfänder und Cynthia Dermarkar die Konferenz „Language contact within language families (romania \& slavia)“ statt. Es wurde aus interdisziplinärer Perspektive die Frage bearbeitet, inwieweit genetische und typologische Verwandtschaft das Ergebnis von Sprachkontakt beeinflusst.

Förderung: Freiburg Institute for Advanced Studies (FRIAS).

\section{Justus-Liebig-Universität Gießen}

Vom 27. - 28. Mai 2010 fand ein vom Institut für Slavistik und vom Gießener Zentrum östliches Europa (GiZo) veranstalteter internationaler Workshop zum Thema „Ausgewählte Probleme der poln., tschech. und dt. Holocaust-Literatur" statt. Teilnehmer kamen von den Universitäten Łódź, Prag und Gießen aus den Bereichen Slavistik, Germanistik, Komparatistik, Osteurop. Geschichte und Theaterwissenschaften. Die Tagung war die erste Veranstaltung im Rahmen einer längerfristig geplanten Kooperation der beteiligten Universitäten, mit der komparatistische, poetologische und kulturwiss. Aspekte der Holocaust-Literatur betrachtet werden sollen. Weitere Tagungen: Łódź 19. - 21. Mai 2011, Prag: 21. - 22. November 2011. DAAD-gefördertes Projekt (PPP-Programm).

Franz Lebsanft (Romanistik, Bonn) und Monika Wingender (Gießen) veranstalteten vom 8. - 10. Oktober 2010 in Bonn die internationale Tagung „Die Europäische Char- 
ta der Regional- oder Minderheitensprachen auf dem Prüfstand. Die Sicht der Linguistik und der Rechtswissenschaft". Im Ergebnis hat sich die inhaltliche Konzeption, Gesamtschau von theoretischen und juristischen Konzepten der Europ. Charta (ECRM) einerseits und die Fallbeispiele ihrer Anwendung in Staaten mit sehr unterschiedlichen Voraussetzungen andererseits, als äußerst fruchtbar erwiesen. Probleme bei der Anwendung in Staaten Ost- und Westeuropas, Vorteile und Grenzen theoret. Konzepte, die der ECRM zugrunde liegen, haben Fragen aufgeworfen, die im Bereich der Mehrsprachigkeit und des Sprachenschutzes für die zukünftige Forschung entscheidende Ansatzpunkte liefern dürften. Ein Sammelband wird im Verlag de Gruyter erscheinen.

Förderung: Fritz Thyssen Stiftung.

Vom 10. - 17. Juli 2011 führte das Gießener Zentrum Östliches Europa (GiZo) zusammen mit dem Gießener International Graduate Centre for the Study of Culture eine internationale Summer School zu „Regionalisierung in der globalisierten Welt" an der Universität Łódź (Polen) durch. In interdisziplinären Arbeitsgruppen arbeiten Doktoranden aus West- und Osteuropa zusammen. Die Summer School richtet sich an Disziplinen wie Linguistik Kultur-, Literatur- und Geschichtswissenschaften, Rechtsund Wirtschaftswissenschaften, Soziologie und Politologie.

\section{Greifswald}

Vom 18. - 19. November 2010 fand unter Leitung von Ute Scholz und Britta Holtz ein Symposium zum Thema "Herrscherlob und Herrscherkritik in den slavischen Literaturen“ statt. Das zu Ehren des 60. Geburtstages von Ulrike Jekutsch durchgeführte internationale Symposium versammelte Teilnehmer aus Polen, Russland, der Ukraine und Deutschland. Es wurden Veränderungen aufgezeigt und analysiert, die Herrscherlob und Herrscherkritik im Rückgriff auf das 18. Jahrhundert in späteren Epochen bis heute erfahren haben. Im Mittelpunkt standen national und historisch konkret aufgeladene Erfahrungen von Modernität, die die facettenreiche Ausgestaltung und den Gebrauch panegyrischer Strategien beeinflussten.

Förderung: Rektorat, Dekanat der Phil. Fak. Greifswald; Akadem. Auslandsamt; Universitäts- und Hansestadt Greifswald - Kulturamt.

\section{Universität Hamburg}

Vom 6. - 8. Oktober 2010 veranstaltete der SFB 538 Mehrsprachigkeit (Organisationskomitee: Kurt Braunmüller, Bernhard Brehmer, Christoph Gabriel, Barbara HänelFaulhaber, Sveja Kranich, Bernd Meyer, Kai Wörner) die Internationale Konferenz „Multilingual Individuals and Multilingual Societies“. Die Schwerpunkte der Vorträge lagen auf mehrsprachigem Spracherwerb, mehrsprachiger Kommunikation, Sprachkontakt und Sprachvariation, Spracherosion, sprachlichen Minderheiten, mehrsprachigen Korpora sowie erziehungswissenschaftlichen Herausforderungen für mehrsprachige Gesellschaften.

Förderung: DFG; Universität Hamburg; RICOH; John Benjamins Publishing Company.

\section{Ruprecht-Karls-Universität Heidelberg}

Vom 26. - 29. Mai 2011 fand am Internationalen Wissenschaftsforum der Universität Heidelberg (IWH) die Konferenz „Bilder des Zivilisationsbruchs zwischen Ost und West. Die Ikonographie von Auschwitz und Hiroshima in den Künsten und der Publizistik Osteuropas" statt. Veranstalter waren Urs Heftrich, Karoline Thaidigsmann, Bettina Kaibach. Ziel der Konferenz war die Erforschung der Bildlichkeit und 
der sich durch starke Asymmetrie auszeichnenden ideologischen Deutung des Holocaust und des Atombombenabwurfs in den Künsten und der Publizistik Osteuropas im Dialog und im Vergleich mit dem westlichen und dem japanischen Kulturraum. Die „Ikonen“ der Massenvernichtung sollen eine differenzierte Wahrnehmung der visual culture dieser Ereignisse zwischen kulturraumspezifischen Deutungsmustern und kulturraumübergreifenden Fluktuationserscheinungen befördern und einen Beitrag zum Diskurs um eine Globalisierung der Erinnerungskultur dieser Erfahrungen leisten. Literatur-, Medien- und Kulturwissenschaftler, Soziologen, Osteuropahistoriker aus Japan, USA, Kanada, Israel, Kroatien, Tschechien, Polen, Österreich und Deutschland nahmen teil.

Förderung: Fritz-Thyssen-Stiftung; Universität Heidelberg.

Vom 1. - 3. Juli 2011 fand die Internationale Konferenz „Linguistic Awareness and Dissolution of Diglossia“ am Internationalen Wissenschaftsforum der Universität Heidelberg (IWH) statt. Veranstalter waren: Forschungsgruppe „Language and cultural translation" im Exzellenzcluster "Asia and Europe in a global context: Shifting asymmetries in cultural flows“, J. Arokay (Inst. f. Japanologie), Jadranka Gvozdanović (Slav. Inst.). Im Falle einer strengen funktionalen Unterscheidung zwischen der Schriftsprache und der gesprochenen Sprache liegt eine Diglossie im Sinne der Definition von Fergusson vor. Obwohl solche funktionalen Differenzierungen über Jahrhunderte erhalten bleiben können, wurden in den letzten Jahrhunderten viele Fälle einer Auflösung dieser Diglossien festgestellt. Die genaue Analyse dieser Prozesse im Japanischen im Vergleich mit ähnlichen Entwicklungen in anderen asiatischen und europäischen Sprachen war das Thema der Konferenz mit Spezialisten aus Japan, Europa und den USA.

Förderung: DFG.

\section{Christian-Albrechts-Universität Kiel}

Vom 20. - 23. Januar 2011 fand unter dem Motto „Junge Slavistik im Dialog“ die VI. Slavistische Studentenkonferenz statt. Das internationale Kontakt-Forum für Nachwuchswissenschaftler im Bereich der slavischen Philologie und der OsteuropaWissenschaften wurde von ca. 40 Teilnehmern aus Deutschland, Russland, Polen, Tschechien, der Slowakei, Estland, Frankreich und der Schweiz besucht. Die Beiträge werden in einem Sammelband veröffentlicht.

\section{Universität Konstanz}

Unter Leitung von Tanja Zimmermann fand vom 25. - 28. Mai 2011 der Zweite Workshop im Rahmen des Südosteuropa-Netzwerks „Untersuchungen zu transnationalen und nationalen Erinnerungskulturen in Südosteuropa“ in Novi Sad statt zu dem Thema: „Distinction and Unification. Regional and Supraregional Memories“. Förderung: DAAD.

Vom 16. - 18. Juni 2011 fand unter Leitung von Dmitrij Zakharine in Konstanz die Tagung „Elektrifizierte Stimmen. Medientechnische, sozialhistorische und kulturvergleichende Aspekte der Stimmübertragung“ statt: Erschließung des Phänomens der elektrifizierten Stimme mit interdisziplinären Zugängen.

Förderung: Thyssen-Stiftung.

\section{Universität Leipzig}

Das Geisteswissenschaftliche Zentrum für Geschichte und Kultur Ostmitteleuropas (GWZO) veranstaltete vom 12. - 13. Mai 2011 unter Leitung von Christine Gölz (Jena) und Barbara Wurm (Basel) den Workshop „Die etwas anderen Helden - Närri- 
sche Strategien in Film und Kunst Ost-Mittel-Europas". In den aktuellen Künsten Ost-Mittel-Europas bevölkern auffällig häufig Narren, ,Idioten' und clowneske Sonderlinge die dargestellten Welten. An ausgewählten Beispielen aus Film und performativer Kunst ging der Workshop dem Funktionsspektrum dieses Figurentyps nach und fragte nach seiner transkulturellen bzw. regionalen Geschichte. Typologische und epistemologische Eigenschaften wurden ebenso diskutiert wie die spezifischen narrativen Strategien und Genremuster, die mit diesen besonderen Helden und ihrem subversiven Potential verbunden sind.

Förderung: BMBF.

Die Fachrichtung Westslawistik veranstaltete vom 26. Mai - 2. Juni 2011 die VIII. Int. interFacess-Konferenz Leipzig - Praha - Wrocław: „Grenzüberschreitungen - polnische, tschechische und deutsche Sprache, Literatur und Kultur". Teilnehmer waren 30 Nachwuchswissenschaftler der Universitäten Prag, Wrocław und Leipzig, die sich mit Themen wie sprachlichen und literarischen Normen, Übersetzbarkeit, postkommunistischer Mythologie, Popular- vs. Kunstliteratur u. v. m. beschäftigten. Veranstalter waren Danuta Rytel-Schwarz, Wolfgang F. Schwarz, Hans-Christian Trepte (Leipzig) und Jiř́i Holý, Petr Mareš (Prag), Anna Dąbrowska, Lesław Cirko, Alina Jurasz (Wrocław).

Förderung: DAAD, Fond budoucnosti (Prag), Stiftung für deutsch-polnische Zusammenarbeit (Wrocław).

\section{Johannes-Gutenberg-Universität Mainz}

Vom 6. - 10. Dezember 2010 fand unter Leitung von B. Wiemer ein Workshop zum DFG-Projekt „Funktionsweisen und Struktur evidenzieller Markierungen im Slavischen" (zwecks Durchführung eines Prätests in 5 slavischen Sprachen) statt.

Vom 10.-11. Juni 2011 wurde von B. Wiemer der Workshop zum DFG-Projekt „Funktionsweisen und Struktur evidenzieller Markierungen im Slavischen“ (zwecks Durchführung einer umfangreichen Befragung in 8 slavischen Sprachen) veranstaltet.

\section{Ludwig-Maximilians-Universität München}

Das Institut für Slavische Philologie (Literaturwissenschaft) führte am 6. November 2010 das Doktorandenkolloquium SPIM (Salzburg / Passau / Innsbruck / München) durch. Doktoranden und Habilitanden süddeutscher und österreichischer Universitäten wurde hier Gelegenheit zur Präsentation eigener aktueller Arbeiten gegeben.

Am 8. November 2010 fand der „Polnisch-Deutsche Workshop zu Wörterbüchern und Korpora" am Institut für Slavische Philologie statt. Die Vorträge widmeten sich zum einen der Frage nach theoretischen und praktischen Aspekten der Erstellung von Wörterbüchern und Korpora, zum anderen wurde ihr Nutzen ebenso wie mögliche Problempunkte bei Anwendungen in Linguistik und Literaturwissenschaft diskutiert.

Vom 10. - 11. Dezember 2010 veranstaltete das Institut für Slavische Philologie zusammen mit dem Institut für Germanistik der Univ. Bamberg die Konferenz „Vocative!“. In der Regel werden Vokative rein formal als Teil des ,Sprachsystems' diskutiert oder funktional, als Strukturen, die sich nur im Sprachgebrauch zeigen. Auf der internationalen Tagung wurde diese Struktur zwischen System und Performanz vor dem Hintergrund unterschiedlicher theoretischer Ansätze sprachübergreifend, in synchroner und diachroner Perspektive diskutiert. 
Das Institut für Slavische Philologie und forumNET.Ukraine veranstalten vom 3. - 6. November 2011 die II. Internationale virtuelle Ukrainistik-Konferenz „Dialog der Sprachen - Dialog der Kulturen. Die Ukraine aus globaler Sicht".

Das Institut für Slavische Philologie, das Promotionsprogramm LIPP und das Institut für Germanistik der Univ. Bamberg veranstalteten vom 24. - 25. März 2011 das „Diskussionsforum Linguistik in Bayern“. Doktoranden und Habilitanden sämtlicher linguistischer Richtungen wurde Gelegenheit zur Präsentation eigener aktueller Arbeiten - auch von work in progress - gegeben. Neben dem inhaltlichen Aspekt stand der Aufbau von Kontakten und Netzwerken im Vordergrund, um so den wiss. Austausch unter den Nachwuchslinguisten auch über die Grenzen der eigenen Disziplin hinaus zu fördern. Rahmenthema des Diskussionsforum 2011 war ,Schnittstellen'.

Die DFG-Forschergruppe "Anfänge“ der LMU unter Beteiligung der Slavistik (Literaturwissenschaft) führte vom 27. - 28. Januar 2011 einen Workshop „Natalität des Schöpferischen" durch. Entwicklungen und Brüche in der künstlerischen Natalitätsmetaphorik der Moderne wurden untersucht. Gefragt wurde nach Familien-, Rechts-, Natur- und Gendermodellen im Einsatz der Geburtsmetapher ebenso wie nach der Reprojektion des maskulin usurpierten Geburts-Konzepts auf die Position der kreativen Frau bzw. Künstlerin, die solchermaßen die maskulin geprägte Weiblichkeit noch einmal integriert und reflektiert. Von Interesse waren ebenfalls Konzepte des Antigenerischen, des Autogenen und des Klonens.

\section{Universität Oldenburg}

Vom 29. - 31. März 2011 fand der Internationale Workshop „Trasjanka in Weißrussland - eine gemischte Varietät als Produkt des weißrussisch-russischen Sprachkontakts" statt. Die Veranstaltung im Rahmen des gleichnamigen von der Volkswagen Stiftung geförderten Forschungsprojekts wurde von Gerd Hentschel (Inst. f. Slavistik) und Bernhard Kittel (Inst. f. Sozialwissenschaften) in Kooperation mit WissenschaftlerInnen der Staatl. Universität Minsk geleitet. Im Mittelpunkt von Projekt und Workshop steht der Einfluss des Russischen auf die sprachliche und soziolinguistische Situation in Weißrussland.

Vom 16. - 19. Juni 2011 wurde der Internationale Workshop „Spezifik und Typologie ,kleiner' Literaturen im ost- westeuropäischen Vergleich“ unter Leitung von GunBritt Kohler, veranstaltet. Unter Fokussierung der belarussischen und der niederländischen Literatur strebte das Projekt einen Vergleich unterschiedlicher ,kleiner' literarischer Systeme aus feldtheoretischer Perspektive an.

Förderung: Universitätsgesellschaft Oldenburg.

\section{Universität Passau}

Vom 3. - 6. Februar 2011 fand die gemeinsam von Dirk Uffelmann (Passau) und Ingunn Lunde (Bergen) organisierte dritte Konferenz des internationalen Forschungsprojekts „The Future of Russian. Language Culture in the Era of New Technology" [http://www.uib.no/rg/future_r] statt. Linguisten, Literatur- und Kulturwissenschaftler gingen der Frage nach, inwieweit rezente Entwicklungstendenzen des RuNet globale kulturelle Veränderungsprozesse widerspiegeln oder vielmehr nationalkulturelle Spezifika darstellen. Das Spektrum der Konferenzbeiträge reichte von linguistischen Textsortenuntersuchungen zu computervermittelter Kommunikation über ästhetische Studien zur Netzliteratur bis hin zu soziologisch informierten Medien- 
analysen. Einen weiteren Schwerpunkt bildeten sprachökologische Untersuchungen zum Stellenwert des Russischen als Netzsprache.

\section{Universität Potsdam}

Am Institut für Slavistik fand unter der Leitung von Peter Kosta und Nadine Thielemann vom 16. - 18. März 2011 die Konferenz "Approaches to Slavic Interaction" statt. Die Konferenz zielte auf Zusammenführung von Forschern ab, die sowohl mit authentischen gesprochenen Texten in Interaktion zwischen tschechischen, polnischen und russischen oder anderen slavischen Gesprächspartnern als auch mit Daten von Sprechern zweisprachiger Sprachgemeinschaften arbeiten. Die Beiträge gingen von unterschiedlichen theoretischen Ausgangspositionen aus und arbeiteten mit divergenten methodischen Ansätzen (z.B. Konversationsanalyse, Diskursanalyse, interpretative Soziolinguistik, Höflichkeitsforschung bzw. Grammatik in der Interaktion). Entsprechend breit war das Themenspektrum: Diskursmarker und Interjektionen, Prosodie und Multimodalität in Interaktion, Code-Switching und CodeMixing-Phänomene.

Förderung: Universitätsgesellschaft Potsdam e.V.

Vom 21. - 23. März 2011 fand in Warschau die Internationale Tagung „Space and Memory: Warszawa - Berlin - Tel Aviv“ statt, veranstaltet vom Institut für Slavistik (Potsdam), dem Institut für Slavistik der Polnischen Akademie der Wiss. und dem Institut für Polnische Literatur der Universität Warschau, in Kooperation mit dem Institut für Slawistik der HU zu Berlin. Projektleiterin war Magdalena Marszałek (Universität Potsdam). Thema war die Beziehung zwischen Raum (Ort, Stadt, Landschaft) und kulturellem Gedächtnis aus kulturanthropologischer Perspektive und in einem gleichberechtigten Dialog zwischen Wissenschaftler/inne/n und Künstler/ inne/n. Diskutiert wurden aktuelle Konzeptualisierungen von topographischem Raum und Gedächtnis im wissenschaftlichen Diskurs (Ethnologie, Soziologie, Literatur-, Medien-, Kunstwissenschaft) und in literarischen, medialen und künstlerischen Koordinaten.

\section{Universität Regensburg}

Vom 3. - 4. Dezember 2010 fand die internationale Tagung „Subjects in Diachrony: Grammatical Change and the Expression of Subjects" statt. Organisatoren waren Björn Hansen, Roland Meyer sowie MitarbeiterInnen des Forschungsprojekts „Korpuslinguistik und diachrone Syntax: Grammatikalisierung nicht-kanonischer Subjekte in slavischen Sprachen". Die Untersuchung von Sprachwandel lässt vielfältige Rückschlüsse auf gesellschaftliche Entwicklungen zu. Dabei hat die Sprachwandelforschung gerade in den letzten Jahren durch Nutzung digitaler Textsammlungen erstaunliche Fortschritte machen können. Historische Bestände einer wachsenden Zahl von Sprachen stehen zur Verfügung und ermöglichen Aussagen zu Geschichte und Entwicklung grammatischer Phänomene. Die Teilnehmer haben sich auf dieser Grundlage mit Problemen des Sprachwandels aus der Perspektive unterschiedlicher Sprachen (germanischer, romanischer, slavischer, aber auch Türkisch und Hethitisch) befasst.

Förderung: Regensburger Universitätsstiftung.

Vom 24. - 26. Februar 2011 fand die Konferenz „Bilingualer Sprachvergleich und Typologie" in Regensburg statt, organisiert von Marek Nekula. Veranstalter waren die Institute für Germanistik (Augsburg, Brno, České Budejovice), das Bohemicum / Institut für Slavistik (Regensburg). 
Förderung: Fritz Thyssen Stiftung; Themenverbund „Ost-West-Transfer“; Tschechisches Zentrum München.

Das Bohemicum / Institut für Slavistik hat zusammen mit dem germanistischen Institut (Prag) auf Burg Hohenberg vom 27. März - 1. April 2011 die Veranstaltung „Vom Eisernen Vorhang zur Integration - vergleichende Aspekte zwischen Deutschland und der Tschechischen Republik (Frühlingsschule für Studierende)“ durchgeführt. Organisation: Marek Nekula.

Unter der Leitung von Marek Nekula und Jindřich Toman (University of Michigan / Alexander von Humboldt Stiftung) fand vom 27. - 28. Mai die Konferenz „Prague as Represented Space“ statt.

Förderung: Hans Vielberth Universitätsstiftung; Themenverbund „Ost-West-Transfer".

Vom 24. - 25. März 2011 veranstaltete Frau Sabine Koller den internationalen Workshop „Rethinking the Diaspora: Jewish Minorities in the Past, Present and Future”.

Förderung: Universität Regensburg; Die Junge Akademie / AG Minderheiten in Vergangenheit, Gegenwart und Zukunft; Volkswagen Stiftung.

\section{Universität Trier}

Im Cusanus-Geburtshaus in Kues fand vom 3. - 5. September 2010 das russischdeutsche Cusanus-Symposium „Die Rezeption des Nicolaus Cusanus in der Religionsphilosophie des 19. und 20. Jahrhunderts" an der Kueser Akademie für Europäische Geistesgeshichte statt, organisiert von der Forschungsstelle der Universitäten Alfter, Mainz, Oldenburg und Trier (Henrieke Stahl) in Verbindung mit der Russischen Cusanus-Gesellschaft an der staatl. Univ. von St. Petersburg.

Vom 12. - 14. November 2010 fand an der Katholischen Akademie Trier unter Leitung von Henrieke Stahl das Symposium „Andrej Belyj - filosof. ,Istorija stanovlenija samosoznajuščej duši' i ee konteksty“ statt.

\section{Eberhard-Karls-Universität Tübingen}

Vom 6. - 8. Oktober 2010 fand die Konferenz „Weltliteratur in der longue durée“ unter Leitung von Thomas Geider ( $\dagger$, Leipzig), Schamma Schahadat (Tübingen), Erhard Schüttpelz (Siegen), Annette Werberger (Tübingen) statt.

Förderung: EXC 16 (Kulturelle Grundlagen von Integration), Universität Konstanz.

Vom 11. - 13. November 2010 fand unter der Leitung von Nadežda Grigor'eva, Schamma Schahadat und Irina Wutsdorff im Evangelischen Stift Tübingen die Konferenz „Literatur und Philosohphie in wechselseitiger Kritik" statt.

Förderung: DFG (Projekt „Literatur und Philosophie“).

Vom 18. - 20. November 2010 fand unter der Leitung von Renata Makarska (Tübingen), Daniel Henseler (Zürich), Przemysław Czapliński (Poznań) die Tagung „Polnische Exilliteratur der 1980er Jahre" statt.

Förderung: Stiftung für deutsch-polnische Zusammenarbeit (Warschau), Universitätsbund Tübingen, Deutsch-Polnische Wissenschaftsstiftung (Frankfurt/Oder).

Im Evangelischen Stift Tübingen fand vom 28. - 29. April 2011 der Workshop „Migration der Künste - Künste der Migration“ statt. Veranstalter waren Schamma Schahadat und Dorothee Kimmich (Tübingen), in Kooperation mit Erika FischerLichte (FU Berlin) und dem Institut für Auslandsbeziehung (ifa), Stuttgart.

Förderung: DFG. 
Unter der Leitung von Schamma Schahadat und Claudia Dathe, in Kooperation mit dem Kulturamt der Stadt Tübingen, fanden vom 4. - 8. Mai 2011 die „Baden-Württembergischen Übersetzertage" statt.

Förderung: MWK Baden-Württemberg, Universität Tübingen, Robert Bosch-Stiftung, weitere Förderer, u.a. Deutsch-Tschechischer Zukunftsfond.

Vom 17. - 18. Februar 2011 fand an der Karlsuniversität Prag die Konferenz „Figurationen der Moderne. Der deutsch- und tschechischsprachige literarische Diskurs im Prag des beginnenden 20. Jahrhunderts" statt. Veranstalter waren Manfred Weinberg, Štěpán Zbytovský (Prag), Irina Wutsdorff (Tübingen).

Förderung: DFG / Netzwerkplattform Universität Konstanz.

Vom 31. März - 1. April 2011 fand an der Karlsuniversität Prag die Konferenz „Zentrum und Peripherie. Transkulturelle Hierarchien (am Beispiel Prags)“ statt. Veranstalter waren: Manfred Weinberg, Štěpán Zbytovský (Prag), Irina Wutsdorff (Tübingen), Kathrin Janka (Konstanz/Berlin), Georg Escher (Zürich).

Förderung: DFG // Netzwerkplattform Universität Konstanz.

Vom 15. - 17. Juli 2011 fand an der Universität Konstanz die Tagung „Soziale/Kulturelle (Stadt-)Räume und Transkulturalität in Prag" statt. Veranstalter waren: Manfred Weinberg (Prag), Irina Wutsdorff (Tübingen).

Förderung: DFG / Netzwerkplattform Universität Konstanz.

\section{Universität Wien}

Vom 26. - 27. November 2010 fand am Institut für Slawistik das Internationale Symposium „An den Anfängen der serbischen Philologie. ,Salo debeloga jera libo azbukoprotres' von Sava Mrkalj (1810-2010)“ statt. Veranstalter: Anna Kretschmer, Gordana Ilić Marković.

Förderung: Phil.-Kulturwiss. Fak.; Kulturministerium der Republik Serbien; Botschaft der Rep. Serbien in Österreich; Medienhaus B92; SKForum; Dachverband der serbischen Vereine in Wien.

Vom 10. - 11. Dezember 2010 fand die Konferenz im Rahmen des START-Projekts „1000 Jahre ukrainische Sprachgeschichte in Galizien“ unter Leitung von Michael Moser sowie der Kommission für Sprachkontakte des Int. Slavistenverbandes (Gerd Hentschel) am Institut für Slawistik statt.

Förderung: Fonds zur Förderung der wissenschaftlichen Forschung (FWF); Stadt Wien.

Vom 2. - 5. Juni 2011 veranstaltete Heinz Miklas, zusammen mit Melanie Gau, die Internationale Konferenz "Sinai and Jerusalem as Crossroads between East und West".

Förderung: Fonds zur Förderung der wissenschaftlichen Forschung (FWF); Phil.Kulturwiss. Fak. 


\section{Slavistische Veröffentlichungen}

\section{Zusammengestellt von Ulrich Steltner (Jena)}

\section{A. Slavistische Reihen und Zeitschriften (Neugründungen oder bisher im BDS nicht verzeichnet)}

Polonistik im Kontext. Hg. v. Alfred Gall.

Ab Feb. 2011.

Schriften des Zentrums für Osteuropa-Studien der Universität Kiel. Hg. v. Michael Düring, Norbert Nübler, Ludwig Steindorff, Alexander Trunk.

$\mathrm{Ab}$ 2010, bisher 2 Bände.

Studies on Language and Culture in Central and Eastern Europe. Hg. v. Christian Voß.

Ab Sommer 2009.

Tusculum slavicum. Hg. v. Elisabeth von Erdmann und Rainer Goldt. Ab Mai 2011.

\section{B. Dissertationen [D] und Habilitationsschriften [H]}

Afonin, Sergej

Die Distanzanrede im modernen Deutschen und Russischen. Eine kontrastivpragmatische Analyse empirischer Daten. Frankfurt am Main 2011. (Europäische Hochschulschriften. Reihe XVI. Slawische Sprachen und Literaturen; 80) [D Berlin (HU)]

Birzer, Sandra

Русское деепричастие. Процессы грамматикализации и лексикализации. München u.a. 2010. (Slavolinguistica; 11) [D Regensburg]

Brüggemann, Natalia

Aktionale Dauer. Untersuchung zum lexikalischen Dauerpotenzial russischer Verben. München 2010. (Slavolinguistica; 13) [D Hamburg]

Ďuranová, Lenka

Lieber tot als elendig. Das Suizid-Motiv in der slowakischen Gegenwartsliteratur am Beispiel der Kurzprosa Dušan Mitanas. Marburg 2010. [D Gießen]

Jahn, Peter Milan

Vom Roboter zum Schulpropheten. Hanso Nepila (1766-1856). Bautzen / Budyšin 2010. (Schriften des Sorbischen Instituts; 52) [D Leipzig]

Kirschbaum, Heinrich

„Valgally beloe vino...“ Nemeckaja tema v poėzii O. Mandel’štama.

Moskva 2010. [D Passau] 
Krauß, Ewa

Roman Ingardens "schematisierte Ansichten“ und das Problem der Übersetzung. Berlin 2011. (TransÜD, Arbeiten zu Theorie und Praxis des Übersetzens und Dolmetschens; 37) [D Jena]

Kreß, Beatrix

Kooperation und Konflikt. Äußerungsstrukturen in Konflikten und Konfliktlösungen auf der Grundlage russischer und tschechischer literarischer Texte. München - Berlin 2010. (Specimina Philologiae Slavicae; 156) [D Frankfurt am Main]

Labocki, Grit

Höflichkeitskonventionen im Wandel. Eine pragmatische Untersuchung anhand von Begrüßungsdialogen im Russischen vom Beginn des 20. Jahrhunderts bis zum Ende des 2. Weltkrieges. München - Berlin 2010. (Specimina Philologiae Slavicae; 160) [D Frankfurt am Main]

Lipinski, Renate

Die Darstellung des christlichen Wortschatzes in allgemeinsprachlichen russischen Wörterbüchern des 20. Jahrhunderts. Frankfurt am Main u.a. 2010. (Europäische Hochschulschriften; 79) [D Bonn]

Nádeniček, Petr

Das tschechische Aspektsystem im Vergleich mit dem Verbalaspekt des Russischen und Polnischen. Hamburg 2011. (Studien zur Slavistik; 27) [D Kiel]

Radünzel, Claudia

Bezeichnungen für Führungspersonen im Russischen im Vergleich mit anderen slawischen Sprachen und dem Deutschen. Heidelberg 2010. (Slavica; 6) [H Marburg]

Sauerwald, Lisanne

Mystisch-hermetische Aspekte im Kunstdenken der russischen Dichter des Absurden. Würzburg 2010 [D München]

Seemann, Katinka

Zur Frage einer spezifischen Konnotation deutscher Lehnwörter im Polnischen. Diachrone Studien an synonymischen Konstellationen. Oldenburg 2009. [URL http://oops.uni-oldenburg.de/volltexte/2010/1077/] [D Oldenburg]

Stadler, Wolfgang

Pragmatik des Schweigens. Schweigeakte, Schweigephasen und handlungsbegleitendes Schweigen im Russischen. Frankfurt a.M. 2010. (Berliner Slawistische Arbeiten; 37) [H Berlin (HU)]

Tsai, Fen-fang

Gender and Identity. Construction across Difference. Bautzen / Budyšin 2010 (Schriften des Sorbischen Instituts; 53) [D Leipzig]

Uffelmann, Dirk

Der erniedrigte Christus - Metaphern und Metonymien in der russischen Kultur und Literatur. Köln 2010 (Bausteine zur Slavischen Philologie und Kulturgeschichte. Reihe A: Slavistische Forschungen; 62) [H Bremen]

Woldt, Claudia

Sprache als Wert - Werte in der Sprache. Untersuchungen zu Bewertungen von 
Sprache allgemein und Komposita im Besonderen in der tschechischen Sprachgeschichte. München - Berlin 2010. (Specimina Philologiae Slavicae; 158) [D Dresden]

\section{Andere Monografien}

Afanasjeva, Irina, Ljubov Klobukova, Swetlana Mengel

Russisch in interkultureller Kommunikation: Zertifizierung der Sprachkenntnisse. Teil II. Basisstufe. Halle (Saale) 2010.

Afanasjeva, Irina, Ljubov Klobukova, Swetlana Mengel, A. Vavulina

Russisch in interkultureller Kommunikation: Zertifizierung der Sprachkenntnisse. Teil III. Erste Zertifizierungsstufe. Halle (Saale) 2011.

Anstatt, Tanja, Boris Norman (unter Mitarbeit von Hanna Robilka) (Hgg.)

Die slavischen Sprachen im Licht der kognitiven Linguistik / Славянские языки в когнитивном аспекте. Wiesbaden 2010. (Slavistische Studienbücher; N.F. 22)

Bartetzky, Arnold, Marina Dmitrieva, Alfrun Kliems (Hgg.)

Imaginationen des Urbanen. Konzeption, Reflexion und Fiktion von Stadt in Mittelund Osteuropa. Berlin 2009.

Belentschikow, Valentin

Boris Lapins expressionistische „Hymnen gegen die Zeit“. Mit dem russischen Text und einer Interlinearversion von Ulrich Steltner. Frankfurt a.M. u.a. 2011. (Vergleichende Studien zu den Slavischen Sprachen und Literaturen; 14)

Besters-Dilger, Juliane, Alois Woldan (Hgg.)

Die Ukraine auf dem Weg nach Europa. Die Ära Juschtschenko. Frankfurt am Main 2011.

Brehmer, Bernhard, Biljana Golubović (Hgg.)

Serbische und kroatische Schriftlinguistik: Geschichte, Perspektiven und aktuelle Probleme. Hamburg 2010.

Breu, Walter (Hg.)

L'influsso dell'italiano sul sistema del verbo delle lingue minoritarie. Resistenza e mutamento nella morfologia e nella sintassi. Atti del $2^{\circ}$ Convegno Internazionale Costanza, 10 - 13 dicembre 2008. Bochum 2011. (Diversitas Linguarum; 29)

Čapo Žmegač, Jasna, Christian Voß, Klaus Roth (Hgg.)

Co-Ethnic Migrations Compared. Central and Eastern European Contexts. München u.a. 2010.

Daiber, Thomas, J. Wierzbiński

Język - Komunikacja Międzykulturowa - Tekst i jego Interpretacja. Łódź 2010. (Acta Universitatis Lodziensis. Folia Linguistica Rossica; 6)

Daiber, Thomas

Jan Kochanowski: Das Schachspiel. Übersetzung aus dem Polnischen, Textkritik, kulturhistorische Interpretation. Rugerup 2011.

Dakova, Bisera

Der unanthologische Trajanov. Die getilgte Dekadenz. Über die Verwandlungen der poetischen Sprache. Hamburg 2009. 
Elle, Ludwig

Die Domowina in der DDR. Aufbau und Funktionsweise einer Minderheitenorganisation im staatlich-administrativen Sozialismus. Bautzen/Budyšin 2010. (Schriften des Sorbischen Instituts; 51)

Fischer, Christine (Hg.)

Russische Literatur als Brückenschlag zwischen Ost und West. Jena 2010. (Schriften und literarische Texte; 8)

Fischer, Christine, Ulrich Steltner

Polnische Dramen in Deutschland. Übersetzungen und Aufführungen als deutschdeutsche Rezeptionsgeschichte 1945-1995. Köln u.a. 2011. (Bausteine zur slavischen Philologie und Kulturgeschichte; N.F. 71)

Gall, Alfred

Humanizm performatywny. Polemika z filozofią w praktyce literackiej Witolda Gombrowicza. Kraków 2011. (Polonica leguntur; 12)

Giesemann, Gerhard, Hans Rothe (Hgg.)

Schulbildung und ihre Weiterentwicklung. Gedenkband zum 100. Geburtstag von Alfred Rammelmeyer. München - Berlin 2010. (Studies on Language and Culture in Central and Eastern Europe; 15)

Goes, Gudrun (Hg.)

Dostojewskij und Europa. München 2010. (Jahrbuch der deutschen DostojewskijGesellschaft; 17)

Graf, Alexander (Hg.)

Festkultur in der russischen Literatur (18. bis 21. Jahrhundert). München 2010. (Sprach- und Literaturwissenschaften; 35)

Hansen, Björn, Jasmina Grković-Major (Hgg.)

Diachronic Slavonic Syntax: Gradual Changes in Focus. München u.a. 2010. (Wiener Slawistischer Almanach; Sonderband 74)

Hodel, Robert

Hundert Gramm Seele. Serbische Poesie aus der zweiten Hälfte des 20. Jahrhunderts. Herausgegeben, übertragen und kommentiert von Robert Hodel. Leipzig 2011.

Höhne, Steffen; Ludger Udolph (Hgg.)

Deutsche - Tschechen - Böhmen. Kulturelle Integration und Desintegration im 20. Jahrhundert. Köln - Weimar - Wien 2010.

Hüchtker, Dietlind, Alfrun Kliems (Hgg.)

Überbringen - Überformen - Überblenden. Theorietransfer im 20. Jahrhundert. Wien u.a. 2011.

Jakiša, Miranda, Andreas Pflitsch

Jugoslawien-Libanon. Verhandlungen von Zugehörigkeit in den Künsten fragmentierter Kulturen. Berlin 2011.

Jekutsch, Ulrike, Petr E. Bucharkin, Natal'ja D. Kočetkova (Hgg.)

Окказиональная литература в контексте праздничной культуры России XVIII века. Sankt Petersburg 2010. 
Jekutsch, Ulrike (Hg.)

Glaubensfragen. Kirche und Religion in der polnischen Literatur des 20. Jahrhunderts. Wiesbaden 2011 (Opera Slavica; N.F. 53)

Keil, Rolf-Dietrich

Puškin- und Gogol'-Studien. Köln - Weimar - Wien 2011. (Bausteine zur slavischen Philologie und Kulturgeschichte. N.F. Reihe A: Slavistische Forschungen; 69)

Kliems, Alfrun, Marina Dmitrieva (Hgg.)

The Post-Socialist City. Continuity and Change in Urban Space and Imagery. Berlin 2010.

Kohler, Gun-Britt (Hg.)

Blickwechsel. Perspektiven der slawischen Moderne. Festschrift für Rainer Grübel.

Wien u.a. 2010. (Wiener Slawistischer Almanach; Sonderband 78)

Koschmal, Walter

Der Dichternomade. Jiří Mordechaj Langer - ein tschechisch-jüdischer Autor. Köln u.a. 2010 (Bausteine zur slavischen Philologie und Kulturgeschichte. N.F. Reihe A: Slavistische Forschungen; 65)

Kosta, Peter; Lilia Schürcks (Hgg.)

Formalization of Grammar in Slavic Languages. Contributions of the Eighth International Conference on Formal Description of Slavic Languages - FDSL VIII held at the University of Potsdam, December 2-5, 2009. Frankfurt am Main u.a. 2011. (Potsdamer Linguistische Untersuchungen; 7)

Kuße, Holger (Hg.)

Bohemicum Dresdense. Beiträge zur Didaktik, Sprachentwicklung und Übersetzung des Tschechischen. München 2010. (Specimina philologiae Slavicae; 153)

Kuße, Holger

Tolstoj und die Sprache der Weisheit. Göttingen 2010.

Kuße, Holger; Claudia Woldt (Hgg.)

Tschechisch und Slovakisch: Nähe und Distanz. Beiträge zum 4. Bohemicum Dresdense 13.-14. November 2009. München - Berlin 2011.

Kwilecka, Irena; Hans Rothe (Hgg.)

Biblia to iest Księgi Starego y Nowego Testamentu [...]. Przez D. Iakuba Wuyka z Wągrowca. 2 Bände. Paderborn - München - Wien - Zürich 2010. (Biblia Slavica II.V.2)

Lauer, Reinhard

Wer ist Miroslav K.? Leben und Werk des kroatischen Klassikers Miroslav Krleža. Klagenfurt / Celovec 2010.

Lehfeldt, Werner

Akcent i udarenie v sovremennom russkom jazyke. Moskva 2010.

Lehfeldt, Werner

Karl Friedrich Gauß und die russische Sprache. Berlin 2011. 
Markovič, Vladimir, Wolf Schmid (Hgg.)

Событие и событийность. Сборник статей. Moskva 2010 (Петербургский сборник; 5)

Marszałek, Magdalena, Sylvia Sasse (Hgg.)

Geopoetiken. Geographische Entwürfe in den mittel- und osteuropäischen Literaturen. Berlin 2010.

Marszałek, Magdalena, Alina Molisak (Hgg.)

Nach dem Vergessen. Rekurse auf den Holocaust in Ostmitteleuropa nach 1989. Berlin 2010.

Mengel, Swetlana, Albina Garbunov (Hgg.)

Vladimir Kaminer auf Russisch. Ein Übersetzungsprojekt. Владимир Каминер: Я беспокоюсь, мама! Halle (Saale) 2010.

Mengel, Swetlana, Natalia Fateeva (Hg.)

Dynamik poetischer Formen. Lyrik-, Prosa- und Dramentexte in Russland um die Jahrtausendwende / Динамика формы художественного текста: стих, проза, драма в конце XX - начале XXI века. Halle (Saale) 2009.

Newerkla, Stefan Michael, Fedor B. Poljakov, Oliver Jens Schmitt (Hgg.)

Das politische Lied in Ost- und Südosteuropa. Redaktion: Hansfrieder Vogel, Armina Galijaš. Wien 2011. (Europa Orientalis; 11)

Pasternak, Evgenij, Elena Pasternak, unter Mitarbeit von Fedor Poljakov (Hgg.)

Boris Pasternak - Kurt Wolff. Im Meer der Hingabe. Briefwechsel 1958-1960. Mit einem Vorwort von Gerd Ruge. Frankfurt am Main u.a. 2010. (Русская культура в Европе / Russian Culture in Europe; 6)

Rabus, Achim, Balázs Nemes (Hgg.)

Vermitteln - Übersetzen - Begegnen. Transferphänomene im europäischen Mittelalter und in der Frühen Neuzeit: interdisziplinäre Annäherungen. Göttingen 2011. (Nova Mediaevalia; 8)

Ressel, Gerhard, Svetlana Ressel (Hgg.)

Vom Umgang mit Geschehenem: Mechanismen der Kriegsverarbeitung und Strategien der Friedenssuche in Geschichte und Gegenwart der kroatischen und serbischen Literatur und Kultur. Frankfurt am Main 2011. (Trierer Abhandlungen zur Slavistik; 10)

Richter, Angela, Brigitte Klosterberg. (Hg.)

D. I. Tschižewskij. Impulse eines Philologen und Philosophen für eine komparative Geistesgeschichte. Münster 2009. (Slavica varia halensia; 9)

Richter, Angela (Hg.)

Der Engel und der rote Hund. Kurzprosa aus Serbien. Berlin 2011.

Rothe, Hans (Hg.)

„Biblia slavica“. Referate bei der öffentlichen Präsentation in der Nordrhein-Westfälischen Akademie der Wissenschaften und der Künste am 28. November 2008. Paderborn - München - Wien - Zürich 2010. 
Rothe, Hans (Bearb.)

Hermann von Boyen und die polnische Frage. Denkschriften von 1794 bis 1846. Köln - Weimar - Wien 2010. (Veröffentlichungen aus den Archiven Preussischer Kulturbesitz, Band 66)

Rothe, Hans

Szkice o literaturze polskiej i ukraińskiej. Siedlce - München 2011.

Schaller, Helmut W.

„Slavica (non) leguntur“. Die deutsche Ost- und Südosteuropaforschung am Anfang oder am Ende - gezeigt am Beispiel von Marburg. München 2010.

Schaller, Helmut W.

Die „Reichsuniversität Posen“ 1941-1945. Vorgeschichte, nationalsozialistische Gründung, Widerstand und polnischer Neubeginn. Frankfurt a.M. u.a. 2010. (Symbolae Slavicae; 29)

Schmid, Wolf

Narratology. An Introduction. Berlin u.a. 2010.

Schruba, Manfred, Oleg Korostelev (Hgg.)

Vokrug redakcionnogo archiva "Sovremennych zapisok“ (Pariž, 1920-1940). Sbornik statej i materialov. Moskva 2010.

Strániková, Jana, Jiřina van Leeuwen Turnovcová

Schreiben im Alltag des 19.Jahrhunderts. Das Schreib- und Schrifttechnische zur Zeit der nationalen Wiedergeburt (1790-1860) in Briefen der patriotischen Kreise. München u.a. 2011. (Specimina Philologiae Slavicae; 161)

Thiergen, Peter

Aufrechter Gang und liegendes Sein. Zu einem deutsch-russischen Kontrastbild. München 2010. (Bayerische Akademie der Wissenschaften. Philosophisch-historische Klasse. Sitzungsberichte. Jg. 2010; 3)

Bodo Zelinsky (Hg.)

Das russische Drama. Köln 2011.

Zlatanova, Rumjana (Hg.)

S. Paskalevski - Triptychon „Mystisches Fest". Hl. Benedikt und die hll. Kyrill und Method in Himmerod. Sofia 2010. (Dialog und Dimensionen des Geistes; 4)

Zlatanova, Rumjana, Helmut Schaller (Hgg.)

Symbolae Ecclesiasticae Bulgaricae. Zum 80. Geburtstag von Prof. Dr. Hans-Dieter Döpmann. München 2011. (Bulgarische Bibliothek; 15) 


\section{Aus der deutschsprachigen slavistischen Forschung}

\section{Zusammengestellt nach den Selbstauskünften der Institute von Ulrich Steltner (Jena)}

Legende: Ort 1.Thema; 2. Verantwortliche; 3. Geldgeber; 4. Laufzeit.

Berlin (HU) (1)

1. Russisches Kirchenslavisch im 15. und 16. Jahrhundert: Zur (In)Variabilität seiner Normen (am Material des Kommentierten Apostolos);

2. Prof. Dr. Christian Voß (mit Prof. Dr. Juliane Besters-Dilger, Universität Freiburg); Berliner Mitarbeiterin: Dr. Marina Bobrik;

3. DFG;

4. Feb. 2011 - Jan. 2013 (Projektverlängerung).

Berlin (HU) (2)

1. Wissenschaftsgeschichte in Südosteuropa;

2. Prof. Dr. Christian Voß;

3. DFG;

4. Sept. 2010 - Apr. 2011.

\section{Bern}

1. The Works of Gregory Palamas and Barlaam the Calabrian in Slavonic Translation;

2. Prof. Dr. Lora Taseva;

3. Schweizerischer Nationalfonds [100012_129571];

4. Sept. 2011 - Aug. 2013.

\section{Bochum (1)}

1. Diskursorientierte Annotationen regionaler Alltagssprache;

2. Prof. Dr. Christian Sappok, Prof. Dr. Tanja Anstatt; Mitarbeiter: Dr. Aleksandr Krasovickij;

3. DFG;

4. Sept. 2009 - Aug. 2011.

\section{Bochum (2)}

1. LesenHQ - Interaktive Studienplattform zu russischen und deutschen Fachtexten im Kontext des Internationalen Masterstudiengangs Russische Kultur;

2. Dr. Dr. h.c. Klaus Waschik, Dr. Holger Gemba;

3. VolkswagenStiftung;

4. Sept. 2009 - Aug. 2012.

\section{Bochum (3)}

1. Estrada! Schlager und Gesellschaft in der Sowjetunion im Zeitraum von 1953 bis 1989;

2. Dr. Ingo Grabowsky;

3. DFG;

4. Sept. 2010 - Aug. 2013. 


\section{Bochum (4)}

1. Integrierte Internationale Studiengänge mit Doppelabschluss;

2. Prof. Uhlenbruch, Dr. Waschik;

3. DAAD;

4. Sept. 2010 - Aug. 2011.

\section{Bonn}

1. Philologischer, historischer und theologischer Kommentar zu Ausgaben der Gottesdienstmenäen (September - Dezember, Februar, April - Juni, August); Edition des Aprilmenäums;

2. Prof. Dr. Hans Rothe; Mitarbeiterinnen: Dr. Dagmar Christians; Dr. Tinatin Chronz; stud. phil. Irena Chibisova;

3. DFG;

4. $2010-2013$.

Cottbus (Sorbisches Institut, Abt. f. niedersorbische Forschungen) (1)

1. Ausbau der Internetversion älterer niedersorbisch-deutscher Wörterbücher $(\mathrm{Zu}-$ gang über die Ausgangssprache Deutsch; Organisation eines systematischen Zugriffs auf niedersorbische Phraseme);

2. Dr. Hauke Bartels, Marcin Szczepański M.A., Katja Atanasow M.A.;

3. Vattenfall Europe Mining AG;

4. Okt. 2010 - Sept. 2012.

Cottbus (Sorbisches Institut, Abt. f. niedersorbische Forschungen) (2)

1. Text corpus of native Lower Sorbian;

2. Dr. Hauke Bartels, Kamil Stumpf M.A. u.a.;

3. Volkswagen-Stiftung (Dokumentation bedrohter Sprachen);

4. Okt. 2010 - Sept. 2011 (Pilotphase).

\section{Dresden}

1. Normative Diskurse in der russischen Sprach- und Argumentationsgeschichte;

2. Prof. Dr. Holger Kuße; Mitarbeiterin: Dr. Claudia Woldt;

3. BMBF (Teilprojekt im Verbundprojekt „Kulturen der Gerechtigkeit. Normative Diskurse im Transfer zwischen Westeuropa und Russland“);

4. $2009-2010$.

\section{Freiburg (1)}

1. Russisches Kirchenslavisch im 15. und 16. Jahrhundert: Zur (In)Variabilität seiner Normen (am Material des Kommentierten Apostolos);

2. Prof. Dr. Juliane Besters-Dilger (zusammen mit Prof. Dr. Christian Voß (HU Berlin)); Freiburger Mitarbeiterinnen: Viktoria Halapats M.A., Natascha Kindermann M.A., Elina Maier M.A.;

3. DFG;

4. Jan. 2011 - Dez. 2012.

\section{Freiburg (2)}

1. Genderdiskurse und nationale Identität in Russland - Historische Perspektiven und aktuelle Tendenzen;

2. Prof. Dr. Elisabeth Cheauré; Mitarbeiterinnen: Dr. Friederike Carl, Olga Gorfinkel M.A., Dr. Regine Nohejl;

3. DFG;

4. Juli 2007 - Juni 2011. 


\section{Freiburg (3)}

1. Napoleon, Borodino und der "Vaterländische Krieg": Geschichtspopularisierungen im Kontext nationaler Identitätsfindung in Russland;

2. Prof. Dr. Elisabeth Cheauré; Mitarbeiterin: Dr. Regine Nohejl;

3. DFG (Forschergruppe „Historische Lebenswelten in populären Wissenskulturen der Gegenwart");

4. Jan. 2011 - Dez. 2013.

\section{Freiburg (4)}

1. Slavistisches Teilprojekt (im Rahmen des interdisziplinären DFG-Projekts „Ziglers ,Asiatische Banise' (1689). Edition des Textes und Dokumentation der europäischen Rezeptions- und Übersetzungsgeschichte“);

2. Prof. Dr. Elisabeth Cheauré, Mitarbeiterin: Dr. Verena Krüger;

3. DFG;

4. Okt. 2010 - Sept. 2011.

\section{Göttingen}

1. Mikrotypologische Variation in Argumentrealisierung und Morphosyntax;

2. Prof. Dr. Uwe Junghanns; Mitarbeiterinnen: Denisa Lenertová, Dorothee Fehrmann;

3. DFG (Forschergruppe 742 "Grammatik und Verarbeitung verbaler Argumente", Göttingen und Leipzig);

4. 2009-2012.

\section{Halle}

1. Aufklärung - Religion - Wissen;

2. (Slavistische Beteiligung);

3. Landesexzellenznetzwerk des Landes Sachsen-Anhalt.

\section{Hamburg (1)}

1. Aktuelle polnisch-deutsche Zweisprachigkeit in Deutschland;

2. Prof. Dr. Bernhard Brehmer; Mitarbeiterin: Agnieszka Czachór M.A.;

3. DFG (Teilprojekt H8 des SFB 538 „Mehrsprachigkeit“);

4. Juli 2008 - Juni 2011.

\section{Hamburg (2)}

1. Genuserwerb bei polnisch-deutschen bilingualen Kindern;

2. Prof. Dr. Bernhard Brehmer, Prof. Dr. Monika Rothweiler; Mitarbeiterin: Kinga Kulaga M.A.;

3. DFG (Matrixprojekt M1 des SFB 538 „Mehrsprachigkeit“ );

4. Juli 2008 - Juni 2011.

\section{Hamburg (3)}

1. Russisch als L3/L4 bei SchülerInnen und StudentInnen mit slavischer Erstsprache in Deutschland;

2. Prof. Dr. Bernhard Brehmer; Mitarbeiterinnen: Tatiana Perevozchikova M.A., Evghenia Goltsev, Silvia Lazar;

3. Behörde für Wissenschaft und Forschung der Freien und Hansestadt Hamburg (Landesexzellenzcluster "Linguistic Diversity Management in Urban Areas" [LIMA]);

4. Juli 2009 - Dez. 2012.

\section{Hamburg (4)}

1. Diskursive Topografie der Mehrsprachigkeit in Hamburg; 
2. Prof. Dr. Angelika Redder, Prof. Dr. Bernhard Brehmer; Mitarbeiter/innen: Claudio Scarvaglieri M.A., Ruth Pappenhagen M.A.;

3. Behörde für Wissenschaft und Forschung der Freien und Hansestadt Hamburg (Landesexzellenzcluster "Linguistic Diversity Management in Urban Areas" [LIMA]);

4. Juli 2009 - Dez. 2012.

Heidelberg (1)

1. Sprache und kulturelle Übersetzung: Asymmetrien bei der Entstehung moderner Schriftsprachen;

2. Prof. Dr. Jadranka Gvozdanović; Mitarbeiterinnen: Katharina Kunz M.A., Darja Miyajima M.A.;

3. DFG (Exzellenzcluster "Asien und Europa im globalen Kontext: Wechselnde Asymmetrien in kulturellen Austauschprozessen")

4. Feb. 2009 - Jan. 2011 (1. Phase).

Heidelberg (2)

1. Isaak Babel: Die Prosa. Neue vollständige, kommentierte deutsche Übersetzung in einem Band;

2. Prof. Dr. Urs Heftrich, Dr. Bettina Kaibach;

3. (Gemeinnützige Ges.) „Perewest“; Johann-Joachim-Christoph-Bode-Stipendium;

4. Bis 2012.

\section{Jena}

1. Kulturelle Orientierungen und gesellschaftliche Ordnungsstrukturen in Südosteuropa;

2. (Slavistische Beteiligung) Prof. Dr. Thede Kahl, Prof. Dr. Andrea Meyer-Fraatz, Prof. em. Dr. Gabriella Schubert;

3. DFG - Graduiertenkolleg 1410;

4. Apr. 2011 - Sept. 2015 (Verlängerung)

\section{Konstanz (1)}

1. Das Reale in der Kultur der Moderne;

2. (Slavistische Beteiligung) Prof. Dr. J. Murašov;

3. DFG (Graduiertenkolleg);

\section{Konstanz (2)}

1. Medien und Memoria - Kulturwissenschaftliches Netzwerk für SüdosteuropaStudien;

2. Prof. Dr. Tanja Zimmermann;

3. DAAD;

4. Seit Feb. 2010.

\section{Konstanz (3)}

1. Das elektrifizierte Wort. Sprache, Technik und Gemeinschaft in der sowjetischen und russischen Moderne des 20. Jahrhunderts;

2. Prof. Dr. Jurij Murašov; Mitarbeiter: PD Dr. Dmitirj Zakharine, Konstantin Kaminskij M.A.;

3. DFG;

4. Apr. 2010 - März 2013.

\section{Konstanz (4)}

1. Buchstaben, Ziffern und Kalkulationen der Macht; 
2. Prof. Dr. Jurij Murašov; Mitarbeiterinnen: Anastasiya Arslan-Kokina (Teilprojekt 1 "Autokratische Sprachmacht und dissidentische Zahlenpoetik in der Epoche Katharina II“); Elena Fedotova M.A. (Teilprojekt 2 „Von der poetischen Magie der Ziffern zur sowjetischen qualitativen Statistik der 1930er Jahre“);

3. DFG (EXC 16, ,Kulturelle Grundlagen der Integration“);

4. Feb. 2009 - März 2012.

\section{Konstanz (5)}

1. Memoria und Medien: Konstruktionen der „Brüderlichkeit und Einheit“ in der Tschechoslowakei und Jugoslawien;

2. Prof. Dr. Tanja Zimmermann;

3. Ministerium für Wissenschaft, Forschung und Kunst;

4. Sept. 2010 - Aug. 2013.

\section{Konstanz (6)}

1. Elektronische Datenbank bedrohter slavischer Varietäten in nichtslavophonen Ländern Europas / Base de données électronique de variétés slaves menacées dans des pays européens non slavophones (Deutsch-Französisches Gemeinschaftsprojekt EuroSlav 2010);

2. Walter Breu (Universität Konstanz), Evangelia Adamou (Lacito, Paris); Mitarbeiterin in Konstanz: Mia-Barbara Mader Skender;

3. DFG/ANR;

4. Jan. 2010 - Dez. 2011.

\section{Leipzig (GWZO) (1)}

1. Imaginationen des Urbanen in Ostmitteleuropa. Stadtplanung - Visuelle Kultur - Dichtung im 20. Jahrhundert;

2. Dr. Alfrun Kliems (GWZO); mit folgenden Slavistik-affinen Teilprojekten: Dr. M. Colombi: „Stadt und Verbrechen. Die Darstellung des urbanen Raums im zeitgenössischen Kriminalroman“; Dr. M. Dmitrieva: „Metropolis: Transatlantischer Topos in der visuellen Kultur Ostmitteleuropas“; Dr. A. Kliems: „Die Wende, der Underground und die Stadt. Urbane Kunst des Underground in Ostmitteleuropa“; D. Poláková: "Subversive poetologische Strategien von Underground und Pop-Kultur in der tschechischen und slowakischen Literatur der 1990er Jahre";

3. DFG / BMBF;

4. $2006-2007$ (DFG), $2008-2010$ (BMBF).

\section{Leipzig (GWZO) (2)}

1. Spielplätze der Verweigerung. Topographien und Inszenierungsweisen von Gegenöffentlichkeit in Ostmitteleuropa;

2. Dr. Alfrun Kliems; mit folgenden Slavistik-affinen Teilprojekten: Dr. A. Kliems: „Der Underground, die Wende und die Stadt. Die urbane Kunst des Underground in Ostmitteleuropa“; Dr. Chr. Gölz: „Die etwas anderen Helden - „Närrische' Strategien in der Filmkunst Ost-Mittel-Europas"; Dr. M. Colombi: ",Gegen-den-Strich-lesen'. Partisanenbild und alternative Kultur in Slowenien“;

3. BMBF;

4. $2011-2013$.

\section{Leipzig (GWZO) (3)}

1. Der ukrainische Dichter Taras Ševčenko als lieu de mémoire von 1960 bis heute;

2. Prof. Dr. Stephan Troebst; Mitarbeiterin: Dr. Jenny Alwart;

3. DFG;

4. $2009-2011$. 
Leipzig (GWZO) (4)

1. Reflexion kultureller Interferenzräume. Ostmitteleuropa im 20. Jahrhundert;

2. Dr. Ute Raßloff, mit folgendem Slavistik-affinen Teilprojekt: „Modellierung kultureller Interferenzräume. Literatur und visuelle Kultur der Slowakei im 20. Jh.";

3. BMBF (Programm "Geisteswissenschaften im gesellschaftlichen Dialog“);

4. Sept. 2007 - Aug. 2010.

Leipzig (GWZO) (5)

1. Zwischen religiöser Tradition, kommunistischer Prägung und kultureller Umwertung: Transnationalität in den Erinnerungskulturen Ostmitteleuropas seit 1989;

2. Prof. Dr. Stefan Troebst; Koordination: Dr. Agnieszka Gąsior; mit folgendem Slavistik-affinen Teilprojekt: Dr. Anne C. Kenneweg: „Der Antemurale-Topos als gedächtnisstrukturierende Denkfigur in der kroatischen Literatur: Literarische Inszenierungen und politische Instrumentalisierung im ostmitteleuropäischen Vergleich";

3. DFG (2006-2008), BMBF (2008-2010);

4. Juni 2006 - Dez. 2010.

\section{Mainz}

1. Funktionsweisen und Struktur evidenzieller Markierungen im Slavischen (integrative Theorie mit Aufbau einer Datenbasis);

2. Prof. Dr. B. Wiemer; Mitarbeiterin: Dr. Veronika Kampf;

3. DFG;

4. Apr. 2010 - März 2013.

\section{Münster (1)}

1. Practices of Literature;

2. Prof. Dr. Alfred Sproede;

3. DFG (Graduiertenkolleg [mit slavistischer Beteiligung]);

\section{Münster (2)}

1. Erzählte Justiz in Russland. Narrative Übersetzungen einer Rechtsordnung, 1864-1918;

2. Prof. Dr. Alfred Sproede;

3. BMBF (Teil des Forschungsverbunds Münster, Bochum und Dresden „Kulturen der Gerechtigkeit. Normative Diskurse im Transfer zwischen Westeuropa und Russland“, hier Teilprojekt 3);

4. Juli 2009 - Mai 2012.

\section{Münster (3)}

1. Recht und Rhetorik;

2. Prof. Dr. Alfred Sproede;

3. BMBF (Teilprojekt C 3 im Kompetenznetz zur Förderung regionaler Studien „Institutionen und institutioneller Wandel im Postsozialismus: Zwischen Geschichtlichkeit und globalem Anpassungsdruck" mit Beteiligten an diversen Universitäten und Forschungsstätten);

4. Mai 2010 - April 2014.

\section{Oldenburg (1)}

1. Die "Trasjanka“ in Weißrussland - eine Mischvarietät als Produkt des weißrussisch-russischen Sprachkontakts. Sprachliche Strukturierung, soziologische Identifikationsmechanismen und Sozioökonomie der Sprache; 
2. Prof. Dr. Gerd Hentschel; Mitarbeiter/innen: Sviatlana Tesch, Oxana Brandes, Diana Lindner;

3. Volkswagen Stiftung;

4. $2008-2011$.

\section{Oldenburg (2)}

1. Flexionsmorphologische Irregularität(en) in „aktuellen“ Kontaktvarietäten nordslawischer Sprachen;

2. Prof. Dr. Gerd Hentschel; Mitarbeiter: Thomas Menzel;

3. DFG;

4. $2009-2012$.

\section{Oldenburg (3)}

1. Das „Wörterbuch der deutschen Lehnwörter in der polnischen Hoch- und Standardsprache vom Mittelalter bis zur Mitte des 20. Jahrhunderts“ als Internetportal;

2. Prof. Dr. Gerd Hentschel; Mitarbeiter: Martin Renz (Oldenburg), Günter Koch (Gesellschaft für wissenschaftliche Datenverarbeitung, Göttingen);

3. Beauftragter der Bundesregierung für Kultur und Medien;

4. Dez. 2008 - Feb. 2011.

\section{Passau (1)}

1. Der erzwungene Bevölkerungstransfer der Jahre 1944-1950 in der deutschen und polnischen Literatur - Fremd- und Kolonisierungswahrnehmungen im Dreieck Deutsche - Polen - Russen, Teilprojekt 1 B „,Oberschlesien“;

2. Mitarbeiterin: Marta Patrycja Podolczak M.A.;

3. Beauftragter der Bundesregierung für Kultur und Medien;

4. Seit Nov. 2010.

\section{Passau (2)}

1. Sommeruniversität "Gemeinsame Vergangenheit - gemeinsame Zukunft?“ in Cholpon-Ata, Issyk Kul, Kirgisistan;

3. DAAD;

4. Sept. 2010.

\section{Regensburg}

1. Mood and modality in the Balto-Finnic languages;

2. Dr. Petar Kehayov (Humboldtstipendiat am Lehrstuhl für slavistische Linguistik [Prof. Dr. Hansen]);

3. Alexander-von-Humboldt-Stiftung;

4. Jan. 2011 - Juni 2012.

\section{Trier}

1. Kommentierte Edition von Andrej Belyjs Geschichte der Bewußtseinsseele;

2. Prof. Dr. Henrieke Stahl; Mitarbeiterinnen: Eva-Maria Mischke M.A., Alla Holzmann M.A.;

3. DFG;

4. $2006-2012$.

\section{Tübingen (1)}

1. Verbalaspekt im Text: Kontextuelle Dynamisierung vs. Grammatik. Ein Vergleich des tschechischen und des russischen Systems;

2. Prof. Dr. Tilman Berger; MitarbeiterInnen: Dr. Anja Gattnar; Valentin Dübbers M.A.; 
3. DFG (SFB 833 „Bedeutungskonstitution - Dynamik und Adaptivitat sprachlicher Strukturen", Projekt C2);

4. Juli 2009 - Juni 2013.

\section{Tübingen (2)}

1. Philosophie als Literatur, Philosophie über Literatur, Philosophie in der Literatur. Zur Interaktion von Literatur und Philosophie in der russischen Literatur;

2. Prof. Dr. Schamma Schahadat; Mitarbeiterinnen: Dr. Nadežda Grigor'eva, Dr. Irina Wutsdorff (bis 03/11), Dr. des. Erik Martin (seit 04/11);

3. DFG;

4. Nov. 2008 - Apr. 2012.

\section{Tübingen (3)}

1. Textabdrücke: Literarisches Übersetzen an der Universität Tübingen;

2. Prof. Dr. Schamma Schahadat; Mitarbeiterin: Dipl-Übersetzerin Claudia Dathe;

3. Robert Bosch Stiftung;

4. Apr. 2009 - März 2012.

\section{Tübingen (4)}

1. Der polnische Film - eine europäische Filmkultur;

2. Prof. Dr. Schamma Schahadat; Mitarbeiter: Christian Nastal M.A.;

3. Deutsch-polnische Wissenschaftsstiftung;

4. Feb. 2010 - Jan. 2012.

\section{Tübingen (5)}

1. Grenzerzählungen in transnationalen Räumen. (Westukraine 19./20. Jh.);

2. Dr. Renata Makarska, Prof. Dr. Schamma Schahadat, Dr. Annette Werberger; Mitarbeiter/innen: Katharina Schwitin M.A., Dr. Alexander Kratochvil;

3. DFG (Exzellenzcluster 16 Konstanz);

4. Feb. 2008 - Dez. 2010.

\section{Tübingen (6)}

1. Forschungsverbund Prag als Knotenpunkt europäischer Modernen;

2. Prof. Dr. Irina Wutsdorff, Prof. Dr. Manfred Weinberg (Konstanz/Prag); Mitarbeiterin: Kathrin Janka M.A.:

3. DFG (Exzellenzcluster 16 Konstanz);

4. Okt. 2010 - März 2011.

\section{Tübingen (7)}

1. Russland und Afrika - ein polyloges Diskursgeflecht;

2. Dr. Gesine Drews-Sylla;

3. Margarete von Wrangell-Habilitationsprogramm Baden-Württemberg;

4. Feb. 2008 - Feb. 2012.

\section{Tübingen (8)}

1. Nach dem Exil. Kulturen Ostmitteleuropas in Zeiten kultureller Migration;

2. Dr. Renata Makarska;

3. Margarete von Wrangell-Habilitationsprogramm Baden-Württemberg;

4. Apr. 2009 - Jan. 2012.

\section{Wien}

1. Das österreichische Galizien und sein multikulturelles Erbe;

3. Fonds für wissenschaftliche Forschung (Doktoratskolleg);

4. Nov. 2006 - Okt. 2012. 


\title{
Slavistische Promotionen 2010-2011
}

\section{Zusammengestellt von Miranda Jakiša (Berlin)}

\begin{abstract}
Afonin, Sergej: „Die Distanzanrede im modernen Deutschen und Russischen. Eine kontrastiv-pragmatische Analyse empirischer Daten“. Humboldt-Universität zu Berlin, 6.9.2010 (betreut von: Wolfgang Gladrow).
\end{abstract}

Alwart, Jenny: „Mit Taras Ševčenko Staat machen? Erinnerungskulturelle Kontroversen um die Dichtergestalt in Literatur und Kunst der spät- und postsowjetischen Ukraine“. Universität Leipzig, 30.11.2011 (betreut von: Stephan Troebst).

Baratynskaya, Zhanna: „Poetik der ,Ewigen Rückkehr' Arsenij Tarkovskijs als Phänomen des Konvergenten Bewusstseins“. Universität Hamburg, 18.5.2011 (betreut von: Robert Hodel).

Bieniek, Beata: „Bruno Schulz’ Mythopoesie der Geschlechteridentitäten: Der Götzenblick im Gender-Spiegel“. Universität Mainz, 8.7. 2010 (betreut von: Alfred Gall).

Caspers, Olga: „Ein großer Schriftsteller und ein großer Reaktionär. Die sowjetische Dostoevskij-Rezeption, dargestellt am Beispiel der Gesamtausgaben“. Ruhr-Universität Bochum, 14.7.2010 (betreut von: Ulrich Schmid, Bernd Uhlenbruch).

Fuchsbauer, Jürgen: „Die Übertragung der Dioptra ins Slavische - Ein Beispiel mittelkirchenslawischer Übersetzungstechnik. Dargestellt anhand des vierten Buches des Werkes“. Universität Wien, 29.6.2010 (betreut von: Heinz Miklas).

Giesel, Christoph: „Identität und Sprachgebrauch der slawophonen bosniakischen Auswanderer in Istanbul“. Universität Jena, 1.12.2010 (betreut von: Gabriella Schubert).

Gorzelniak, Samanta: „,Es war schwer die Grenze zwischen dem Einklang mit dem eigenen Gefühl und der Pflicht zu erfassen'. Die Ehe als Schwellenphänomen in den Texten polnischer Romantikerinnen“. Eberhard-Karls-Universität Tübingen, 18.5. 2011 (betreut von: Schamma Schahadat).

Graf, Elena: „Interjektionen im Russischen als interaktive Einheiten“. HumboldtUniversität zu Berlin, 6.9.2010 (betreut von: Wolfgang Gladrow).

Hofeneder, Philipp: „Galizisch-ruthenische Schulbücher in der Zeit von 1848 bis 1918. Sprachliche Konzeption und thematische Ausrichtung“. Universität Wien, 17.3.2010 (betreut von: Michael Moser).

Holzschuster, Marta: „Irrationalität im Werk von Arnošt Lustig: Modlitba pro Kateřinu Horovitzovou“. Universität Wien, 26.5.2010 (betreut von: Stefan Michael Newerkla). 
Hürner, Dana: „Paläographie und Graphematik der westkirchenslawisch-glagolitischen Kiever und Prager Blätter im Kontext der sinaitischen Tradition und unter besonderer Berücksichtigung des ,Demetrius Sinaiticus”“. Universität Wien, 14.2.2011 (betreut von: Heinz Miklas).

Kaulfürst, Fabian: „Studije k rěči Michała Frencla“, Universität Leipzig, 9.12.2010 (betreut von: Eduard Werner).

Klose-Henrichs, Matthias: „Literarische Deutungen jüdischer Existenz im Werke Julian Stryjkowskis“. Ruhr-Universität Bochum, 14.7.2010 (betreut von: Ulrich Schmid, Mirja Lecke).

Malygin, Erna: „Die Literatur als Fach in der sowjetischen Schule der 1920er und 1930er Jahre. Die Bildung eines literarischen Kanons“. Otto-Friedrich-Universität Bamberg, 22.3.2010 (betreut von: Elisabeth von Erdmann).

Martin, Erik: „Formen der Negation bei L.N. Tolstoj“, Eberhard-Karls-Universität Tübingen, 6.5.2011 (betreut von: Schamma Schahadat).

Meger, Andreas: „Makro- und mediostrukturelle Aspekte in Neologismenwörterbüchern. Ein Beitrag zur Theorie und Praxis der Neografie des Polnischen, Russischen, Tschechischen und Deutschen“. Johann-Gutenberg-Universität Mainz, 17.12. 2010 (betreut von: Erika Worbs).

Nemere, Maja: „Belesene Helden. Die Demontage ästhetisierter Lebenswelten in der Prosa des russischen Realismus“. Universität Hamburg, 1.11.2010 (betreut von: Wolf Schmid).

Park, Zoon Woo: "Aspekttypologie - im Fall des Polnischen und Koreanischen“. Universität Hamburg, 20.9.2010 (betreut von: Volkmar Lehmann).

Petrović, Ksenija: „Religion und Nation. Die Konzeption der nationalen Identität in Serbien und Kroatien im Wandel der Systeme im Vergleich“. Universität Jena, 1.12.2010 (betreut von: Gabriella Schubert).

Philipp, Torben: "Zwischen Blindheit und Allsicht. Fotografische und poetische Konstellationen des Sichtbaren im russischen Realismus". Universität Zürich, 8.3. 2011 (betreut von: Sylvia Sasse).

Rethage, Wilma: „Strukturelle Besonderheiten des Russischen in Deutschland - kontaktlinguistische und soziolinguistische Aspekte“. Universität Gießen, 26.7.2010 (betreut von: Monika Wingender).

Salamurović, Aleksandra: „Das Deutschlandbild in der serbischen Presse von 1990 bis 2006. Wie viele Gesichter hat Deutschland?“, Universität Jena, 1.12. 2010 (betreut von: Gabriella Schubert).

Scharlaj, Marina: „Null und Atlantis: Metadiskursive metaphorische Konzeptualisierungen des Weißrussischen“. TU Dresden, 16.11.2010 (betreut von: Holger Kuße). 


\title{
Theater in Disjunktion Ivana Sajkos Rose is a rose is a rose is a rose
}

\author{
Von Miranda Jakiša (Berlin)
}

Die Herstellung von Gegenwärtigkeit, von Präsenzen gehört zu den zentralen Vorhaben und ist zugleich ein Effekt der Konzeption von Postdramatischem Theater. Die kroatische Dramaturgin und Theaterautorin Ivana Sajko vergegenwärtigt in ihrem Theater der Disjunktion nicht nur die Theatron-Achse (Lehmann 1999: 230), jene Achse, die zwischen Bühne und Publikum verläuft, sondern auch die Erfahrung des Einbruchs von Krieg und Ausnahmezustand. Beide führt Sajko im Begriff der "disjunkcija“ zusammen. In Sajkos postdramatischem Stück Rose is a rose is a rose is a rose, das "Disjunktion" mehrfach explizit anführt, ist es die Präsenz des Publikums im Raum, die postdramatisch vor Augen gestellt wird. Neben den Kriegs- und Separationserfahrungen der adressierten Mitte lässt das Stück vor allem die location den Ort der ereignishaften Begegnung von Akteuren und Zuschauern - zur geschauten Szene werden und bringt darin eine sich ihrer selbst gewahr werdende Zuschauerschaft hervor. Es sind ausgerechnet postdramatische Störungen von Illusionsbildung im Theater, in den Worten des Stücks „Disjunktionen“, die hierbei Verfahren zur affizierenden Publikumsansprache bereitstellen. Sajkos (letztlich) politisches Theater der "Unterbrechungen" (Lehmann 2002: 16) zielt mit den Disjunktionen auf eine Form ,erweiterter Aufklärung' (vgl. Brincken/Englhart 2008: 59) ab, die über die Integration recht unterschiedlicher Theaterverständnisse - zum einen post-Brechtschem Verfremdungstheater, zum an- deren einem Theater intensiver Wirkung in der Nachfolge Artauds - erwirkt wird.

Am Beispiel der Aufführung von Sajkos Rose is a rose is a rose is a rose am ZKM (Zagrebačko Kazalište Mladih) im März 2010 lässt sich zeigen, wie Sajko Disjunktionen zur Herstellung präsentischen Theaters als Raum gemeinsamer Erfahrung einsetzt. Die "disjunkcija“ entspricht neben der Separations- und Zersplitterungserfahrung - als Erfahrung des adressierten (kroatischen und darüber hinaus postjugoslawischen) Publikums - der Desintegration der dramatischen Theaternorm. Der Frankfurter Theaterwissenschaftler Hans-Thies Lehmann, der mit seinem Begriff „postdramatisch" ein weitgehend konsensfähiges Label für das neuere Theater geliefert hat - auch Sajko umschreibt die eigene Arbeit als postdramatisch -, sieht im postdramatischen Theater eine Photographie der Explosion des Theaters. Auf diesem Standbild einer ,angehaltenen Explosion" sehe der Zuschauer das, woraus Theater sich einst zusammensetzte: „Körper, Gesten, Organismen, Raum, Objekte, Architekturen, Installationen, Zeit, Rhythmus, Dauer, Wiederholung, Stimme, Sprache, Klang, Musik...", "fixiert im Auseinanderfliegen“ (Lehmann 1999: Vorwort, o.S.).

An der Disjunktion der Elemente Bild und Laut in Rose, an deren Herauslösen aus dem Gesamtkomplex Theater im Sinne der Lehmannschen Explosion, wird deutlich, wie das Durchbrechen der Vierten Wand den Weg zur 
emotionalen Publikumswirkung öffnet. Im Zentrum des Stücks Rose is a rose is rose is a rose steht frka (dt.: Aufruhr, Aufstand, Ärger, Angst, Ausnahmezustand) als abstrakt-kolloquialer tropischer Ersatz für traumatischen Gewalteinbruch. Das in Sajkos Roman Rio Bar (2005) und im Stück Prizori s jabukom (2009) konkret benannte Thema Krieg erscheint in Rose als frka abstrahiert und in ,disjunkten' theatralen Mitteln auf die Bühne gebracht.

Zunächst zur Disjunktion auf der Ebene der Bildlichkeit: Sajkos Bühne in Rose greift aus der Theorie des Postdramatischen die Idee horizontaler Theaterlandschaft (Gertrude Stein) auf und entspricht buchstäblich einem $\mathrm{zu}$ schauenden tableau vivant als mit lebendigen Personen nachgestelltem Gemälde. Als solches stellt es bereits die Frage nach der Interferenz und dem Übergang zwischen Kunst und Leben in den Bühnenraum.

Die Bühne präsentiert ein ,Standbild' bestehend aus einer Reproduktion von Rembrandts Die Nachtwache, einer dem Gemälde nachempfundenen Licht- und Farbkomposition, aus der Person Ivana Sajkos und Musikern, die die Konstellation wiederum nachstellen, sowie aus Fragmenten des Theatertextes Rose selbst, der auf Notenständern oder auf ins Publikum gehaltenen Plakaten ausgestellt wird.

Auf ein Referat des französischen Philosophen Badiou zur Nicht-Hintergehbarkeit der Disjunktion zwischen Liebenden (einer dritten, hier nicht berücksichtigten Disjunktionsebene) folgen im Stück Erläuterungen zu Rembrandts Nachtwache von 1642, dessen Repro in der Bühnenmitte auf die Rolle des Bühnenbildes als illusionsbildendes Moment im Theater verweist. Sajko verstärkt die aus- und bloßstellende Disjunktion des Bühnenbildes, indem sie zum Bild ausführt: „Scena oslikava poziv na oružje." (Sajko 2008: 11) (Die Szene illustriert den Aufruf zu den
Waffen). Eine von Sajko mit einem Kontrabass-Bogen als Zeigestock vorgetragene Bildanalyse, die kompositorische Elemente des Bildes sowie allegorische Darstellungen darauf erläutert und das Bildgeschehen historisiert, gerinnt somit zum Theater- und Mediums-Metakommentar.

Rembrandt portraitierte eine Amsterdamer Bürgerwehr, die ihm am Vorabend des 30-jährigen Krieges als living picture Modell stand. Die mise-enabyme Struktur des Titels Rose is a rose is a rose is a rose (Zitat einer Zeile aus Gertrude Steins Gedicht Sacred Emily) wiederholt sich in der nachgestellten Szene einer nachgestellten Szene und ruft in postmodernistischer Schachtelung (das Bild ist Teil der Bühne, wie die Bühne Teil der Situation ist, in der sich die Zuschauer befinden) die Theatersituation selbst auf den Plan.

Auf dem Gemälde selbst nun greift der Schatten der Hand Kapitän Cocqs nach dem Schwert des Befehlshabers van Ruytenburch und deutet auf den Ausbruch von Gewalt hin, der auch in Rose folgen wird. Sajko expliziert an dieser Stelle: „Na pozornici se tek naizgled ništa ne događa./ No ako čovjek bolje pogleda, primjetit će da sjena ruke kapetana Cocqa hvata mač zapovjednika van Ruytenburcha." (Auf der Bühne scheint auf den ersten Blick nichts vorzugehen./ Doch sieht man genauer hin, bemerkt man, dass der Schatten der Hand Kapitän Cocqs nach dem Schwert des Befehlshabers van Ruytenburch greift). Unmittelbar auf diese Sätze folgt im Stück der als frka umschriebene Gewaltausbruch:

Vrijeme je da krene frka:

Razbijeno je toliko i toliko izloga.

Toliko i toliko telefonskih govornica.

Toliko i toliko kioska.

Spaljeno je toliko i toliko automobila.

Toliko i toliko kontejnera za smeće.

I jedan autobus.

SVI SU VEĆ ZAUZELI POZICIJE.

Policija je na ulicama. 
Vojska je na ulicama.

Ljudi su na ulicama.

I večernje izdanje sutrašnjih novina $u$ njihovim rukama.

***

I MI SMO TAMO.

U disjunkciji.

Čekamo autobus.

I dio smo scene.

(A radije ne bi. $)^{1}$

Während es nahe liegt, das Gemälde als allegorisches Vorausweisen auf die gewalttätigen Ereignisse im Stück (und als Anspielung auf den nicht lange zurückliegenden ,Bürgerkrieg' und den kroatischen ,Bürgerwehr'-Einsatz) zu lesen, ist hier vielmehr der konspirative Hinweis auf Peter Greenaways ein Jahr vor Rose erschienen Film Nightwatching entscheidend. Dieser intertextuelle/intermediale Bezug entspricht dem versteckten Griff nach dem Schwert auf dem Gemälde. Greenaways Film ist um die These organisiert, dass es sich bei Rembrandts Nachtwache nicht um Malerei, sondern um Theater handelt. Analog dazu postuliert Rose statt Theater Musik zu sein das Stück führt im Untertitel die Bezeichnung ,partitura".

Die Nachtwache dient also auf verschiedenen Ebenen mehr als dem frkaThema der Disjunktion des Dramatischen Theaters. Das Stück Rose ist durch Aussparungen und Achronismen eine weder in Aufführung noch Lektüre zu einem stringenten Plot verdichtbare Geschichte; das frka-Thema realisiert sich lediglich in assoziativen Zwischenräumen. Führt die Disjunktion, wie am Herauslösen des Bühnenbildes aus der dramatischen Norm sichtbar, zur Schwächung der innerszenischen Achse (der Bühnenhandlung), so bedeutet dies in theaterlogischer Konsequenz zugleich die Konturierung der Theatron-Achse zwischen

1 Ivana Sajko. Rose is a rose is a rose is a rose. Frankfurt/M. 2008, 11-12.
Szene und Zuschauerraum. Das postdramatische Theater, das sich von einem zentralen Konflikt, von dramatischer Steigerung und überhaupt von einer durch Figuren dargestellten Handlung verabschiedet hat, zielt stets - so auch bei Sajko - auf das In-Erscheinung-Treten der Räumlichkeit und Zeitlichkeit des Bühnengeschehens selbst. Die postdramatische Wiederherstellung des theatron, als Ort auf den und von dem aus geschaut wird, seine Wiedereinsetzung als „öffentlicher und zugleich politischer Schauplatz" (Primavesi 2004: 10), wiederholt dabei Gesten und Verfahren der historischen Avantgarden in deren Versuchen, das Guckkastenprinzip des bürgerlichen Theaters zu überwinden.

Erika Fischer-Lichte, PerformanzForscherin und Theaterwissenschaftlerin, setzt in ihrer Grundlagen-Studie "Ästhetik des Performativen", die leibliche Kopräsenz von Zuschauer und Akteuren und damit einen gemeinsamen Erfahrungsraum zentral für alle performativen Künste. Diese spezifische Räumlichkeit, die die Erfahrung von Kopräsenz herzustellen vermag, bezeichnet der Philosoph Gernot Böhme in seinen Essays zur neueren Ästhetik als Atmosphäre (Böhme 1995). Die Atmosphäre entsteht dadurch, lässt sich Böhme paraphrasieren, dass sich zwischen Ding und Subjekt etwas in den Raum ergießt (Fischer-Lichte 2004: 203). Diesem Etwas entspricht in Rose das Element des Klangs, der Lautlichkeit der Aufführung. Bildlich gesprochen durchbricht Sajko in Rose die Vierte Wand des dramatischen Theaters mit post-Brechtschen Verfahren und gießt durch das entstehende Loch in der Wand emotional tingierende Atmosphäre in Form von Laut in den $\mathrm{Zu}$ schauerraum.

In Rose erfolgt diese auditive, Gegenwärtigkeit generierende RaumHerstellung durch die klingende Stimme einerseits und den Laut als Ge- 
räusch oder Musik andererseits.

Die postdramatische Stimme - losgelöst vom Konzept Figur und befreit vom entthronten König Text, den sie nicht mehr auszuagieren braucht treibt präsentische Potentiale der menschlichen Stimme hervor. Die Stimme ist noch vor der Aktivierung von Inhalten ein Appell an den Hörenden, responsiv zu reagieren. Der Vernehmende von Stimme ist vor allem ein Angesprochener, ein Adressat, von dem ein Akt der Hinwendung zum Sprecher und die Anerkennung der Sprecher-Gegenwart erwartet wird. Die Stimme, die solchermaßen als „ungefilterte seelisch-geistige Ausstrahlung der Person" (Lehmann 1999: 275) ,erscheint”, erfüllt die „Urszene des Theaters" (Kolesch 2004: 157), in der ein Körper sich aus dem Chor löst, hervortritt und spricht. „Wer spricht, wird sichtbar" (Kolesch 2004: 159). Während Manfred Pfister den theatralen Monolog, das Sprechen der Einzelstimme, noch als Normalisierung eines pathologischen Sprechens-mit-sichselbst beschreibt, versteht sich der Monolog des postdramatischen Akteurs als Rede, die echte Kommunikation, nämlich zwischen Bühne und $\mathrm{Zu}$ schauerraum, betreibt. Im Drama, hält Lehmann gegen Pfister, wird „im dialogischen System das Versagen des Sprechens als Kommunikation zwischen Menschen" (Lehmann 1999: 232) offenbar, das revitalisierte theatronTheater nimmt hingegen den Kontakt zu anwesenden, zu echten Menschen wieder auf.

Neben den Affekte regenden und gemeinschaftstiftenden Potentialen der auf Responsivität ausgerichteten Stimme (Sajko spricht im Stück beschwörend, flüsternd, rhythmisiert, radikal leise und tritt durch diesen Stimmeinsatz als, echte historische Person' in Erscheinung), gehört zur Ebene der Lautlichkeit auch das Geräusch, der Laut und die Musik. Sie dringen in den
Hörenden ein und machen ihn zum (mitschwingenden) Resonanzkörper. Sajko hat in der Inszenierung von Rose mit den Avantrock-Musikern Nenad Sinkauz, Vedran Peternel, Alen Sinkauz und Krešimir Pauk zusammengearbeitet, die Musik eigens für Rose komponiert haben. Ihre Musik dient im Stück nicht der Illustration des Bühnengeschehens, sondern inszeniert es mit der ihr eigenen Sprache parallel zur Inszenierung des Texts. Neben Sirenengeheul, berstenden Scheiben und anderen bei der Aufführung zum Einsatz kommenden, elektronisch erzeugten Geräuschen zeichnet sich die musikalische Ebene der Aufführung durch einen unterschiedliche Musikrichtungen aufnehmenden Stilmix, einen experimentellen Umgang mit Versatzstücken dieser Stile, insbesondere des Swing, Rock und Punk, mitunter sehr hohe Lautstärken, repetitive Strukturen und invasive Soundhöhen aus, die die Grenzen des Ertragbaren herausfordern. Durch die Invasion des Auditiven, die sie produzieren und der sich der Zuschauer nicht entziehen kann, und durch das Öffnen eines gemeinsamen Klangraums wird das Gegenüber von Zuschauerraum und Szene erneut (durchaus gewaltsam) aufgehoben.

Erika Fischer-Lichte schreibt: „Mit den Lauten dringt die Atmosphäre in den Leib der Zuschauer ein und öffnet ihn für sie" (Fischer-Lichte 2004: 208). Die körperliche Affizierung des Publikums, die solchermaßen im „Dritten Raum" (Lehmann 1999: 274) des in Schnittmenge über Szene und $\mathrm{Zu}$ schauerraums gelegten Klangs stattfindet (vgl. hierzu den DisjunktionsBegriff aus der Logik und die VennDiagramme der Mengenlehre!), stellt das Einfallstor des Politischen in Sajkos Theater dar. An Schmerzgrenzen geführt, wird seine Anwesenheit im Theater dem Zuschauer ebenso fühlbar gegenwärtig, wie er die Fortführung 
seiner Präsenz im Raum der geteilten Aufführung zu befragen aufgefordert wird. Sajko führt hier, wenn der $\mathrm{Zu}-$ schauer den Zuschauer fragend ansieht, Theater auf das zurück, was es dem postdramatischen Mantra nach immer schon bedeutet hat: die „ereignishafte Begegnung von Akteuren und Zuschauern" (Primavesi 2004: 9). In Rose wird dabei die ganz konkrete Verantwortung/Mitverantwortung, die Erfahrung von Gewalteinbruch nicht in vorgeschützten Alltag aufzulösen, in der Begegnung der Anwesenden untereinander evoziert:

(To treba reći publici. Oči u oči. Usta u usta. Osobno)

Imali smo sreće.

Tihi ljudi su tiho izgorjeli.

Mi nismo.

[...]

Skoro su umrli. Umrli. Skoro. Jebote.

Vidjeli su je. Frku. Vlastitim očima.

I okrenuli su glavu da ne gledaju.

Morali su a posao.

Sutra se radi.

Sutra se rano ustaje. ${ }^{2}$

Die verantwortliche Gemeinschaft, die den Einbruch von Gewalt in ihrer Mitte aus Sicht des Stücks voreilig für fertig therapiert erklärt hat, wird von Sajkos Aufführung mit einem der cernasFormel der rhetorischen evidentiaHerstellung entsprechenden "Wir" konsequent herbei beschworen, vgl. u.a.: „I MI SMO TAMO./ U disjunkciji./ [...]/ I dio smo scene." (vgl. FN 1)

Theatrale Disjunktionen werden als verfremdende Verfahren wirksam, die die Ansprüche und Fragen der Brechtschen Konzeption, nicht aber dessen Illusionen über die Wirkmacht des Theaters teilen. Brechts jegliche Affizierung verneinende Antwort auf die Frage nach dem politischen Theater wird vom postdramatischen Theater Ivana Sajkos im Einsatz von Intensität und Emotion herstellenden Mitteln in der Nachfolge von Artauds Grausamkeitentheater abgelehnt und erweitert. Erst das tingierende Potential der in die Zwischenräume der Disjunktion einbrechenden Atmosphäre ermöglicht für Sajkos Stück die Evidenz des ZuSchauenden im Raum der geteilten Erfahrung.

\section{Literatur}

Gernot Böhme: Atmosphäre: Essays zur neuen Ästhetik. Frankfurt/M. 1995.

Jörg von Brincken/Andreas Englhart: Einführung in die moderne Theaterwissenschaft. Darmstadt 2008.

Doris Kolesch: „Szenen der Stimme. Zur sinnlich-auditiven Dimension des Gegenwartstheaters". In: Heinz Ludwig Arnold (Hg.), Theater fürs 21. Jahrhundert, München (edition text+kritik) 2004, 156-165.

Hans-Thies Lehmann: Postdramatisches Theater. Frankfurt/M. 1999.

Hans-Thies Lehmann: Das Politische Schreiben. Essays zu Theatertexten. Berlin 2002.

Erika Fischer-Lichte: Ästhetik des Performativen. Frankfurt/M. 2004.

Patrick Primavesi: „Orte und Strategien postdramatischer Theaterformen". In: Heinz Ludwig Arnold (Hg.): Theater fürs 21. Jahrhundert, München (edition text+kritik) 2004, 8-25.

Ivana Sajko: Rose is a rose is a rose is a rose, Frankfurt/M. 2008.

2 Ivana Sajko. Rose is a rose is a rose is a rose. Frankfurt/M. 2008, S. 14, 10, 19. 


\title{
Von der Schneeidylle zur Eishölle. Russland-Winterbilder im (anti-)imperialen intertextuellen Spannungsfeld zwi- schen Vjazemskij, Puškin, Ryleev und Mickiewicz
}

\author{
Von Heinrich Kirschbaum (Passau)
}

Eine der Besonderheiten der russischen imperialen Rhetorik der 181020er Jahre bestand unter anderem in der beschleunigten Konzeptualisierung des geographischen Raumes und des Klimas des Landes ${ }^{1}$; die zentrale Rolle bei solchen Auto-Geo-Konstruktionen, die man auch als Landschaftsbzw. Jahreszeitennationalisierungen bezeichnen könnte, kommt der Winterlandschaft zu. Den wichtigsten rhetorisch-poetischen Raum für die Erfindung der nationalen Geo- und KlimaIdentität bildete dabei die russische Dichtung.

Zum unwillkürlichen Zeugen dieses poetisch-politischen Diskurses wurde der polnische Dichter A. Mickiewicz, der in der russischen Verbannung (1824-29) die wichtigsten russischen Dichter und Publizisten dieser Zeit

1 Entscheidend hat zur Etablierung geopoetologischer Fragestellungen in der Slavistik Susi Frank in ihren diversen Publikationen beigetragen (Grundlegendes s. bei Frank 2002 und 2010). Vgl. auch Franks Fallstudien zu Sibirien $(1997,2011)$. Einige Aspekte des geopoetischen Schreibens in Bezug auf die Jahreszeiten und ins Besondere auf den Norden/Winter wurden bereits in den Monographien von Ėpštejn (1990) und Boele (1996) herausgearbeitet. Vom wachsenden wissenschaftlichen Interesse für die slavischen Geo- und Klima-Diskurse zeugen auch Marszałek/Sasse (2010) und eine Reihe von Artikeln in Novoe literaturnoe obozrenie (vgl. Bogdanov 2009, Anisimov 2009, Kelli 2009). persönlich kennen lernte. In der zweiten Hälfte der 1820er Jahren wurden Mickiewicz' Person und Werk zum untrennbaren Bestandteil des russischen literarischen Lebens. Erst 1829 durfte Mickiewicz Russland verlassen: In seinem Ustęp zum dritten Teil des Dramas Dziady (1832) rechnete er in bissigen und grotesken Invektiven mit dem Imperium ab. Beim Entwurf seiner Russlandbilder griff er dabei viele Motive und Metaphern auf, die den innerrussischen poetisch-politischen Russland-Diskurs und darunter auch den Russland-als-Winter-Diskurs mitgeprägt und bedient haben. Im folgenden Beitrag, der sich in einem theoretisch-methodischem Dreieck zwischen Geopoetologie, postkolonialistischen Ansätzen und Intertextualitätsforschung begreift, wird versucht, russische poetische Winter-Konzeptualisierungen der 1810-20er Jahre und deren Dekonstruktionen in Mickiewicz' Ustęp zu skizzieren.

Zwar setzen russische ,Nationalisierungen' des Nordens und des Winters bereits Ende des 18. - Anfang des 19. Jh.s ein, die Tempi und Topoi dieses Diskurses ändern sich jedoch entscheidend nach 1812, als der Frost als Russlands Komplize konzipiert wird. Da der Krieg von 1812 als historischer Reim zu 1612 konzipiert wird, bekommt der Diskurs auch eine (anti-) polnische Komponente, die durch die Teilnahme Polens am Napoleonischen Feldzug an Aktualität gewonnen hat. So setzt V.A. Žukovskij in Pevec vo stane russkich voinov die Ereignisse von 
1812 mit den Suvorovschen Feldzügen gegen die Polen in Verbindung 2 . Für die weitere Verschränkung des napoleonischen und polnischen Themas mit Wintertopoi sorgte das nach 1812 immer populärer werdende Ivan-Susanin-Sujet. Die Polen, die Michail Romanov umbringen wollen und die der einfache russische Bauer Susanin in die Irre führt, verlaufen sich in einer Winterlandschaft. K.F. Ryleevs Duma "Ivan Susanin", begonnen mit einem Winterbild, endet programmatisch mit einer pathetisch-patriotischen Russifizierung des Schneemotivs: „Снег чистый чистейшая кровь обагрила:/ Она для России спасла Михаила" (Ryleev 1971: 155). Susanins „reinstes Blut" bildet einen Superlativ der Reinheit des russischen Schnees, der bei der glücklichen Rettung des künftigen Zaren mitgeholfen hat. Die Schneelandschaft wird zur Metonymie und Metapher des Russentums.

Das Winterlich-Sibirische der russischen Landschaft wird in Vjazemskijs Schneeidylle Peroyj sneg (1958: 129132) zum Attribut der jungen russischen Schönheit. Die Schlittenfahrt durch die russische Schneelandschaft erhält die für den Orientalismus charakteristische Erotisierung. Die Motive der Eroberung der eigenen bzw. einheimischen Jungfräulichkeit der jungen Rossija dominieren Vjazemskijs winterliche Liebespastorale, die zum Muster des russischen Winter-Textes wird, auf den die nachfolgenden Dichter Bezug nehmen werden, darunter auch Puškin. Der polemische Dialog mit Vjazemskij bestimmt viele Stellen in Evgenij Onegin. Die Eigenschaften der "russischen Seele" Tat'janas werden durch die Winterlandschaft her-

2 Frühe Beispiele für die Vernetzung der Frost- und Polendiskurse sind auch die Ballade Poljak von A.A. Del'vig (1963: 109-112) oder ein Kriegsgedicht von V.F. Raevskij (1967: 53). auskristallisiert (vgl. Sokolova 1975: 72). Tat'janas Vorliebe für den Winter, die textgenetisch auf Vjazemskijs schöne Jungfrau zurückgeht, wird zum Markenzeichen ihrer paradigmatischen Russizität. Eine weitere Winterbeschreibung Puškins reiht sich ins Paradigma des "kriegerischen“ Winters ein: Sie findet sich nicht zufällig im VII. Kap. von Evgenij Onegin, in dem auch Napoleons Russlandfeldzug thematisiert wird. Im Gedicht Borodinskaja godovščina (das eines der Gedichte darstellt, über die sich Mickiewicz in seiner Invektive empört), in dem der Sieg über Polen von 1831 mit demjenigen über Napoleon parallelisiert wird, artikuliert Puškin erneut das Thema des Unterganges der potenziellen Beschützer Polens und Invasoren Russlands durch den russischen Winter (vgl. Puškin 1950: 224). Die Verteidiger Polens werden in der russischen Schneewüste ihren Untergang finden. Eine andere, „dämonische“ Linie in den Winterbeschreibungen wird allerdings in Puškins Besy angeschlagen. Der sonnigen Winteridylle wird der Wintersturm gegenübergestellt. Das Bild des teuflischen Schneesturms wird Puškin später in Metel' und in Kapitanskaja dočka verwenden: Es wird bis zu A.A. Bloks Dvenadcat' zum Protobild der russischen Wirren.

Einen weiteren alternativen Winterentwurf liefert K.F. Ryleev in seinem Poem Vojnarovskij. Zunächst wird Sibirien als eine erhabene, wenn auch raue Idylle beschrieben, in die sich allerdings allmählich eine düstere Stimmung einschleicht, die die späteren Schilderungen der Seelenlandschaft Vojnarovskijs, des verbannten Mitstreiters Mazepas, unterstützen soll. Die Wintermonotonie Sibiriens, das mit Einheimischen, Verbrechern und ihren Bewachern bevölkert ist, wird zum rhetorischen Ort, in dem sich Ryleevs Diktionen der inneren Kolonisie- 
rung mit denjenigen des Imperialen und zugleich des Antiautokratischen bzw. Antiimperialen kreuzen. Die Winterlandschaft avanciert dabei zudem zu einem verdrehten Äquivalent einer orientalischen Landschaft. Die Selbstorientalisierung des russischen Winters, die bei Ryleev stattfindet, kann man weiter in Selbstkosakisierung und Selbstasiatsierung unterteilen, die später für Mickiewicz relevant wird. Während die sibirische Winterwüste zum Ort des Exils und zum Zeichen der implizit kritisierten Repressionen wird, wird die kriegerische ukrainische Steppenidylle zur äsopischen Kulisse eines Freiheitskampfes.

Diese Mehrdeutigkeit der Ryleevschen Winterlandschaft nimmt prätextuell Mickiewiczs Russland-Beschreibungen vorweg. Der autobiographische Protagonist des Ustęp geht nach Russland in die Verbannung. In Bezug auf die Winterthematik ist das UstepAuftaktgedicht Droga do Rosji von Bedeutung $^{3}$. Hier verschmelzen Mickiewiczs Erinnerungen an seine Einreise nach Russland mit den späteren Winterüberquerungen des Landes. Dabei überlappen sie sich autotextuell mit den ukrainischen Steppenbildern aus den Krimsonetten (vgl. das Motiv des Steppenozeans u.a.). Die autotextuellen Umkodierungen zwischen dem Ustep und den in Russland entstandenen Russland- und Ukraine-Bildern finden ihrerseits vor einer prätextuellen russischen Folie statt, sei es Vjazemskij mit seinem Motiv der Schlittenreise durch eine Schneelandschaft oder Puškins Bild von der KibitkaFahrt („Летит кибитка удалая“) aus Evgenij Onegin.

In einem noch größeren Maße lassen sich Verbindungen zu Ryleevs Vojnarovskij feststellen. Das Schicksal der

3 Vgl.: „Po śniegu, coraz ku dzikszej krainie/ Leci kibitka jako wiatr w pustynie [...]" (Mickiewicz 1991: 412).
Dekabristen (und ihrer polnischen Kameraden) stellt dabei das umrahmende Thema des Ustęp dar. Somit bildet Mickiewiczs Winterdekonstruktion zugleich auch eine Art intertextuelle Hommage an Ryleev und seine Mitstreiter, deren verhängnisvolles Ende in Sibirien in Vojnarovskij prophezeit wurde. Die für Mickiewiczs Ustęp relevanten Bilder der Überführung eines Verbannten in einer Kibitka werden dabei mithilfe der Ozeanmetaphorik der russischen Winterlandschaft entfaltet, wohl nicht zuletzt in Anlehnung an Ryleev ${ }^{4}$. Bei Ryleev und nach ihm bei Mickiewicz wird der romantische Dandy-Prophet in der russischen (Schnee-)Weltwüste mit den Zügen des verbannten Revolutionärs angereichert, der für die Ehrensache der Vaterlandsbefreiung (in beiden Fällen von Russland) seine Strafe verbüßt. Bei seinen Beschreibungen der Winterapokalypse Russlands schlüpft Mickiewiczs Held zugleich in die Kolonisatorenperspektive: Die Verbannung wird $\mathrm{zu}$ einer zivilisatorischen Mission. Der verbannte Missionär geht aber wie Napoleon in der endlosen Winterweite Russlands unter ${ }^{5}$. Nicht nur historische Assoziationen sind hier im Spiel, sondern auch metaliterarische. Napoleon, ein Kind, Ideal und Idol der Romantik, wird zu ihrem tragischen Opfer: Er findet in der (Winter-)Weite Russlands, die ihn verführte, sein Ende. In der Metaphorik des russischen Winters demontiert Mickiewicz die romantischen Topoi der Endlosigkeit. Es kommt zu einer allegorischen Beschreibung des Todes der Romantik und des romantischen Helden. Mic-

4 Vgl.: „Бродия по целым он часам/ По океану снеговому" (Ryleev 1971: 195).

5 Vgl.: „Wicher, wdarłszy się do cichego boru,/ Po bryłach lodu i po śniegów puchu,/ Jak Napoleon biega bez oporu,/ W końcu zdrętwiały, upada bez duchu“" (Mickiewicz 1991: 416). 
kiewiczs prätextuelle russische Winterbilder bzw. seine Winterbilder für Russland werden $\mathrm{zu}$ metaphorischideologischen Leitmotiven des Ustepp, sei es in den Beschreibungen vom verschneiten Petersburg und seiner Vororte in Przedmieścia stolicy und Petersburg oder in den Versen der Hoffnung auf das baldige Schmelzen des vereisten Wasserfalls der Tyrannei in Pomnik Piotra Wielkiego oder bei der karnevalesken Beschreibung der Truppenschau bei eisigem Frost auf dem Marsfeld im Gedicht Przeglad wojska.

Mickiewicz schaltet sich im Ustęp auf der autotextuellen Basis seiner Russland- und Ukrainebilder der Sonety Krymskie - nicht nur in den intertextuellen Streit zwischen Ryleev und Puškin um das antipetrinische Sujet (Vojnarovskij-Poltava) ein, sondern vor allem in die russischen poetischen Konzeptualisierungen des russischen Winters. Der Schnee und das Eis, bis zur dantesk anmutenden Konzeptualisierung Russlands als der ahistorischen Eishölle mit Peter dem Großen als Luzifer, werden dabei zu geopoetischen und geopolitischen antiimperialen und amtiabsolutistischen Metaphern und Metonymien Russlands. Dabei kreiert sie Mickiewicz nicht zuletzt aus dem Material der russischen Dichtung seiner Zeit; es entsteht dabei ein im Sinne Harold Blooms zu interpretierendes revisionistisches AntiBild Russlands, das bis heute, sowohl von russischer als auch von polnischer Literatur, polemisch und interferierend fortgeschrieben und dekonstruiert wird.

\section{Literatur}

Anisimov, K. 2009. Klimat kak „zakosnelyj separatist". Simvoličeskie i političeskie metamorfozy sibirskogo moroza. Novoe literaturnoe obozrenie, Nr. 99, 98-114.

Boele, O. 1996. The North in Russian Romantic Literature. Amsterdam - Atlanta.
Bogdanov, K. 2009. Klimatologija russkoj kul'tury. Prolegomen. Novoe literaturnoe obozrenie, Nr. 99, 60-97.

Del'vig, A.A. 1963. Stichotvorenija. Moskva - Leningrad.

Ėpštejn, M. 1990. Priroda, mir, tajnik vselennoj... Moskva.

Frank, S. 1997. Sibirien: Peripherie und Anderes der russischen Kultur. In: Mein Russland, Wiener Slawistischer Almanach 1997, 357-383.

- 2002. Überlegungen zum Ansatz einer historischen Geokulturologie. In: ZeitRäume. Neue Tendenzen in der historischen Kulturwissenschaft aus der Perspektive der Slavistik. Wiener Slawistischer Almanach Bd. 49, 55-75.

- 2010. Geokulturologie und Geopoetik: Definitions- und Abgrenzungsvorschläge. In: M. Marszałek, S. Sasse (Hg.), Geopoetiken: Geographische Entwürfe in den mittel- und osteuropäischen Literaturen, Berlin, 19-43.

- 2011. Imperiale Aneignung. Diskursive Strategien der Kolonisation Sibiriens durch die russische Kultur. München.

Kelli, K. Sorok sorokov doždej: kak delali "peterburgskuju pogosu". Novoe literaturnoe obozrenie, Nr. 99, 115-138.

Marszałek, M., Sasse, S. (Hgg.) 2010. Geopoetiken: Geographische Entwürfe in den mittel- und osteuropäischen Literaturen. Berlin.

Mickiewicz, A. 1991. Die Ahnenfeier. Köln.

Puškin, A.S. 1950. Polnoe sobranie sočinenij. T. III. Moskva - Leningrad.

Ryleev, K.F. 1971. Polnoe sobranie stichotvorenij. Leningrad.

Sokolova, K.I. 1975. Ėlegija P. A. Vjazemskogo "Pervyj sneg” v tvorčestve A. S. Puškina. In: Problemy puškinovedenija. Leningrad. 


\title{
Perspektivität und Textstruktur im Balkanslavischen
}

\author{
Von Barbara Sonnenhauser (München)
}

\section{Einleitung}

Die balkanslavischen Sprachen weisen in Form der sogenannten 'Balkanismen' sprachliche Merkmale auf, die sie auch innerhalb des Ost-Südslavischen auszeichnen. In der jüngeren Literatur wird zunehmend von einer isolierten und negativen ('Verlust von ...') Betrachtung dieser Merkmale abgerückt. Statt dessen tritt eine Analyse der oberflächlichen Gemeinsamkeiten innerhalb der einzelsprachlichen Systeme in den Vordergrund (Joseph 2001), und es erfolgt eine Fokussierung auf die Entstehung neuer funktionaler Distinktionen (Topolinjska 1994, 2007). Diese werden in engen Zusammenhang mit der Organisation des Diskurses und der Grammatikalisierung von Diskursfunktionen gesehen (Fielder 1999, Friedman 2000). Damit wird es möglich, den Blick auf semantischfunktionale Gemeinsamkeiten und Interaktionen dieser Merkmale zu lenken.

Der Faktor der Diskursrelevanz steht auch diesem Beitrag im Zentrum, der sich mit dem dreifachen Artikel im Makedonischen und der Auxiliarvariation in der 3. Person beim l-Partizip (kurz: \pm Aux) im Bulgarischen beschäftigt und eine semantische Beschreibung vorschlägt, die die Interpretationsmöglichkeiten dieser Formen erfassen und ihre Gebrauchsmuster auf der Textebene erklären kann. Eine entscheidende Rolle dabei spielt der Begriff der 'Perspektivität'.

\section{Textstruktur}

So intuitiv plausibel traditionelle Charakterisierungen des makedonischen
Artikels als 'räumlich-deiktisch' und der bulgarischen -Aux-Formen als 'Renarrativ' scheinen, die Verwendung im Textzusammenhang folgt oft nicht den daraus ableitbaren Regeln. Zwar zeigen sich regelmäßige Verwendungsmuster, allerdings können diese nicht immer mit Kriterien wie Sprecherbezug oder Informationsquelle in Verbindung gesetzt werden.

\subsection{Artikel}

In der Regel wird der dreifache Artikel des Makedonischen durch die Art des Sprecherbezugs charakterisiert: $-o v$ als Bezug auf sprechernahe, -on auf sprecherferne Referenten, -ot als diesbezüglich neutral, vgl. die Beispiele aus Koneski (1996: 229) in (1):

(1) a. na ti ja knigava (ovaa do mene)

'dieses Buch<ov> (dieses bei mir) ist für dich'

b. daj mi ja knigana (onaa što ja gledame dvajcata malce ponastrana)

'gib mir jenes Buch<on> (jenes dort, das wir zwei etwas weiter weg sehen)'

Possessive Interpretationen, vgl. (2), werden ebenso auf den Sprecherbezug zurückgeführt, wie expressive (-ov mit positiver, -on mit negativer Konnotation), vgl. (3):

(2) Vo zemjava nema slučaj na zarazen od gripot A, koj so golema brzina se širi niz svetot. (www.novamakedonija. com.mk, 4.5.2009)

'In dem [unserem] Land cov $_{\text {s }}$ gibt es keine Fall von Grippe A, die sich mit großer Geschwindigkeit auf der Welt ausbreitet.'

(3) Onoj, mojon, utrinava pak zamina. [...], ponekogaš mi se čini kako da ne sum se omažila za maž [...] tuku za politika [...]. (Kole Čašule. Izbrani drami: Crnila) 
'Der da, der meine<on», ist heute früh wieder weggefahren. Manchmal kommt es mir vor, als wäre ich nicht mit einem Mann verheiratet, sondern mit der Politik.'

In Fällen wie (4) jedoch kann das Kriterium des Sprecherbezugs die Verwendung der Artikelformen nicht erklären:

(4) Gospodinot Ǵorgi so lakirata palka go pokaža mestoto koe site veḱe go znaeja [....]. ,Nie sme tuka - reče gospodinot Ǵorgi - i da pretpostavime deka sakame da otideme na sever od gradov." Toj go promeni slajdot i sega [...] se pojavija severnite predgradija i celiot region na sever od gradot, do stotina kilometri. Možeme samo od pregradievo, od starata severna stanica, do S. [...]. (Slobodan Mickovik', Kuḱata na Mazarena)

'Der Herr<ot Ǵorgi zeigte mit dem lackierten $<0 \triangleright$ Stock den Ort<o», den alle schon kannten. "Wir sind hier - sagte der Herr $<0$ เ Ǵorgi - und nun stellen wir uns vor, daß wir in den Norden der Stadt $<$ ov gehen wollen." Er wechselte die Folie $<$ ๖, und jetzt erschienen die nördlichen $<0$ เ Vororte und die ganze $<0<$ Region im Norden der Stadt $<0\rangle$, bis zu 100 Kilometer. Wir können von der Vor-

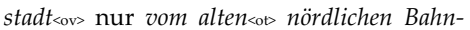
hof, nach S.'

Gerade in solchen narrativen Texten aber zeigen sich Muster der Artikelverwendung, die Hinweise auf eine adäquatere semantische Beschreibung liefern. Als Haupthindernis, diese Muster festzustellen, erweist sich der monolithische Begriff des "Sprechers", der in nicht-dialogischen Texten nicht haltbar ist. Vielmehr ist (zumindest) zwischen Sprecher bzw. Erzähler und Personen im Text zu unterscheiden. Dass diese Unterscheidung hier relevant ist, zeigt sich auch daran, dass nur -ot, nicht aber -ov/-on, in generischer Funktion verwendet werden kann (z.B. Usikova 1985), -ov/-on also in jedem Fall spezifisch interpretiert werden. Wird Spezifizität als referentielle Verankerung eines Referenten mit einem anderen Referenten, also nicht notwendigerweise mit dem
Sprecher, sondern möglicherweise auch mit einer Person im Text, verstanden (vgl. von Heusinger 2002), können -ov/-on als Markierung von [+Verankerung mit Person] und -ot als $[ \pm$ Verankerung mit Person oder Erzähler] aufgefasst werden. Damit liefert Spezifizität das semantische Potential dieser Formen, das sich auf der Textebene in der Strukturierung in Personen- und Erzählertext äußert (vgl. Sonnenhauser 2009). Und damit kann auch die Verwendung der Artikel in (4) erklärt werden: -ov verankert die Referenten mit der Person (hier: Gospodin Ǵorgi) und stellt so die referentielle Bezugnahme aus deren Perspektive dar.

\subsection{Auxiliarvarition}

Mit dem Begriff der 'Auxiliarvariation' anstelle von 'Renarrativ' oder 'Evidential' wird auf das formale Kriterium des möglichen Auxiliarausfalls der 3. Person beim l-Partizip bezug genommen, ohne durch die Terminologie bestimmte Interpretationen als definierend $\mathrm{zu}$ implizieren. 'Renarrativ' und 'Evidential' erweisen sich nämlich insofern als problematisch, als in Kontexten, in denen demzufolge eine -Aux-Form zu erwarten wäre, diese nicht notwendigerweise auftreten muss, beispielsweise in der indirekten Redewiedergabe.

Trotz der intensiven Beschäftigung mit \pm Aux bestehen weiter Unklarheiten in Bezug auf semantische Beschreibung und grammatische Einordnung (vgl. die kritische Diskussion in Levin-Steinmann 2004). Es lässt sich eine grobe Einteilung vornehmen in Ansätze, die eine grammatische Kategorie mit eigenem Paradigma und strikten Verwendungsregeln ansetzen (z.B. Nicolova 2008), und Ansätze, beginnend mit Friedman (1982), die den Status als grammatische Kategorie zunehmend in Frage stellen und das Fehlen des Auxiliars der 3. Person als diskursbasiert auffassen. 
Den relevanten Faktor dafür sieht Fielder $(1995,1999)$ in der Relation des Erzählers zum Erzählten, die sich auf der Textebene in der Vordergrundierung der Erzählung bei gleichzeitigem Zurücktreten des Erzählers zeigt.

Auf der Textebene lassen sich für -Aux-Formen regelmäßig auftretende Verwendungsmuster feststellen. Ein typisches Muster liegt in (5) vor: der Aorist in (5i) führt ein Ereignis ein und verankert es auf der Zeitachse, die -Aux-Formen in (5ii)-(5iv) elaborieren dieses weiter:

(5) Tijneijdžări ot Stara Zagora (i) nabicha šof'or i go (ii) izchvărlili ot kolata. Sled tova (iii) se povozili i (iv) zarjazali voziloto $\mathrm{v}$ grada. (www. standartnews.com, 10.11. 2009)

‘Teenager aus Stara Zagora (i) schlugen einen Autofahrer und (ii) warfen ihn aus seinem Auto. Danach (iii) fuhren sie weiter und (iv) ließen das Auto in der Stadt stehen.'

Die Verwendung einer +Aux-Form innerhalb einer Abfolge von -Aux-Formen führt eine off-plotline ein, in der ein Erzähler auftritt, um beispielsweise das bisherige Geschehen zusammenzufassen (vgl. dazu Fludernik 1991). Dies zeigt sich in (6), der Fortsetzung von (5): hier tritt der Erzähler in Erscheinung und orientiert den Leser in Bezug auf Ort und Zeit des Ereignisses:

(6) Ekšănăt $e$ stanal na okolovrăstnija păt na razklona za s. Chrišteni [...] prez uikenda okolo 22,00 č., no be oglasen ot policijata dnes. (www. standartnews.com, 10.11. 2009)

'Der Vorfall hat auf der Umgehungsstraße, an der Abzweigung zum Dorf Chrišteni, am Wochenende gegen 22h stattgefunden, wurde aber von der Polizei erst heute bekannt gegeben.'

In (7), der Fortsetzung von (6), wird die plotline wieder aufgegriffen; -Aux-Formen dienen der Vordergrundierung der Erzählung:
(7) Haglite banditčeta, koito pătuvali s [...] avtomobil, blăsnali otzad sprjalata pred tjach kola 'Reno Laguna'. Jadosani, te slezli ot kolata, izchvărlili ot 'Reno'-to [...] 26-godišnija šof'or ot s. Dălboki, i podkarali kolata mu kăm grada. (www.standartnews.com, 10.11.2009)

'Die gemeinen Gauner, die mit einem Auto unterwegs waren, haben den Renault Laguna, der vor ihnen gehalten hat, von hinten gerammt. Verärgert sind sie aus dem Auto ausgestiegen, haben den 26jährigen Fahrer aus dem Dorf Dălboki aus dem Auto geworfen und sein Auto in die Stadt gefahren.'

Das Zurücktreten des Erzählers und die Vordergrundierung der Erzählung bei der Verwendung von -Aux-Formen kann auch eine explizite Personenperspektive bewirken, beispielsweise in der indirekten Rede, vgl. (8):

(8) Makedonka razfasova măža si, (i) kaz$v a, \check{c} e$ (ii) bil na rabota v Italija

M.T. ot makedonskija grad Štip (iii) prizna, če (iv) e ubila săpruga si Branko, kojto (v) „izčeznal“ predi tri godini. [www.dnes.bg, 27.12.09]

'Makedonierin zerstückelt Ehemann, (i) sagt, dass er in Italien beim Arbeiten (ii) sei M.T. aus der makedonischen Stadt Štip (iii) gestand, dass sie ihren Mann Branko (iv) getötet hat, der vor drei Jahren (v) "verschwunden" sei.

In (8iv) zeigt sich, dass -Aux-Formen in der indirekten Redewiedergabe nicht zwingend sind. Die Verwendung dieser Formen dient in der indirekten Rede der Disambiguierung der charakteristischen de re/de dicto Ambiguität (vgl. Sonnenhauser 2011), vgl. (8ii) und (8v): mit -Aux findet eine Perspektivenverlagerung nicht nur weg vom Erzähler (Nicht-Erzählerperspektive), sondern hin zur Person (Personenperspektive), d.h. dem Subjekt des Matrixsatzes (der 'Makedonierin' M.T.), statt. Dies ist in (8v) zusätzlich durch die interpunktorische Markierung als wörtliche Wiedergabe unterstützt.

Hier stellt sich nun, wie auch beim dreifachen Artikel, die Frage, wie eine 
semantische Beschreibung aussehen kann, die in der Lage ist, die Interpretation der Formen und ihre Verwendungsmuster zu erfassen.

\section{Perspektivität}

Die Ausführungen zum dreifachen Artikel im Makedonischen deuten an, dass es sich dabei um ein Mittel zum Etablieren einer Relation zwischen einem Ausgangspunkt (-ot: Erzähler oder Person; -ov/-on: Person) und einem Objekt handelt, die der Textstrukturierung dient. Die Daten für die Verwendung der -Aux-Formen des Bulgarischen legen nahe, dass es sich dabei um den Ausdruck der Beziehung zwischen einem Ausgangspunkt (Nicht-Erzähler oder Person) und einem Sachverhalt handelt, die ebenfalls textstrukturierend wirkt. Beide Phänomene weisen damit einen grundlegend relationalen Charakter auf. Dieser relationale Charakter kann mit Graumanns (2002) Konzeption von 'Perspektivität' erfasst werden. Perspektivität in Graumanns Sinn beschreibt das Einnehmen eines Standpunkts in Bezug auf etwas, und zwar in einer bestimmten Hinsicht. Perspektivität ist dabei als emergentes Phänomen zu verstehen, das aus dem Zusammenspiel verschiedener Komponenten und Faktoren im Diskurs entsteht. Weder die Artikel noch die -Aux-Formen kodieren Perspektivität: so ist die Bezugsrelation zwar stabil (Referenzobjekt bzw. Sachverhalt), der eingenommene Standpunkt (Erzähler, NichtErzähler, Person) jedoch ergibt sich aus der Verwendung der Formen im Text, die Relation der Hinsicht aus weiteren lexikalisch-semantischen und kontextuellen Faktoren.

Ein Beispiel für die Variabilität der Relation der Hinsicht stellt die possessive Interpretation von -ov dar. Zwar liefert die relationale Natur von -ov eine Voraussetzung für diese Interpretation, dennoch ist sie nicht für alle mit -ov determinierten Nomen möglich.
Vielmehr legen die Daten nahe, dass sie hinsichtlich der Art der Possession, und in Hinblick auf Possessor (bevorzugt wird die 1. Person) und Possessum (bevorzugt werden inalienable und als inalienabel konzipierbare Possessa) beschränkt ist, vgl. (9) vs. (10):

(9) Ama, [...] i srcevo i obrazov ne mi davaat da ne dojdam ... (Anton Panov, Pečalbari)

'Aber, das [mein] Herz<ov> und die [meine] Ehre< $<$ ov lassen es mir nicht $\mathrm{zu}$, dass ich nicht komme [...].'

(10) Kate, zapali go ti ognot, a jas da go zapalam kandilovo pred ikonava. (Risto Krle, Parite se otepuvačka)

'Kata, zünde du das Feuer an, und ich zünde die Öllampe<ov> vor der Ikone<ov> an.'

Eine genauere Analyse der possessiven Interpretation von -ov steht noch aus. In Arbeiten zur Possessivität im Makedonischen (z.B. Mitkovska 2005) wird diese Möglichkeit nicht erwähnt, in Arbeiten zum Artikel nur kurz angesprochen.

Das Konzept von Perspektivität als emergentes Phänomen erfasst auch die Tatsache, dass das Entstehen der jeweils spezifischen Relationen und deren genaue Interpretation auch von den weiteren sprachlichen Mitteln, die verwendet werden, abhängig ist. Fielder $(1995,1999)$ weist darauf hin, dass die Auxiliarvariation im Text auf zwei Ebenen zu betrachten ist: auf der Ebene der Ereignisstruktur interagiert +Aux mit Aorist und Imperfekt in Hinblick auf Hinter- vs. Vordergrundierung von Ereignissen, auf der Ebene der Erzählstruktur interagiert +Aux mit -Aux in Hinblick auf das Verhältnis zwischen Erzähler und Erzählung. Dabei rückt -Aux den Erzähler in den Hintergrund, die Erzählung in den Vordergrund; die Distanz zwischen beiden kann in bestimmten Kontexten als Personenperspektive interpretiert werden (s.o.).

'Perspektivität' erweist sich damit als Begriff, der geeignet scheint, Artikelverwendung und \pm Aux adäquat zu 
beschreiben, indem ihre relationale Semantik herausgearbeitet und ihr Verhalten - Vorkommen und Interpretation - im Textzusammenhang erklärt werden kann. Zugleich kann damit ihre Rolle bezüglich der für die balkanslavischen Sprachen als zentral angenommene Strukturierung der Textebene gezeigt werden.

\section{Fazit}

Die Betrachtung der Verwendung des dreifachen Artikels und der Auxiliarvariation auf der Textebene lässt „verborgene Mechanismen" (Civ'jan 2005: 164) erkennen, die bei einer rein lokalen semantischen Analyse unentdeckt bleiben. Die vorgeschlagene Analyse im Rahmen von Perspektivität erlaubt es zudem, weitere potentiell perspektivische Phänomene wie den dativus ethicus oder die Verwendung von če vs. $d a$ in Einbettungsstrukturen und die damit einhergehende Verwendung von Indikativ vs. Subjunktiv in die Untersuchung einzubeziehen.

Dieses textbasierte Vorgehen kann den Anforderungen einer integrierten statt isolierten Betrachtung von sprachlichen Merkmalen innerhalb eines gemeinsamen sprachlichen Areals gerecht werden, ohne dabei einzelsprachliche Unterschiede, die sich u.a. aus den Positionen der Formen im jeweiligen System ergeben, $\mathrm{zu}$ übergehen.

\section{Literatur}

Civ'jan, T.V. 2005. Model' mira i ee lingvističeskie osnovy. Moskva.

Fielder, G. 1995. Narrative perspective and the Bulgarian 1-participle. The Slavic and East European Journal 39/4, 585-600.

Fielder, G. 1999. The origin of evidentiality in the Balkans: linguistic convergence or conceptual convergence? Mediterranean Language Review 11, 5989.

Fludernik, M. 1991. The historical present tense yet again. Tense switching and narrative dynamics in oral and quasioral storytelling. Text 11, 365-398.

Friedman, V. 1982. Reportedness in Bulgarian: category or stylistic variant? In: Naylor, K. et al. (eds.). Slavic linguistics and poetics. Studies for Edward Stankiewicz on his 60th birthday, Bloomington, 149-163.

Friedman, V. A. 2000. Pragmatics and contact in Macedonia. Convergence and differentiation in the Balkan Sprachbund. Južnoslovenski Filolog 56/3-4, 1343-1351.

Graumann, C. F. 2002. Explicit and implicit perspectivity. In: Graumann, C. F. \& W. Kallmeyer (eds.). Perspective and perspectivation in discourse, Amsterdam - Philadelphia, 25-39.

Heusinger, K. von. 2002. Specificity and definiteness in sentence and discourse structure. Journal of Semantics 19, 245274.

Joseph, B. 2001. Is Balkan comparative syntax possible? In: Rivero M. \& A. Ralli (eds.). Comparative syntax of Balkan languages, Oxford, 17-43.

Koneski, B. 1996. Gramatika na makedonskiot jazik. Skopje.

Levin-Steinmann, A. 2004. Die Legende vom bulgarischen Renarrativ. Bedeutung und Funktionen der kopulalosen 1-Periphrase. München.

Mitkovska, L. 2005. Izrazuvanje posesivnost na nivo na imenskata sintagma vo makedonskiot $i$ vo angliskiot jazik. Skopje.

Nicolova, R. 2008. Bălgarska gramatika. Morfologija. Sofija.

Sonnenhauser, B. 2009. The Macedonian tripartite article: a discourse-oriented account. Makedonski jazik 60, 123-136.

Sonnenhauser, B. 2011. 'Renarrativ' und indirekte Rede im Bulgarischen. Die Welt der Slaven 56/1, 131-154.

Topolinjska, Z. 1994. Factivity as a grammatical category in Balkan Slavic and Balkan Romance. Slavia Meridionalis 1, 105-121.

Topolinjska, Z. 2007. Towards a reformulation of the inventory of balkanisms. Prilozi MANU 32/1, 65-72.

Usikova, R. P. 1985. Makedonskij jazyk. Grammatičeskij očerk, teksty dlja čtenija s kommentarijami i slovarjem. Skopje.

Dieser Beitrag ist im Rahmen des DFG-Projektes "Perspektivität im Balkanslavischen: semantische Grundlagen und diskurspragmatische Relevanz" (SO 949/2-1) entstanden. 
Wort in die Zeit

\section{Der siebte Bruder \\ (Gedanken zu einer sich verändernden Rezeption in zwei politischen Kontexten)}

\section{Von Robert Hodel (Hamburg)}

Ein Brennpunkt der Platonov-Konferenz in Gent (26.-28.5. 2011, Veranstalter: Thomas Langerak, Ben Dhooge) war die didaktische Vermittlung dieses sowjetischen Autors, der zu Beginn der Neunziger Jahre in den Kanon russischer Schulen einging. Als eine zentrale Hürde im Verständnis seines Werks stellte sich dabei der Umstand heraus, dass Platonov in einem ungewöhnlich hohen Maß sowohl auf die große Politik als auch das vielgestaltige Tagesgeschehen reagiert. So besteht zu Recht ein Gutteil der philologischen Forschung in der Rekonstruktion des kommunikativen Kontextes seiner Werke auf der Basis von Meldungen aus der Tagespresse, Dekreten des Kreml', Urteilen führender Literaturkritiker oder Akten des KGB (bzw. FSB), die, nachdem sie in den 1990er Jahren für kurze Zeit zugänglich waren, nun erneut unter Verschluss stehen.

Parallel zu dieser kontinuierlichen philologischen Aufarbeitung ist in Russland jedoch eine Generation herangewachsen, die die sowjetische Wirklichkeit nur mehr aus Geschichten ihrer Eltern und Großeltern kennt. Es erstaunt deshalb nicht, dass ein Schüler nicht nur nicht mehr weiß, wer die Roten, die Weißen und die Kulaken waren, sondern auch den Sowjetjargon in weiten Teilen nicht mehr versteht. In einer Umfrage unter Studierenden des „Moskauer Instituts für Linguistik“ (durchgeführt von Olga Frolova) betraf dies selbst Wörter wie „otnošenie“ (in der Bedeutung von „Dokument") oder „mjasosovchoz". Letzteres vermochte gar nur ein Einziger mit einem Fleisch produzierenden landwirtschaftlichen Betrieb zu verbinden. Damit wird auch nachvollziehbar, warum sich heute immer mehr Lesarten Platonovscher Texte durchsetzen, die den historischen Kontext weitgehend ausblenden.

Von einer veränderten Rezeptionslage zeugen u.a. auch neue Inszenierungen Platonovscher Prosastücke. In einer dramatisierten Fassung der Erzählung Reka Potudan' (2009, Studija teatral'nogo iskusstva, Moskau) konzentriert sich der Regisseur Sergej Ženovač auf die emotionale Seite der Beziehung zwischen dem (zunächst impotenten) Protagonisten und seiner Geliebten. Das Ergebnis ist eine neosentimentalistische Suche nach wahrhaften und tiefen Gefühlen in einer Welt, die sich durch ihre Kargheit dezidiert von den Verführungen des Konsums absetzt: Schon vor der Aufführung wird auf grob gezimmerten langen Holztischen weißer Speck (salo), Brot und Tee serviert, die Aufführung erlebt der in ein Bühnenrund integrierte Zuschauer hautnah auf harten Hockern. Wer hier an neue „Bodenständigkeit“ im Sinne des „počvenničestvo“ denkt, dürfte nicht falsch liegen. In Lev Dodins Inszenierung des Romans Čevengur (1999, Malyj dramatičeskij teatr, Sankt-Peterburg) hingegen ertönen gleich zu Beginn Radio-Stationen aus aller Welt, u.a. auch Al-Dschasira und unverkennbar - die Stimme Putins. So wird das Drama von den ersten Repliken an ins Licht der neuen „Vertikale“ gestellt. 
Beide Inszenierungen wiederholen interessanterweise, auch wenn sie sich gleichermaßen vom angestammten historischen Kontext lösen, hochgradig die bis anhin dominante, ambivalente Rezeptionslage des Autors zwischen Fedorovismus und Sowjetsatire.

Verwandt und zugleich diametral entgegengesetzt ist die Rezeption von zeitgenössischen Texten, die in einem markierten politischen Umfeld entstanden sind. Symptomatisch hierfür sind Texte im Umkreis der "Jugoslawienkrise". Während Platonov allmählich zum "historischen“ Autor mutiert, indem sein ursprünglicher Kontext Historie wird, verhindert der aktuelle Kontext dieser südslavischen Autoren weitgehend eine zeit-transzendierende Lesart. Der heutige Leser ist in einer Intensität über die tragischen Ereignisse der 1990er Jahre informiert, dass dieser historische Kontext unweigerlich zum dominanten Rezeptionsrahmen gerät. Dies geschieht auch bei Texten, in denen entsprechende Zeichen durchaus spärlich gesät sind. Ein Beispiel hierfür ist das Gedicht „Ponekad“ („Manchmal“) von Stevan Tontić. ${ }^{1}$

\section{Ponekad \\ Ponekad dođu prijatelji, sjedimo tako svijet hvaleći i postojanje slaveći.}

Ponekad $u$ isto vrijeme dopre do nas plač djeteta iz susjedstva glas o strogim presudama te moramo odmah da opovrgnemo ono što je maločas, bez razloga izlazilo na naša usta.

Ponekad ne govorimo ništa
gledamo se
i smiješimo.

Ponekad nam oko srca korone straha blješte

A ponekad moja žena kaže Hajdemo odavde.

\section{Manchmal}

Manchmal kommen Freunde, und wir sitzen zusammen, loben die Welt und preisen das Dasein.

Manchmal, zur selben Zeit, dringt aus der Nachbarschaft Kinderweinen zu uns, die Nachricht von scharfen Urteilen und wir müssen unverzüglich widerrufen, was eben noch, grundlos, über unsere Lippen kam.

Manchmal sagen wir nichts, schauen uns an und lächeln.
Manchmal blitzen um unser Herz Angstkoronen auf
Und manchmal sagt meine Frau Gehen wir weg von hier.

Tontić (1946) kam, nachdem er fast ein Jahr im belagerten Sarajevo ausgeharrt hatte, 1993 ins Exil nach Deutschland. 2001 kehrte er nach Bosnien zurück. Das Gedicht wurde in der ersten Hälfte der achtziger Jahre verfasst und ging 1986 in den Erzählband Prag (Schwelle) ein.

Ohne die Kriegsereignisse der Neunziger Jahre wären, so kann man vermuten, die „(scharfen) Urteile“, die über die juristische Bedeutung hinaus auch die Bedeutung von „mišljenje, ocjena“ („Einschätzung“) haben (vgl. V. Anić: Rječnik hrvatsko-

1 Dieses und die folgenden Gedichte sind in der zweisprachigen Anthologie Hundert Gramm Seele. Deset deka duše. Serbische Poesie aus der zweiten Hälfte des 20. Jahrhunderts (Leipziger Buchverlag 2011) erschienen; herausgegeben und übertragen von Robert Hodel. 
ga jezika), in einem weitgehend abstrakt-lyrischen Raum angesiedelt, den Autor und Leser teilen. Es wäre die Geschichte eines lyrischen Subjekts, das sich mit den Verhältnissen seiner Umgebung, die zugleich für eine condition humaine stehen, nicht abfinden will. Im Bewusstsein des Bosnienkrieges jedoch assoziiert man nicht nur die „scharfen Urteile“ mit einem ethnisch-religiösen Hintergrund, selbst das Wort „Nachbarschaft" gerät in einen ethnischen Sog. Das Gedicht rückt somit in die Aura einer Prophezeiung oder Vorahnung. Wie der (historische) Autor in einem Brief an den Verfasser dieser Zeilen schreibt, bezieht sich das Gedicht für ihn dabei noch auf einen weiteren - dritten - Kontext. Er dachte bei dessen Niederschrift in erster Linie an einen "Intellektuellen aus Sarajevo", der aufgrund eines jugoslawienkritischen Artikels zu acht Jahren Haft verurteilt worden war. Der Artikel war noch nicht veröffentlicht, als ihn die Polizei in der Schublade des Schreibtisches beschlagnahmte. Als Zweites nennt Tontić den Prozess eines muslimischen Dichters im Umkreis von Alija Izetbegović (1983). Die Rekonstruktion der historischen kommunikativen Situation führt also in erster Linie auf eine Kontroverse mit dem Titoismus zurück, bei der die ethnisch-religiöse Komponente noch eine untergeordnete Rolle spielte.

Ähnliche semantische Verschiebungen ergeben sich auch bei Texten, die deutlich nach den Kriegsjahren, d.h. bereits im 21. Jahrhundert geschrieben worden sind. Ein solches Gedicht ist "Sedmi brat“ („Der siebte Bruder“) von Novica Tadić (1949-2011), das 2003 im Erzählband Tamne stvari (Dunkle Dinge) erschienen ist.

\section{Sedmi brat}

Vratio se naš brat, sedmi brat. Eno ga dole, na travnjaku, pored žbuna ruža leži.

Drhti kao list, dok ga jutarnje sunce greje.

Ne znamo šta je sve radio, ni gde je bio, ni šta je trpeo. Plaho nas samo odmerava. Odaziva se na ime Pacov.

Zatvorili smo vrata i prozore i na krov se popeli, da ga odozgo s mukom i zebnjom gledamo.

\section{Der siebte Bruder}

Unser Bruder ist zurück, der siebte Bruder. Schau, da unten, auf dem Rasen liegt er, neben dem Rosenstrauch.

Er zittert wie ein Blatt, während ihn die Morgensonne wärmt.

Wir wissen nicht, was er alles trieb, weder wo er war, noch was er erlitt. Scheu nur mustert er uns. Hört auf den Namen Ratte.

Wir haben Türen und Fenster verriegelt und sind aufs Dach gestiegen, um ihn von oben voll Qual und Schauder zu betrachten.

In ein paar Jahrzehnten wird man den siebten Bruder möglicherweise mit Kafkas Verwandlung, mit der Figur des Smerdjakov aus den Brüdern Karamasow oder dem siebten Engel aus der Offenbarung (11:15) assoziieren, dessen Posaune die neue, ewige Herrschaft ankündigt. Es wird jener Bruder sein, der die dunklen, vor Tür und Tor gesperrten Seiten der eigenen Seele verkörpert.

Zweifellos klingt diese Bedeutungsdimension auch heute an. Jedoch wird man sich heute nicht verwehren können, das Gedicht in erster Linie im Kontext der Verarbeitung des Jugoslawienkrieges zu lesen. Der aus Montenegro stammende serbische Dichter fragt nach seiner Rolle in einem Konflikt, den er zunächst als etwas außer ihm Liegendes zu deuten geneigt ist. Doch drängt das Bild des Bruders mächtig die anstehende qualvolle Revision dieses Selbstbildnisses auf. 
Noch abstrahierter stellt sich diese Schuldfrage in Jovan Zivlaks Gedicht „U sumrak“ („In der Dämmerung“), dessen zeitlicher Rahmen in der Kindheit des lyrischen Subjekts angesiedelt ist.

\author{
U sumrak \\ U sumrak pred kosom \\ otkriše leglo zeca \\ donesoše mladunca koji je drhtao \\ bejah dečak kad ga stiskah na grudima \\ treperio sam kao srce koje je htelo \\ da postane vatra koja razliva milost. \\ u mojim rukama razveja se vreme \\ krv mu na nozdrve izbi \\ ljubav se sa smrću pomeša \\ $i$ dah mu se ugasi. \\ ja bejah kosa koja se u zamahu ne zaustavi \\ koja pade kao da ni trenutak nije otkupila \\ $i$ disanje saže u samrtni ropac.
}

\author{
In der Dämmerung \\ In der Dämmerung, unter der Sense \\ deckten sie ein Hasennest auf \\ sie brachten ein Junges heim, es zitterte. \\ ich war ein Bub, als ich es an die Brust drückte \\ ich bebte wie ein Herz, das Feuer \\ werden will, das Erbarmen verströmt. \\ in meinen Armen zerstob die Zeit; \\ Blut schoss ihm aus den Nüstern \\ Liebe mengte sich mit Tod \\ und sein Atem erlosch. \\ ich war die Sense, die ihren Schwung nicht \\ anhielt \\ die fiel, ohne den kleinsten Aufschub \\ herauszuschlagen \\ und die den Hauch in ein Todesröcheln presste.
}

Zivlak ist 1947 in Nakovo im nordserbischen Banat geboren und gilt als Vertreter einer philosophisch orientierten, hermetischen Dichtung. Während der Dichter selbst den Aufschub der Zeit mit Finnegans Wake assoziiert, wird der heutige Leser den kleinen Hasen nolens volens mit den zivilen Opfern des Jugoslawienkonflikts verbinden. Das Gedicht thematisiert die Ohnmacht vor einer Ungerechtigkeit, die wie eine selbstverständlich agierende, mechanische Gewalt daherkommt. Zugleich steht das lyrische Ich mit diesem Sensemann in einer organischen Beziehung - die Sense ist insofern auch Symbol einer gewachsenen Tradition -, doch umso intensiver ist der Wunsch, ihren Schwung aufzuhalten.

Beide Gedichte, „Der siebte Bruder" und „In der Dämmerung“, sind Ausdruck einer intellektuellen und moralischen Aufarbeitung der jüngsten Kriegsgeschichte, die man als Voraussetzung für eine gemeinsame europäische Zukunft halten möchte. Insofern sind die Gedichte Zeugen aus einem anderen Land. Zugleich aber bewahrt die ihnen inhärente symbolisch-allegorische Überhöhung der Wirklichkeit die Möglichkeit der Adaption an neue - nicht weniger konfliktreiche - Verhältnisse.

So liegt der siebte Bruder sehr schnell vor dem eigenen Haus. Und dieses Haus steht für die Vorstellung von einer besseren Welt, die auch die selbstlosen Erbauer der Steppenstadt Čevengur anstrebten. 



\section{Deutscher Slavistentag 2012}

Der 11. Deutsche Slavistentag findet 2012 in Dresden und Bautzen statt, veranstaltet vom Deutschen Slavistenverband, dem Institut für Slavistik der TU Dresden und dem Sorbischen Institut e.V. in Bautzen.

Erstmalig hat ein deutscher Slavistentag einen thematischen Schwerpunkt:

Region, Sprache und Nation.

Dieser Dreiklang nimmt die Lage Dresdens und Bautzens im Dreiländereck und Bautzens im obersorbischen Sprachgebiet auf. Das Wissen über die slavischen Kulturen in ihren regionalen und nationalen Kontexten ist ein wichtiger Faktor für die kulturelle und wirtschaftliche Entwicklung der deutsch-slavischen Euroregion und nicht weniger für den kulturellen und wirtschaftlichen Austausch mit Russland und anderen slavischen Ländern innerhalb und außerhalb der Europäischen Union. Das Thema ist darüber hinaus grundsätzlich motiviert. In den slavischen Ländern haben die Nationalsprachen für das kulturelle und politische Selbstverständnis eine kaum zu überschätzende Bedeutung. Dass aber die Verbindung von nationalem Selbstbewusstsein und sprachlicher Identität heikel ist, kann nicht verschwiegen werden. Der Einheit, die sie nach Innen stiften soll, steht negativ die Abgrenzung nach Außen gegenüber. Sprachen können ideologisiert und sogar zum Vorwand kriegerischer Auseinandersetzungen werden. Im positiven Sinne gehören Sprachen und Sprachenvielfalt jedoch zur kulturellen Eigenheit großer und kleiner Kulturräume. In der Slavistik, besonders an zwei Standorten in der Umgebung von slavischen Sprachen, ist das dreifache Spannungsfeld von regionaler kultureller Identität und Sprache und natio-

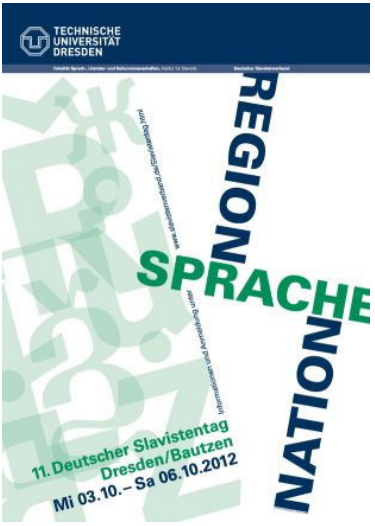
nalem Selbstverständnis im Verhältnis zu regionalen Besonderheiten ein zentraler Gegenstand der Forschung wie der Vermittlung von Sprach- und Kulturwissen über die Slavia. Das gilt für die Sprach-, Literatur- und Kulturwissenschaften ebenso wie für die Sprachdidaktik.

Auf dem 11. Deutschen Slavistentag sind in Dresden zum Eröffnungsabend sowie zum Abend des ersten Konferenztages spezielle Vorträge zum Thema Region, Sprache und Nation geplant. Panels, die das Thema aufgreifen, sind ebenfalls Teil der Konzeption.

Der 11. Deutsche Slavistentag ist aber ebenso offen für alle Themen aus der Slavistik, die in Panels oder in Einzelvorträgen innerhalb der geplanten Sektionen präsentiert werden. 


\section{Das Bulletin der Deutschen Slavistik}

ist das offizielle Organ des

\section{Deutschen Slavistenverbandes}

(www.slavistenverband.de)

und erscheint einmal jährlich

Worldwide Distributor

\section{KUBON \& SAGNER}

Servicing libraries since 1947

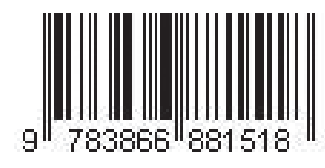

ISBN (print): 978-3-86688-151-8

ISBN (eBook): 978-3-86688-152-5

ISSN: 0949-3050 